\title{
BROOKHFUEN
}

NATIONAL LABORATORY

BNL-77901-2007-IR

\section{Advanced Cements for Geothermal Wells}

\author{
Toshifumi Sugama
}

July 2006

\section{Energy Sciences and Technology Department/Energy Resources Division \\ Brookhaven National Laboratory \\ P.O. Box 5000 \\ Upton, NY 11973-5000 \\ www.bnl.gov}

Notice: This manuscript has been authored by employees of Brookhaven Science Associates, LLC under Contract No. DE-AC02-98CH10886 with the U.S. Department of Energy. The publisher by accepting the manuscript for publication acknowledges that the United States Government retains a non-exclusive, paid-up, irrevocable, world-wide license to publish or reproduce the published form of this manuscript, or allow others to do so, for United States Government purposes. 


\section{DISCLAIMER}

This report was prepared as an account of work sponsored by an agency of the United States Government. Neither the United States Government nor any agency thereof, nor any of their employees, nor any of their contractors, subcontractors, or their employees, makes any warranty, express or implied, or assumes any legal liability or responsibility for the accuracy, completeness, or any third party's use or the results of such use of any information, apparatus, product, or process disclosed, or represents that its use would not infringe privately owned rights. Reference herein to any specific commercial product, process, or service by trade name, trademark, manufacturer, or otherwise, does not necessarily constitute or imply its endorsement, recommendation, or favoring by the United States Government or any agency thereof or its contractors or subcontractors. The views and opinions of authors expressed herein do not necessarily state or reflect those of the United States Government or any agency thereof. 


\title{
Advanced Cements for Geothermal Wells
}

\section{Final Report}

July 2006

Prepared for

The U.S. Department of Energies Office of Geothermal Technologies 1000 Independence Avenue SW

Washington, D.C. 20585-0121

\author{
Prepared by \\ Toshifumi Sugama \\ Energy Resources Division \\ Energy Science \& Technology Department \\ Brookhaven National Laboratory \\ Upton, NY 11973
}

This manuscript, issued by DOE Office of Geothermal Technologies, has been authored by Brookhaven Science Associates, LLC under Contract No. DE-AC0298CHI-886 with the U.S. Department of Energy. The United States Government retains, and publisher, by accepting the article for publication, acknowledges, a world-wide license to publish or reproduce the published form of this manuscript, or allow others to do so, for the United States Government purposes. 


\section{TABLE OF CONTENTS}

Summary 4

$\begin{array}{ll}\text { 1. Introduction } & 10\end{array}$

2. Fly Ash-modified Calcium Aluminate Phosphate Cements $\left(\mathrm{Na}_{2} \mathrm{O}-\mathrm{CaO}-\right.$ $\mathrm{Al}_{2} \mathrm{O}_{3}-\mathrm{SiO}_{2}-\mathrm{P}_{2} \mathrm{O}_{5}-\mathrm{H}_{2} \mathrm{O}$ system) 14

2.1. Maintenance of Pumpability 14

2.1.1. Experimental 15

2.1.2. Results 16

2.2. Low Density Slurry 20

2.2.1. Air-foamed Cement Slurry 20

2.2.1.1. Experimental 22

2.2.1.2. Results 24

2.2.2. Polymer-modified Air-foamed Slurry 26

2.2.2.1. Experimental 27

2.2.2.2. Results 29

2.3. Toughness 32

2.3.1. Ceramic Fiber Reinforcement 32

2.3.1.1. Experimental 32

2.3.1.2. Results 33

2.3.2. Milled Carbon Microfiber Reinforcement 36

2.3.2.1. Experimental 37

2.3.2.2. Results 38

2.4. Bond Durability to Casing Pipe Surface 41

2.4.1. Experimental $\quad 42$

2.4.2. Results 44

2.5. Field Demonstration $\quad 47$

2.5.1. Experimental 47

2.5.2. Results 49

2.6. Cost-effective CaP Cement Systems 50 
2.6.1. Experimental 51

2.6.2. Results 52

2.7. Conclusions $\quad 54$

$\begin{array}{ll}\text { 2.8. Patent } & 60\end{array}$

2.9. Technology Transfer 60

2.10. Awards 60

2.11. Publications $\quad 61$

3. Economical Slag-based Cement Systems 61

3.1. Sodium Silicate-activated Slag Cements $\left(\mathrm{Na}_{2} \mathrm{O}-\mathrm{CaO}-\mathrm{SiO}_{2}-\mathrm{MgO}\right.$ $\begin{array}{ll}-\mathrm{H}_{2} \mathrm{O} \text { system) } & 61\end{array}$

3.1.1. Experimental $\quad 62$

3.1.2, Results 63

3.2. Sodium Silicate-activated Fly Ash/Slag Blend Cements $\left(\mathrm{Na}_{2} \mathrm{O}-\right.$ $\mathrm{CaO}-\mathrm{Al}_{2} \mathrm{O}_{3}-\mathrm{SiO}_{2}-\mathrm{MgO}-\mathrm{H}_{2} \mathrm{O}$ system) 68

3.2.1. Experimental $\quad 69$

3.2.2. Results $\quad 70$

$\begin{array}{ll}\text { 3.3. Conclusions } & 74\end{array}$

$\begin{array}{ll}\text { 3.4. Publications } & 75\end{array}$

$\begin{array}{ll}\text { References } & 76\end{array}$ 


\section{Summary}

Using the conventional well cements consisting of the calcium silicate hydrates $\left(\mathrm{CaO}-\mathrm{SiO}_{2}-\mathrm{H}_{2} \mathrm{O}\right.$ system) and calcium aluminum silicate hydrates $\left(\mathrm{CaO}-\mathrm{Al}_{2} \mathrm{O}_{3}-\mathrm{SiO}_{2}-\mathrm{H}_{2} \mathrm{O}\right.$ system) for the integrity of geothermal wells, the serious concern confronting the cementing industries was their poor performance in mechanically supporting the metallic well casing pipes and in mitigating the pipe's corrosion in very harsh geothermal reservoirs. These difficulties are particularly acute in two geological regions: One is the deep hot downhole area ( 1700 m depth at temperatures of $\sim 320^{\circ} \mathrm{C}$ ) that contains hyper saline water with high concentrations of $\mathrm{CO}_{2}(>40,000 \mathrm{ppm})$ in conjunction with $\sim 100$ ppm $\mathrm{H}_{2} \mathrm{~S}$ at a mild acid of $\mathrm{pH} \sim 5.0$; the other is the upper well region between the well's surface and $~ 1000 \mathrm{~m}$ depth at temperatures up to $200^{\circ} \mathrm{C}$. The specific environment of the latter region is characterized by highly concentrated $\mathrm{H}_{2} \mathrm{SO}_{4}(\mathrm{pH}<1.5)$ brine containing at least $5000 \mathrm{ppm} \mathrm{CO}_{2}$. When these conventional cements are emplaced in these harsh environments, their major shortcoming is their susceptibility to reactions with hot $\mathrm{CO}_{2}$ and $\mathrm{H}_{2} \mathrm{SO}_{4}$, thereby causing their deterioration brought about by $\mathrm{CO}_{2}$-catalyzed carbonation and acid-initiated erosion. Such degradation not only reduced rapidly the strength of cements, lowering the mechanical support of casing pipes, but also increased the extent of permeability of the brine through the cement layer, promoting the rate of the pipe’s corrosion. Severely carbonated and acid eroded cements often impaired the integrity of a well in less than one year; in the worst cases, casings have collapsed within three months, leading to the need for costly and time-consuming repairs or redrilling operations. These were the reasons why the geothermal well drilling and cementing industries were concerned about using conventional well cements, and further their deterioration was a major impediment in expediting the development of geothermal energy resources.

To deal with this problem, over the past eight years, R\&D work at Brookhaven National Laboratory (BNL) in the U.S. Department of Energy’s (DOE’s) Geothermal Drilling program aimed at reducing $25 \%$ of drilling and reservoir management costs has been focused on developing and characterizing new types of cementitioius materials that confer outstanding resistance to $\mathrm{CO}_{2}$ and acid at brine temperatures up to $320^{\circ} \mathrm{C}$. To 
facilitate the achievement of this program's goal, three major geothermal industries, Halliburton, Unocal Corporation, and CalEnergy Operating Corporation, supported BNL's work by cost-sharing collaborative efforts. Halliburton played a pivotal role in evaluating the technical and economical feasibility of BLN-developed cements, and consequently in formulating field-applicable ones. Unocal provided us with information on whether the developed cements are compatible with conventional well cementing operations and processes in the field, while CalEnergy conducted a field exposure test for validating the integrity and reliability of newly developed cements.

BNL succeeded in synthesizing hydrothermally two new cements in response to this program's objectives: One of those synthesized was a calcium aluminate phosphate (CaP) cement involving $\mathrm{CaO}-\mathrm{Al}_{2} \mathrm{O}_{3}-\mathrm{P}_{2} \mathrm{O}_{5}-\mathrm{H}_{2} \mathrm{O}$ and $\mathrm{Na}_{2} \mathrm{O}-\mathrm{CaO}-\mathrm{Al}_{2} \mathrm{O}_{3}-\mathrm{SiO}_{2}-\mathrm{P}_{2} \mathrm{O}_{5}-\mathrm{H}_{2} \mathrm{O}$ systems; the other was a sodium silicate-activated slag (SSAS) cement consisting of $\mathrm{Na}_{2} \mathrm{O}-\mathrm{CaO}-\mathrm{SiO}_{2}-\mathrm{MgO}-\mathrm{H}_{2} \mathrm{O}$ and $\mathrm{Na}_{2} \mathrm{O}-\mathrm{CaO}-\mathrm{Al}_{2} \mathrm{O}_{3}-\mathrm{SiO}_{2}-\mathrm{MgO}-\mathrm{H}_{2} \mathrm{O}$ systems. The $\mathrm{CaP}$ cements with four basic components, calcium aluminate cement, sodium polyphosphate, Class F fly ash, and water, were designed as $\mathrm{CO}_{2}$-resistance cements for use in mildly acidic ( $\mathrm{pH} \sim 5.0$ ) $\mathrm{CO}_{2}$-rich downhole environments. The SSAS cements with four starting materials, slag, Class F fly ash, sodium silicate, and water, were designed to resist a hot strong acid containing a low level of $\mathrm{CO}_{2}$. They also were characterized as being costeffective economical cements because of their use of inexpensive cement-forming byproducts yielded from coal combustion and steel-manufacturing processes.

\section{CaP Cements :}

The four crystalline hydrothermal reaction products, the hydroxyapatite $\left[\mathrm{Ca}_{5}\left(\mathrm{PO}_{4}\right)_{3}(\mathrm{OH})\right]$, boehmite $(\gamma-\mathrm{AlOOH})$, hydrogarnet $\left(3 \mathrm{CaO} \cdot \mathrm{Al}_{2} \mathrm{O}_{3} \cdot 6 \mathrm{H}_{2} \mathrm{O}\right)$, and analcime $\left(\mathrm{NaAlSi}_{2} \mathrm{O}_{6} \cdot \mathrm{H}_{2} \mathrm{O}\right.$ ) phases, were responsible for strengthening and densifying the $\mathrm{CaP}$ cements, as well as conferring on them resistance to $\mathrm{CO}_{2}$ and mild acid. The mechanism underlying $\mathrm{CO}_{2}$-resistance was the replacement of the $\mathrm{OH}$ groups within the hydroxyapatite phase by $\mathrm{CO}_{3}{ }^{2-}$, thereby leading to the formation of $\mathrm{CO}_{3}$ - intercalated hydroxyapatite; $2 \mathrm{Ca}_{5}\left(\mathrm{PO}_{4}\right)_{3}(\mathrm{OH})+\mathrm{CO}_{3}{ }^{2-} \rightarrow 2 \mathrm{Ca}_{5}\left(\mathrm{PO}_{4}\right)_{3} \cdot\left(\mathrm{CO}_{3}\right)$. The analcime phase favorably intercalated $\mathrm{CO}_{2}$, transforming it into the cancrinite $\left[\mathrm{Na}_{5}(\mathrm{AlSi})_{12} \mathrm{O}_{24} \mathrm{CO}_{3} \cdot 3 \mathrm{H}_{2} \mathrm{O}\right.$ ] phase, while the boehmite phase displayed chemical inertness to $\mathrm{CO}_{2}$. Although the hydrogarnet phase showed some sensitivity to carbonation, these hydroxyapatite $\rightarrow$ 
$2 \mathrm{Ca}_{5}\left(\mathrm{PO}_{4}\right)_{3} \cdot \mathrm{CO}_{3}$ and analcime $\rightarrow$ cancrinite phase transitions occurring without any destruction of their structures together with the $\mathrm{CO}_{2}$-inert boehmite phase were major reason why the $\mathrm{CaP}$ cements had an excellent resistance to $\mathrm{CO}_{2}$.

A further requirement of the $\mathrm{CaP}$ cements was to improve the following five properties for formulating field-applicable cements with upgraded properties: 1) The maintenance of pumpability by means of the set-retarding activity of cement slurries; 2) low density slurry; 3) toughness, 4) bond durability to the casing pipe’s surface; and, 5) low cost.

To improve the first property, we found that citric acid was the most effective set retarder in extending the thickening and downhole pumping times of the cement slurries. Its set-retarding activity was due to the uptake of $\mathrm{Ca}^{2+}$ ions from the calcium aluminate cement (CAC) reactant by carboxylic acid groups within the citric acid. This uptake precipitated Ca-complexed carboxylate compounds as a set-retarding barrier layer on the CAC grain's surfaces.

Lowering of the density of the cement slurry, the second property played a pivotal role in eliminating the problem of lost circulation during pumping and circulating operations of cement slurry. Among the several ways to prepare low-density slurries, we identified an air-foaming technology using simple foaming surfactants as the most costeffective and efficient way. The air-foamed $\mathrm{CaP}$ cement revealed some advanced properties, such as a high compressive strength and lower porosity, at a hydrothermal temperature of $288^{\circ} \mathrm{C}$, compared with those of conventional $\mathrm{N}_{2}$ gas-foamed Class $\mathrm{G}$ well cement made from a slurry of similar density under high pressure and the same hydrothermal temperature. However, one shortcoming was an increase in water permeability due to the formation of an undesirable continuous porous structure caused by coalesced air bubble cells, so raising concerns that the rate of corrosion of the casing pipes might be promoted. To solve this problem, a styrene acrylic emulsion (SAE) as high-temperature anti-corrosion additive was incorporated into the air-foamed cement slurries. The following three factors of the SAE-modified foamed cements contributed to a significantly abating corrosion of the casing pipes: 1) A decrease in the conductivity of corrosive $\mathrm{NaCl}$ ions; 2) an inhibition of the cathodic oxygen reduction reaction at the 
corrosion sites of steel; and, 3) the good coverage of the steel's surface by the foamed cements.

In a long-term exposure of cements in such a very harsh environment, one critical issue that emerged was their shrinkage and expansion caused by the in-situ phase transformation and the excess growth of crystalline hydrothermal reaction products. These phenomena frequently imposed internal stresses, followed by the initiation of cracks. Thus, in response to the third property, the cements were required to have a sufficient resiliency and toughness to avoid the creation and effects of stress. Among the various different fibrous materials explored as reinforcements, milled carbon microfibers ( $7.5 \mu \mathrm{m}$ diam. $\mathrm{x} 100-200 \mu \mathrm{m}$ long) offered the best performance in improving the toughness and ductility of cements. In fact, the fracture toughness and displacement of the non-reinforced cements was raised 3.1-and 2.7-fold, respectively, by incorporating 14 wt\% (21.8 vol. \%) fibers.

Regarding the fourth property, bond durability, when superheated steam and fluid went through the cement-sheathed casing pipes, the two factors caused the development of stress cracking, namely the thermal shock of cement layers directly contacted with pipe's surface, and the thermal expansion of pipes. Hence, the bond durability of the cements adhering to the casing pipe was one of the important factors governing the integrity of the cement covering the casing pipes under repeated superheat-cold fatigue cycles in geothermal wells. To obtain this information, we exposed the carbon microfiber-reinforced CaP and conventional Class G well cement composite-sheathed steel pipes to a superheating-cooling fatigue test (one cycle $=250^{\circ} \mathrm{C}$ for 15 hours + room temperature for 9 hours). For the Class $\mathrm{G}$ cement, the needle-like xonotolite crystals that formed in interfacial critical regions between the cement and pipe were detrimental to bond durability because of the development of an undesirable porous microstructure, thereby resulting in a decline in shear bond strength in the first 70 cycles. In contrast, the shear bond strength of $\mathrm{CaP}$ cement markedly increased between the 0 and 100 cycles, beyond that, it leveled off. The reason for such outstanding bond durability was due to the development of dense microstructure of hybrid phases including plate-, block- and foil-like hydroxyapatite, boehmite, hydrogarnet, and analcime crystals at the contact zones with the pipe's surface. 
The upgraded CaP cements with advanced properties described above contributed to a considerable reduction in the costs of repairing and maintaining the wells. However, another factor that can lead to a reduction in drilling and reservoir management expenses is by using low cost cement. In response to this important issue, we investigated the usefulness of coal-combustion by-products, Class C fly ash (2.0 $\$ / \mathrm{lb})$, as a replacement for the expensive calcium aluminate cement $(35.0 \mathrm{\$} / \mathrm{lb})$ that was one of starting materials of $\mathrm{CaP}$ cements. We demonstrated that blending Class $\mathrm{C}$ and $\mathrm{F}$ fly ashes with a $\mathrm{C} / \mathrm{F}$ ratio of 70/30 gave the most suitable properties for $\mathrm{CO}_{2}$ - and mild acid-resistant CaP cement systems.

Based upon the information described above, the field applicable CaP cements formulated by BNL and our cost-sharing industrial partners satisfactorily met all the following material criteria: 1) Maintenance of pumpability for at least 3 hours; 2) compressive strength, > 500 psi (3.5 MPa) at 24 hour-curing time; 3) water permeability, $<1 \times 10^{-4}$ Darcy; 4) bond strength to steel casing, $>50 \mathrm{psi}$; 5) carbonation rate, $<5 \mathrm{wt} \%$ after 1 year in $40,000 \mathrm{ppm} \mathrm{CO}_{2}$-laden brine at $300^{\circ} \mathrm{C}$; 6 ) fracture toughness, $>0.008$ $\mathrm{MN} / \mathrm{m}^{3 / 2}$ at 24 hour-curing time; 7) resistance to mild acid ( $\mathrm{pH} \sim 5.0$ ) at $300^{\circ} \mathrm{C},<5 \mathrm{wt} \%$ loss after 30 days exposure; 8) cost, $<\$ 15 /$ bag; and, 9) slurry density of foamed cement, $<1.3 \mathrm{~g} / \mathrm{cc}(13 \mathrm{lb} / \mathrm{gal})$.

In 1997, our industrial partners, Unocal and Halliburton emplaced this cement in the geothermal wells in northern Sumatra, Indonesia, completing four wells with this new cement; these cementing jobs represent the first ever applications of $\mathrm{CaP}$ cement. To monitor the integrity of such cement, BNL conducted a 7-mo. exposure test in an inhouse environment similar to that in the Indonesia wells $\left(\sim 20,000 \mathrm{ppm} \mathrm{CO}_{2}\right.$ and 400 ppm $\mathrm{H}_{2} \mathrm{~S}$ at $280^{\circ} \mathrm{C}$ ). The post-test analyses revealed no decomposition of the cements, nor was there any carbonation-caused erosion, suggesting that the CaP cements had excellent durability in a hostile geothermal environment.

In 1999, Halliburton commercialized this CaP cement under the trade name “ThermaLock Cement”, and in 2000, this cement technology received the prestigious “Research and Development (R\&D) 100 Award” honoring BNL, Unocal, and Halliburton. As of 2006, more than 1000 tons of "ThermaLock ${ }^{\circledR}$ ” have been used to complete geothermal wells in Indonesia, Japan, and the United States, and in other 
applications including a P\&A injector in Oklahoma, steam injection wells in Kuwait and New Zealand, casing repair and liner completions for a $\mathrm{CO}_{2}$ flood field in Kansas, foamed for steam injections in California, 18,000-ft. sour gas injection wells in Wyoming and foamed for off-shore use in the North Sea. One major reason for this cement becoming increasingly popular is that drilling and cementing operators estimated that its useful service life is about 20 years before repairs will be needed. In contrast, conventional well cements become severely deteriorated in such $\mathrm{CO}_{2}$-rich geothermal wells after only one year, and the damaged wells must be repaired in an operation involving redrilling and recementing. The estimated annual cost of remediation is $\$ 150,000$ per well. There are no annual repair costs whatsoever for wells completed with this cement, thereby eliminating substantial expenses for remedial operations.

\section{SSAS Cements:}

The combination of two crystalline phases, calcium silicate hydrate $\left(\mathrm{CaO} . \mathrm{SiO}_{2} \cdot \mathrm{xH}_{2} \mathrm{O}, \mathrm{CSH}\right)$ and tobermorite $\left(5 \mathrm{CaO} .6 \mathrm{SiO}_{2} \cdot \mathrm{xH}_{2} \mathrm{O}\right)$ phases, was responsible for maximizing the strength and minimizing the water permeability of autoclaved costeffective SSAS cements. Although these phases were vulnerable to reactions with hot $\mathrm{H}_{2} \mathrm{SO}_{4}(\mathrm{pH}<1.5)$, the $\mathrm{CSH}$ phase played an important role in retarding the rate of acid erosion. After the uptake of $\mathrm{Ca}$ by $\mathrm{H}_{2} \mathrm{SO}_{4}$, Ca-destitute CSH preferentially reacted with the Mg from slag to form magnesium silicate hydrate $\left[\mathrm{Mg}_{2} \mathrm{Si}_{2} \mathrm{O}_{5}(\mathrm{OH})_{4}\right.$, the lizardite phase] that not only retarded the rate of acid erosion, but also retained the integrity of the cemenetitious structure. Thus, after undergoing acid damage, the SSAS cement exhibited a self-repairing characteristic.

In addition, modifying the SSAS cement with Class F fly ash enhanced further the extent of resistance to acid. When such modified SSAS cements were exposed for 15 days to $90^{\circ} \mathrm{C} \mathrm{CO}_{2}$-laden $\mathrm{H}_{2} \mathrm{SO}_{4}(\mathrm{pH} 1.1)$, their weight loss by acid erosion was less than 7 \%. Two factors contributed to minimum acid erosion: One was the self-repairing property of cement itself; the other was the anti-acid zeolite phase formed by interactions between the mullite in fly ash and the Na ions liberated from the sodium silicate activator. Therefore, the economical SSAS cement has a high potential as acid-resistant geothermal well cement at temperatures up to $200^{\circ} \mathrm{C}$. 


\section{Introduction}

The principal application of the geothermal well cementing materials is to support mechanically metallic well casings as well as to protect them against hot brine-initiated corrosion at brine temperatures up to $320^{\circ} \mathrm{C}$. The cementitious materials not only must possess high-hydrothermal temperature stability, but also they must be inert and resist against very harsh geothermal environments involving the $\mathrm{CO}_{2}$-enriched brine $(>40,000$ ppm $\mathrm{CO}_{2}$ ) encountered in a bottomhole depth of $\sim 1700 \mathrm{~m}$ at temperature of $\sim 320^{\circ} \mathrm{C}$, and a highly concentrated $\mathrm{H}_{2} \mathrm{SO}_{4}(\mathrm{pH}<1.5)$ brine containing at least $5000 \mathrm{ppm} \mathrm{CO}_{2}$ in an upper well region between the well's surface and $~ 1000 \mathrm{~m}$ depth at temperatures up to $200^{\circ} \mathrm{C}$. When the conventional well cements consisting of the calcium silicate hydrates $\left(\mathrm{CaO}-\mathrm{SiO}_{2}-\mathrm{H}_{2} \mathrm{O}\right.$ system) and calcium aluminum silicate hydrates $\left(\mathrm{CaO}-\mathrm{Al}_{2} \mathrm{O}_{3}-\mathrm{SiO}_{2}-\mathrm{H}_{2} \mathrm{O}\right.$ system) were emplaced in geothermal wells, one serious concern confronting the geothermal cementing industries was their vulnerability to attack of these corrosive $\mathrm{CO}_{2}$ and $\mathrm{H}_{2} \mathrm{SO}_{4}$ species. Once the deterioration of their cements around well casings was detected, the damaged areas must be repaired as soon as possible in a costly remedial operation to avoid the catastrophic collapse of the wells. Thus, the susceptibility of cements to these harsh environments has been a major impediment to the development of geothermal energy resources.

In the $\mathrm{CO}_{2}$-enrich geothermal environment, one well-known factor is carbonation due to interactions between the $\mathrm{CO}_{2}$ in geothermal brine and the calcium silicate or calcium aluminum silicate hydrates present in conventional cements. This hydrothermalpromoted carbonation resulted in the formation of calcite, $\mathrm{CaCO}_{3}$, followed by its conversion into the water-soluble calcium bicarbonate, $\mathrm{Ca}\left(\mathrm{HCO}_{3}\right)_{2}$, which leaches out from the cement hydrate phases; $\mathrm{CaCO}_{3}+\mathrm{H}_{2} \mathrm{O}+\mathrm{CO}_{2} \rightarrow \mathrm{Ca}\left(\mathrm{HCO}_{3}\right)_{2}$. This leaching process continues in the presence of excess $\mathrm{CO}_{2}$, thereby producing a large amount of an amorphous silica and aluminum silicate gels dissociated from the Ca-depleted these hydrate phases [1]. This was reason why the carbonated well cements often fail in less than a year, and in some worst cases, well casing have collapsed within three months.

On the other hand, when conventional cement hydrates came in contact with $\mathrm{H}_{2} \mathrm{SO}_{4}$, the $\mathrm{Ca}^{2+}$ cations were rapidly leached out from the cement hydrates, and then reacted with the $\mathrm{SO}_{4}{ }^{2-}$ from $\mathrm{H}_{2} \mathrm{SO}_{4}$ to deposit gypsum gel $\left(\mathrm{CaSO}_{4} \cdot 2 \mathrm{H}_{2} \mathrm{O}\right)$ scales as the 
acid-corrosion products on the surfaces of cements. Although the gypsum gel scale clinging to the cements was thought to serve as a primary barrier layer against a further acid attack, their spallation promoted the extent of acid erosion of the cement.

Furthermore, an excessive growth of this corrosion product caused undesirable expansion and swelling phenomena of the cements, following the development of destructive cracks or complete failure.

To deal with this problem, the Brookhaven National Laboratory (BNL) has succeeded in developing a new type of the hydrothermal cements in the U.S. Department of Energy's (DOE’s) Geothermal Materials Program aimed at synthesizing and formulating the $\mathrm{CO}_{2}$-resistant well cements. This U.S. patented cement [2] called as the calcium aluminate phosphate (CaP) cementitious material ( $\mathrm{CaO}-\mathrm{Al}_{2} \mathrm{O}_{3}-\mathrm{P}_{2} \mathrm{O}_{5}-\mathrm{H}_{2} \mathrm{O}$ system) was synthesized through three-step reaction pathways; hydrolysis, acid-base interaction, and hydrothermal hydration, between two starting materials, the calcium aluminate cement (CAC) as the basic solid reactant (a proton-acceptor cation-leachable powder) and the sodium- or ammonium-polyphosphate solution as the acidic reactant (a proton-donator anion-yielding liquid) [3,4]. The major chemical ingredients of CAC used

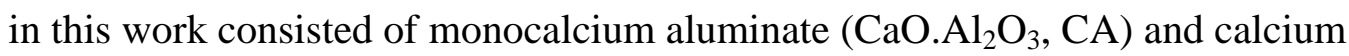
bialuminate $\left(\mathrm{CaO} .2 \mathrm{Al}_{2} \mathrm{O}_{3}\right)$. Using the sodium polyphosphate, $-\left[-\left(-\mathrm{NaPO}_{3}\right)_{\mathrm{n}}-, \mathrm{NaP}\right]$, as the acidic reactant, the following three-step reactions between the CAC and $\mathrm{NaP}$ led to the formation of hydroxyapatite $\left[\mathrm{Ca}_{5}\left(\mathrm{PO}_{4}\right)_{3}(\mathrm{OH}), \mathrm{HOAp}\right]$ and boehmite $(\gamma-\mathrm{AlOOH})$ :

Hydrolysis of reactant:

CaO. $\mathrm{Al}_{2} \mathrm{O}_{3}+4 \mathrm{H}_{2} \mathrm{O} \rightarrow \mathrm{Ca}^{+}+2 \mathrm{Al}(\mathrm{OH})_{4}{ }^{-}$,

$\mathrm{CaO} .2 \mathrm{Al}_{2} \mathrm{O}_{3}+7 \mathrm{H}_{2} \mathrm{O}+2 \mathrm{OH}^{-} \rightarrow \mathrm{Ca}^{2+}+4 \mathrm{Al}(\mathrm{OH})_{4}{ }^{-}$

$-\left[-\mathrm{NaPO}_{3}-\right]_{\mathrm{n}^{-}}+\mathrm{nH}_{2} \mathrm{O} \rightarrow \mathrm{nNaHPO}_{4}^{-}+\mathrm{nH}^{+}$,

Acid-base reaction:

$\mathrm{Ca}^{+}+\mathrm{NaHPO}_{4}^{-} \rightarrow \mathrm{Ca}\left(\mathrm{HPO}_{4}\right)$, $\mathrm{Al}(\mathrm{OH})_{4}{ }^{-}+\mathrm{H}^{+} \rightarrow \mathrm{AlH}(\mathrm{OH})_{4}$,

Hydrothermal hydration: 
$\mathrm{Ca}\left(\mathrm{HPO}_{4}\right)+4 \mathrm{Ca}^{2+}+2 \mathrm{NaHPO}_{4}^{-}+\mathrm{xH}_{2} \mathrm{O} \rightarrow \mathrm{Ca}_{5}\left(\mathrm{PO}_{4}\right)_{3}(\mathrm{OH})+2 \mathrm{Na}^{+}+\mathrm{xH}^{+}+\mathrm{yOH}^{-}$, $\mathrm{AlH}(\mathrm{OH})_{4} \rightarrow \gamma-\mathrm{AlOOH}+2 \mathrm{H}_{2} \mathrm{O}$.

Concurrently, hydrogarnet, $3 \mathrm{CaO} \cdot \mathrm{Al}_{2} \mathrm{O}_{3} \cdot 6 \mathrm{H}_{2} \mathrm{O}$, phase was formed through the following hydrothermal reaction between the hydrolysate species; $3 \mathrm{Ca}^{2+}+2 \mathrm{Al}(\mathrm{OH})_{4}{ }^{-}+4 \mathrm{OH}^{-} \rightarrow$ $3 \mathrm{CaO} . \mathrm{Al}_{2} \mathrm{O}_{3} \cdot 6 \mathrm{H}_{2} \mathrm{O}$.

When the HOAp phase came in contact with $\mathrm{CO}_{2}$-derived $\mathrm{CO}_{3}{ }^{2-}$ anions in an aqueous media, the $\mathrm{OH}$ groups within crystalline $\mathrm{HOAp}$ phase were replaced by $\mathrm{CO}_{3}{ }^{2-}$; thereby forming the $\mathrm{CO}_{3}$-intercalated $\mathrm{HOAp} ; 2 \mathrm{Ca}_{5}\left(\mathrm{PO}_{4}\right)_{3}(\mathrm{OH})+\mathrm{CO}_{3}{ }^{2-} \rightarrow$ $2 \mathrm{Ca}_{5}\left(\mathrm{PO}_{4}\right)_{3} \cdot \mathrm{CO}_{3}$. Such intercalation of $\mathrm{CO}_{3}{ }^{2-}$ into the HOAp molecular structure without any destructions of its structure was reason why the HOAp was responsible for minimizing the rate of cement's carbonation [5,6]. Meanwhile, the boehmite phase was unsusceptible to reactions with $\mathrm{CO}_{2}$. These reaction products not only alleviate carbonation-caused disintegration of cements, but also provided the development of high compressive strength of $>90 \mathrm{MPa}$ in the hydrothermal temperature in the range of $150^{\circ}$ to $300^{\circ} \mathrm{C}$ and a low water permeability of $<1 \times 10^{-4}$ Darcy [7].

In 1996, in an attempt to formulate the field-applicable CaP cement and to improve further its resistance to a highly concentrated $\mathrm{H}_{2} \mathrm{SO}_{4}(\mathrm{pH}<1.5)$ brine containing at least $5000 \mathrm{ppm} \mathrm{CO}$ encountered in an upper well region between the well's surface and $\sim 1000 \mathrm{~m}$ depth at temperatures up to $200^{\circ} \mathrm{C}$, BNL agreed to conduct the costsheared collaborating work with two private geothermal industries, Unocal Corporation and Halliburton Company, to expedite the achievement of this ultimate goal. In this work, the original formulation of $\mathrm{CaP}$ cement was modified with Class F fly ash as the coal combustion by-product to enhance its acid resistance and to reduce the material's cost. The objectives of our research for formulating the filed-applicable fly ash-modified CaP cement $\left(\mathrm{Na}_{2} \mathrm{O}-\mathrm{CaO}-\mathrm{Al}_{2} \mathrm{O}_{3}-\mathrm{SiO}_{2}-\mathrm{P}_{2} \mathrm{O}_{5}-\mathrm{H}_{2} \mathrm{O}\right.$ system) included the following six topics: 1. Maintenance of Pumpability

A set retarder is an inevitable additive in formulating cement slurry for completing deep and hot geothermal wells, and it imparts an extended pumpability of the cement slurry in the down hole pumping operation. Pumpability is associated directly with thickening time allowing long enough for cement to fill up the space between the metallic casing pipe and the wall's foundation before it sets. 


\section{Low Density Slurry}

In pumping and circulating a cement slurry of typical density, 1.9 to $2.0 \mathrm{~g} / \mathrm{cc}$, used in geothermal wells, there is a considerable risk of creating undesirable fracture zones in a weak unconsolidated rock foundation with very fragile gradients due to the high hydrostatic pressure that is required to circulate such dense slurry, thereby causing the problem of lost circulation. Thus, it is very important to use cement slurry with the minimum density responsible for reducing this hydrostatic pressure, so minimizing the possibility of experiencing lost circulation.

\section{Toughness}

In such a very harsh environment, one issue to be addressed is the in-situ phase transformation and the excess growth of crystalline hydrothermal reaction products formed in the cements from long-term exposure. Such unavoidable phase transitions and crystal growths frequently lead to some shrinkage and expansion of the aged cements, reflecting the imposition of internal stress, followed by the initiation of cracks. The propagation of cracks then allows the brine to permeate easily through the cement layer, promoting the corrosion of pipes. Thus, the cements are required to have a sufficient resiliency and toughness to avoid the creation and affects of stress.

\section{Bond Durability to Casing Pipe Surface}

When geothermal wells were brought into the production of superheated steam and fluid through the cement-sheathed metallic casing pipes, the two factors, the thermal shock of cement layers contacted directly with pipe's surface and the thermal expansion of pipes, caused the development of its stress cracking. Thus, the bond durability of the cements adhering to the casing pipe is one of the important factors governing the integrity of the cement covering the casing pipes under a repeated superheat-cold fatigue cycles.

\section{Field Demonstration}

To validate the integrity and reliability of developed field-workable cement, two geothermal industrial partners, Unocal Corporation and Halliburton, emplaced it in the geothermal wells in northern Sumatra, Indonesia. BNL conducted long-term monitoring test to answer to one important question that must be asked: How durable is this downhole cement in supporting casing pipes during a log-term exposure in high $\mathrm{CO}_{2}$-laden acid brine at $200^{\circ} \mathrm{C}$. 


\section{Low Cost}

The developed cements would provide the following three bottom-line benefits for successful wellbore completions: 1) Extension of the casing's lifecycle; 2) reduction of substantial expenditures needed for abandoning, redrilling, or reconstructing wells, thereby saving in excess of $\$ 200,000$ per well in avoiding remedial operations; and, 3) improvement of the efficiency and lowering of the costs of energy-extracting operations at the plants. In addition, cost-effective cements would be needed to reduce the capital investment.

In 2002, BNL in collaboration with Halliburton Company and CalEnergy Operating Corporation had succeeded in developing and formulating two very economical acid-resistant cement systems: One system $\left(\mathrm{Na}_{2} \mathrm{O}-\mathrm{CaO}-\mathrm{SiO}_{2}-\mathrm{MgO}-\mathrm{H}_{2} \mathrm{O}\right)$ consisted of the sodium silicate activator and the ground granulated blast furnace slag, yielded as by-product of the steel-manufacturing process; the other one $\left(\mathrm{Na}_{2} \mathrm{O}-\mathrm{CaO}\right.$ $\mathrm{Al}_{2} \mathrm{O}_{3}-\mathrm{SiO}_{2}-\mathrm{MgO}-\mathrm{H}_{2} \mathrm{O}$ ) included the sodium silicate activator, slag, and Class $\mathrm{F}$ fly ash as the coal combustion by-product. The factors to assess the potential of these cements included the setting time of cement slurries at room temperature, changes in compressive strength, porosity, water permeability as a function of $\mathrm{SiO}_{2} / \mathrm{N}_{2} \mathrm{O}$ mol ratio in the sodium silicate activator; autoclave temperature; activator content and slag/fly ash ratio; the identification of phase composition assembled in autoclaved cements; and the development of the microstructure in cements at different temperatures. All the information obtained was correlated directly with acid erosion-related studies, including weight loss and the visual observation of the appearance of the cements after exposure for 15 days in a $\mathrm{CO}_{2}$-laden $\mathrm{H}_{2} \mathrm{SO}_{4}$ solution ( $\mathrm{pH} \mathrm{1.1)} \mathrm{at} 90^{\circ} \mathrm{C}$.

\section{Fly Ash-modified Calcium Aluminate Phosphate Cements $\left(\mathrm{Na}_{2} \mathrm{O}-\mathrm{CaO}-\mathrm{Al}_{2} \mathrm{O}_{3}\right.$ - $\mathrm{SiO}_{2}-\mathrm{P}_{2} \mathrm{O}_{5}-\mathrm{H}_{2} \mathrm{O}$ system)}

\subsection{Maintenance of Pumpability}

As part of ongoing evaluations, one of our concerns was the effect of set retarders on the extent of the cement's acid erosion. Among the various different retarders, the citric acid commonly is used for calcium aluminate phosphate $(\mathrm{CaP})$ cement. However, there has been virtually no study of the resistance of the citric acid-retarded cement to a 
strong acid containing some $\mathrm{CO}_{2}$. For comparison with this organic retarder, we also used $\mathrm{NaCl}$, known as one of the inorganic retarders of $\mathrm{CaP}$ cement. To obtain this information, we explored the following six parameters: 1 ) the $\mathrm{pH}$ values of the pore solution in the retarded cement slurries; 2) the beginning of setting temperature, and the total energy generated in exothermal acid-base reactions; 3) the reaction products formed by interactions between the cement and the retarder; 4) the porosity and compressive strength of autoclaved cements before exposure to acid; 5) the composition of phases formed in autoclaved cement bodies; and, 6) the identification of corrosion products of the cement after exposure to acid. All the information was integrated and correlated directly with the weight loss caused by acid erosion of the retarded cements after exposure for 20 days to a $\mathrm{H}_{2} \mathrm{SO}_{4}$ solution $(\mathrm{pH}, 1.1)$ containing $\sim 3000 \mathrm{ppm} \mathrm{CO}_{2}$ at $90^{\circ} \mathrm{C}$.

\subsubsection{Experimental}

Secar 51 calcium aluminate cement (CAC), supplied by Lafarge Aluminates Corporation, was used as the base solid reactant. The X-ray powder diffraction (XRD) data showed that Secar 51 had three major crystalline components, gehlenite (2CaO. $\left.\mathrm{Al}_{2} \mathrm{O}_{3} \cdot \mathrm{SiO}_{2}, \mathrm{C}_{2} \mathrm{AS}\right)$, monocalcium aluminate $\left(\mathrm{CaO} \cdot \mathrm{Al}_{2} \mathrm{O}_{3}, \mathrm{CA}\right)$, and pervoskite $\left(\mathrm{CaTiO}_{3}\right) . \mathrm{XRD}$ data (Philips Electronic Instruments) was recorded using nickel-filtered $\mathrm{Cu} \mathrm{K \alpha}$ radiation at $40 \mathrm{kV}$ and $20 \mathrm{~mA}$. Granular sodium polyphosphate, -[-(- $\left.\mathrm{Na}^{+} \mathrm{PO}_{3}{ }^{-}-\right)_{\mathrm{n}^{-}}$, $\mathrm{NaP}$ ], was supplied by the Aldrich Chemical Company Inc. The NaP then was dissolved in water to make a $25 \mathrm{wt} \%$ solution for use as the cement-forming acid aqueous reactant. Organic citric acid, [HOC $\left(\mathrm{CO}_{2} \mathrm{H}\right)\left(\mathrm{CH}_{2} \mathrm{CO}_{2} \mathrm{H}\right)_{2}$ ], also was obtained from the Aldrich Chemical Company and the sodium chloride, $\mathrm{NaCl}$, was used as reference inorganic retarder.

The formula of the neat cement slurry was $62 \mathrm{wt} \%$ CAC and $38 \mathrm{wt} \% \mathrm{NaP}$ (25 wt\% solution). Before mixing thoroughly these two components, the retarder at 2, 4, 6, and $8 \%$ by weight of the total amount of CAC was dissolved in the NaP solution at room temperature. Retarded and non-retarded cement slurries were cast in cylindrical molds (30 mm diam. and $70 \mathrm{~mm}$ long), and left for 24 hours to harden at room temperature. The hardened specimens then were exposed for 20 hours in an autoclave at $180^{\circ} \mathrm{C}$ before immersing them for 20 days in the $\mathrm{H}_{2} \mathrm{SO}_{4}$ solution ( $\mathrm{pH} 1.1$ ) containing $0.5 \mathrm{wt} \%$ sodium 
hydrogen carbonate $\left(\mathrm{NaHCO}_{3}\right)$ as a source of $\sim 3000 \mathrm{ppm} \mathrm{CO}_{2}$ at $90^{\circ} \mathrm{C}, \mathrm{H}_{2} \mathrm{SO}_{4}+$ $2 \mathrm{NaHCO}_{3} \rightarrow \mathrm{Na}_{2} \mathrm{SO}_{4}+2 \mathrm{CO}_{2}+2 \mathrm{H}_{2} \mathrm{O}$. To maintain the $\mathrm{pH}$ at 1.1, the $\mathrm{H}_{2} \mathrm{SO}_{4}$ solution was replenished with a fresh solution every 5 days. The volume proportion of the cement specimens to the acid solution was 1 to 25 .

A non-isothermal differential scanning calorimeter (DSC, DuPont 910) with a heating rate of $10^{\circ} \mathrm{C} / \mathrm{min}$. in $\mathrm{N}_{2}$ gas was used to determine the onset temperature of setting and to obtain the total energy generated in an acid-base exothermic reaction. The phases formed in the autoclaved cement bodies before and after exposure to acid was identified using XRD and Fourier Transform Infrared Spectroscopy (FT-IR, Perkin Elmer Model 1600). These techniques also were used in exploring the phase transition occurring in a superficial layer of the cement after exposure to acid. The image analysis was performed by the scanning electron microscopy (SEM). The porosity of autoclaved cements was determined by helium comparison pycnometry (Micromeritrics, AccuPyc 1330). The compressive strength was determined from the average of three specimens.

\subsubsection{Results}

An increase in the set temperature of $\mathrm{CaP}$ cement by citric acid was due to the precipitation of $\mathrm{Ca}^{2+}$-complexed carboxylate compound as a set-retarding reaction product on the surfaces of the CAC reactant. This carboxylate complexity was yielded by the interactions between the $\mathrm{Ca}^{2+}$ ions liberated from the CAC reactant and the carboxylic acid groups within citric acid. The carboxlate complexity acted as a barrier layer, which hindered contact between the CAC as the base solid reactant and sodium polyphosphate solution as the acid liquid reactants. This obstruction significantly increased the onset temperature of setting of the cement slurry, thereby extending its thickening time at high temperature (Table 1). However, this barrier layer was vulnerable to disintegration due to the following two possible factors: One is the attack by free $\mathrm{Ca}^{2+}$ ions from CAC; the other is associated with degradation at high temperature. This directly reflected the great deal of exothermic energy generated by acid-base reactions between the $\mathrm{Ca}^{2+}$ and $\mathrm{Na}^{+} \mathrm{H}_{2}\left(\mathrm{PO}_{4}\right)^{-}$in an aqueous medium after the disintegration of barrier layers at the elevated temperature (Figure 1). 
In contrast, the uptake of $\mathrm{Ca}^{2+}$ by the $\mathrm{NaCl}$ retardant led to the formation of a $\mathrm{CaCl}_{2} \cdot \mathrm{xH}_{2} \mathrm{O}$ reaction product as barrier layer that increased the setting temperature of slurry. Unlike the carboxlate complexity layer, this layer deposited on the CAC grain's surfaces was resistant to disintegration by further $\mathrm{Ca}^{2+}$ dissociation from CAC and to degradation at high temperature, causing a considerable attenuation of exothermic energy generated by acid-base reaction between reactants (Figure 2). Such low reaction energy was detrimental to the development of strength in the cement (Table 1). Correspondingly, the compressive strength of $180^{\circ} \mathrm{C}$-autoclaved $\mathrm{NaCl}$-retarded cements fell more than 45 $\%$, compared with that of citric acid-modified cements.

Table 1. Changes in the onset and peak temperatures and the total energy on the DSC exothermic reaction curve of cement as a function of the concentration of $\mathrm{NaCl}$ and citric acid.

\begin{tabular}{|c|c|c|c|c|}
\hline NaCl, wt\% & $\begin{array}{c}\text { Citric acid, } \\
\mathbf{w t} \%\end{array}$ & $\begin{array}{c}\text { Onset } \\
\text { temperature of } \\
\text { exothermic } \\
\text { curve, } \boldsymbol{T}_{\boldsymbol{o}},{ }^{\circ} \mathbf{C}\end{array}$ & $\begin{array}{c}\text { Peak } \\
\text { temperature of } \\
\text { exothermic } \\
\text { curve, } \boldsymbol{T}_{\boldsymbol{p}},{ }^{\circ} \mathbf{C}\end{array}$ & $\begin{array}{c}\text { Exothermic } \\
\text { reaction } \\
\text { energy, } \Delta \mathbf{H}, \\
\mathbf{J} / \mathbf{g}\end{array}$ \\
\hline 0 & & 54.3 & 58.9 & 87.3 \\
\hline 2 & & 62.2 & 65.5 & 77.6 \\
\hline 4 & & 74.2 & 77.7 & 24.2 \\
\hline 6 & & 86.9 & 91.9 & 12.9 \\
\hline 8 & & 104.5 & 119.8 & 5.9 \\
\hline & 2 & 85.8 & 94.2 & 90.5 \\
\hline & 4 & 109.3 & 116.0 & 93.3 \\
\hline & 6 & 117.9 & 123.6 & 97.4 \\
\hline & 8 & 134.9 & 140.7 & 101.4 \\
\hline
\end{tabular}




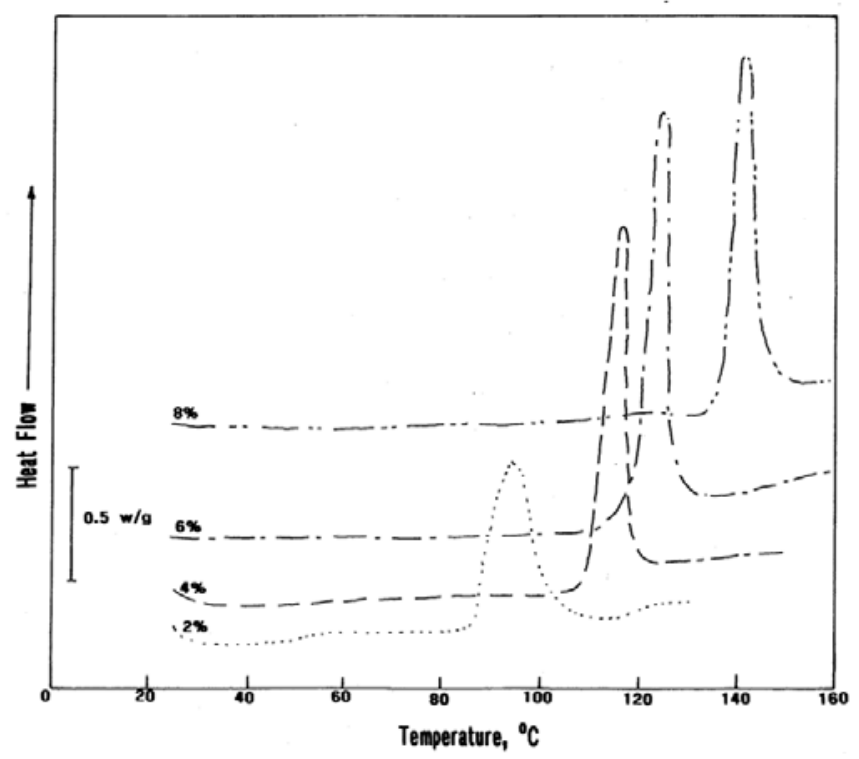

Figure 1. DSC exothermic curves for citric acid-retarded cement slurries.

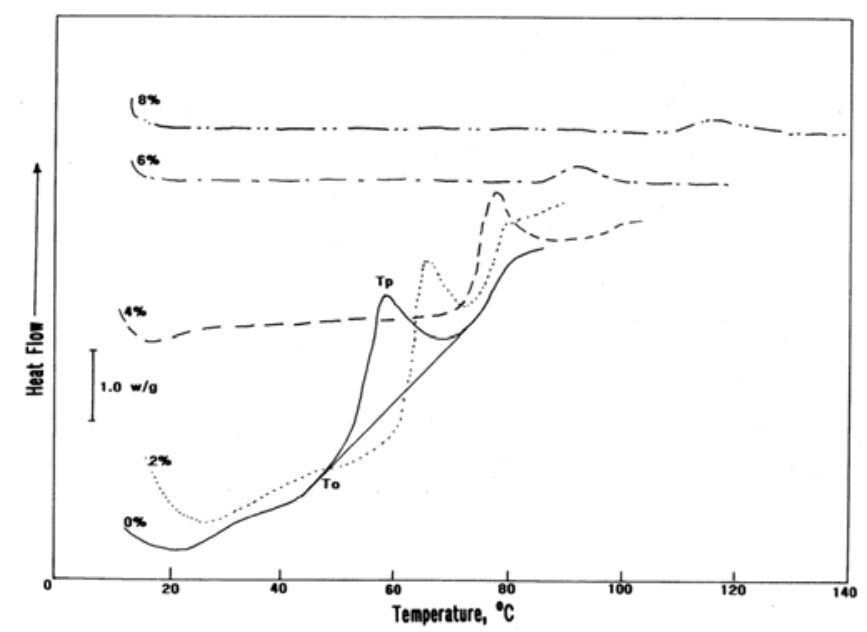

Figure 2. Non-isothermal DSC exothermic curves for NaCl-retarded and nonretarded cement slurries.

Although some of these set-retarding reaction products still remained in the cement's bodies cured at room temperature, they were completely eliminated after exposure in the 
$180^{\circ} \mathrm{C}$ autoclave for 24 hours. The phase composition assembled in all the retarded and non-retarded cements' bodies after autoclaving was comprised of three reaction products and two remaining non-reacted reactants. The former included the hydroxyapatite, boehmite, and hydrogarnet, and the latter were the moncalcium aluminate and pervoskite. When the retarded and non-retarded cements were exposed for 20 days to $\mathrm{CO}_{2}$-laden acid solution at $90^{\circ} \mathrm{C}$, the acid erosion of both the citric acid- and $\mathrm{NaCl}$-retarded cements depended on the amount of retarders; the loss in weight of the cements rose as the amount of retarders increased. However, the rate of its loss with citric acid was much lower than that for $\mathrm{NaCl}$ (Figure 3). Nevertheless, the extent of loss for all cements was related directly to the phase transition of hydroxyapatite and hydrogarnet into the crystalline bassanite scale as acid-induced corrosion product (Figure 4), signifying that these phases as reaction products were susceptible to reactions with $\mathrm{H}_{2} \mathrm{SO}_{4}$ and $\mathrm{Na}_{2} \mathrm{SO}_{4}$. With sulfuric acid, bassanite was formed through following possible interactions; $\mathrm{Ca}_{5}\left(\mathrm{PO}_{4}\right)_{3}(\mathrm{OH})+$ $5 \mathrm{H}_{2} \mathrm{SO}_{4} \rightarrow 5 \mathrm{CaSO}_{4}+3 \mathrm{H}_{3} \mathrm{PO}_{4}+\mathrm{H}_{2} \mathrm{O}$, and $3 \mathrm{CaO} . \mathrm{Al}_{2} \mathrm{O}_{3} \cdot 6 \mathrm{H}_{2} \mathrm{O}+3 \mathrm{H}_{2} \mathrm{SO}_{4} \rightarrow 3 \mathrm{CaSO}_{4}+$ $2 \mathrm{Al}(\mathrm{OH})_{3}+6 \mathrm{H}_{2} \mathrm{O}$. For sodium sulfate, these reactions are as follows; $\mathrm{Ca}_{5}\left(\mathrm{PO}_{4}\right)_{3}(\mathrm{OH})+$ $5 \mathrm{Na}_{2} \mathrm{SO}_{4} \rightarrow 5 \mathrm{CaSO}_{4}+3 \mathrm{Na}_{3} \mathrm{PO}_{4}+\mathrm{NaOH}$, and $3 \mathrm{CaO} . \mathrm{Al}_{2} \mathrm{O}_{3} \cdot 6 \mathrm{H}_{2} \mathrm{O}+3 \mathrm{Na}_{2} \mathrm{SO}_{4} \rightarrow 3 \mathrm{CaSO}_{4}$ $+2 \mathrm{Al}(\mathrm{OH})_{3}+6 \mathrm{NaOH}$. Compared with these phases, the susceptibility of boehmite phase to reactions with $\mathrm{H}_{2} \mathrm{SO}_{4}$ and $\mathrm{Na}_{2} \mathrm{SO}_{4}$ is negligible, implying that it displays a great resistance to acid and sulfate.

Although the bassanite scales clinging to the cement's surfaces served as the primary barrier against further attack by acid and sulfate on the HOAp and hydrogarnet in the superficial layers, their spallation eventually led to an overall loss of weight of the cements. Nevertheless, we believe that the repetitive processes of HOAp and hydrogarnet $\rightarrow$ bassanite $\rightarrow$ spallation play an important role in extending the useful lifetime of the $\mathrm{CaP}$ cement in a low $\mathrm{pH}$ environment at $90^{\circ} \mathrm{C}$. 

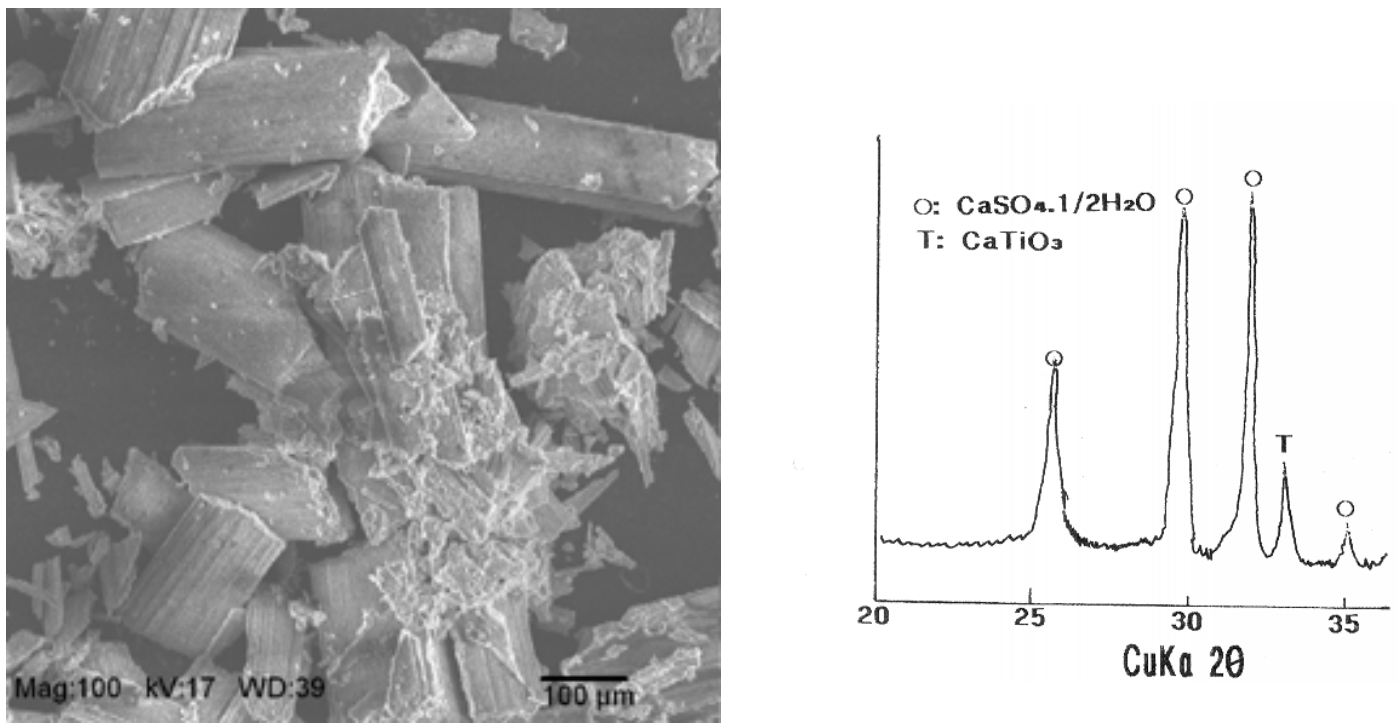

Figure 3. SEM image and XRD pattern of the acid corrosion products formed on cement's surfaces during the 20-day-long exposure.

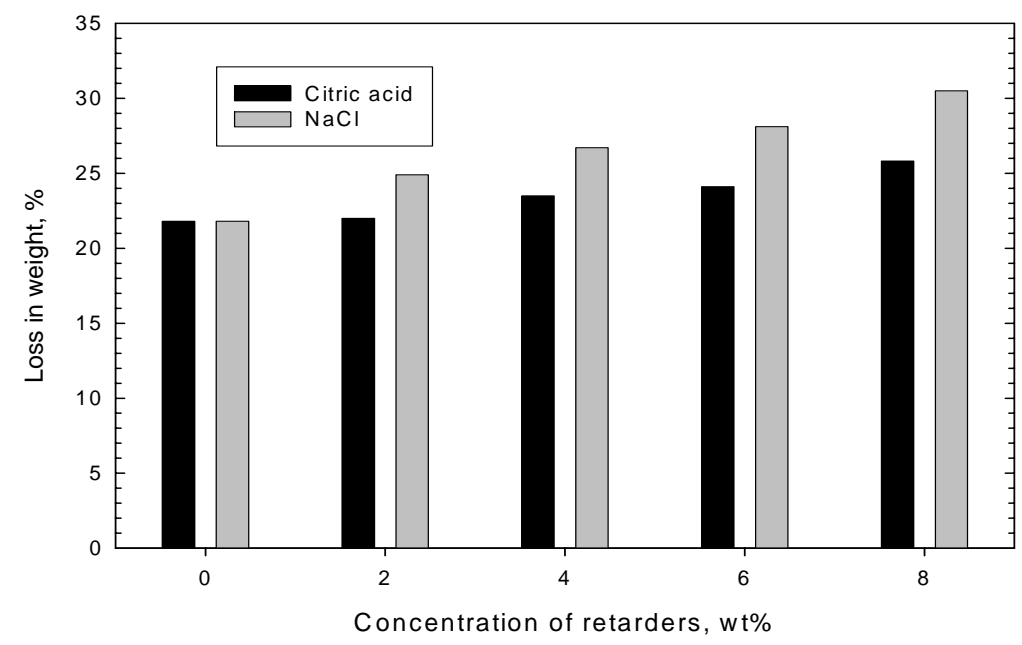

Figure 4. Loss in weight of retarded and non-retarded cements afte exposure for 20 days in $\mathrm{CO}_{2}$-laden acid at $90^{\circ} \mathrm{C}$.

\subsection{Low Density Slurry}

\subsubsection{Air-foamed Cement Slurry}

There are three ways to prepare the low-density slurries with CaP cement: First is to incorporate pressure- and high temperature-resistant hollow ceramic-shelled 
microspheres, with a density of $\sim 0.7 \mathrm{~g} / \mathrm{cc}$ and a particle size of $75-200 \mu \mathrm{m}$, into the slurry; the second is to disperse fine $\mathrm{N}_{2}$ gas bubbles created by injecting highly pressured $\mathrm{N}_{2}$ into a slurry containing the foaming additive; and, the third is to introduce small, fine air bubbles into the slurry by adding a foaming reagent to it. For the first method, we reported that among the various ceramic microspheres available, an aluminosilicateshelled hollow microsphere was most suitable for the CaP cement; it provided a lowdensity slurry of $\sim 1.3 \mathrm{~g} / \mathrm{cc}$ in conjunction with a compressive strength of more than 6.89 MPa [8]. Regarding the second method, the $\mathrm{N}_{2}$ gas-foamed CaP cement slurry was successfully placed in Coso geothermal wells at temperature range of $160-200^{\circ} \mathrm{C}$ in the U.S.A. by a reverse circulation placement technique (RCPT) in 2002. Almost two years after it was placed, Moore, et al. reported that this foamed cement retained its integrity by showing a great adherence to the casing pipes, and displaying both good mechanical and physical behavior [9]. In addition, the $\mathrm{N}_{2}$ - foamed cement served as an excellent thermal insulator and corrosion inhibitor for geothermal steam production pipes [10].

Although the $\mathrm{N}_{2}$-foamed CaP cement slurry has offered very promising results thus far, the third method using a simple foaming reagent was thought of as the most cost-effective and inexpensive technology because it eliminated the use of expensive ceramic microspheres and the time-consuming, complicated $\mathrm{N}_{2}$-injection process. The microscale air bubble cells are simply created within the slurry by adding a certain amount of foaming reagent to it, and can be dispersed uniformly in it by mixing in a shear blender at room temperature. Using the same foaming technology, an aerosol foam cement in terms of the cellular cement containing air bubbles of more than $50 \%$ of the volume was widely applied to the building materials encompassing lightweight cores in a sandwich structure, thermal insulators, sound barriers, fire wall, structural backfill, and foundations because of its good creep resistance, high specific stiffness and strength [1113], low thermal conductivity [14], and good freeze-thaw durability [15]. However, there are four important issues to be addressed before this technology is applied to geothermal wells: The first concerns the stability of air bubble cells dispersed in the slurry under a high hydrothermal temperature; second are the changes in the mechanical and physical properties of set foam cement as a function of the extent of foaming; third is whether the crystalline phase composition responsible for strengthening the cement is changed by 
varying the content of foaming reagent; and, fourth is the effectiveness of foamed cement in mitigating corrosion of carbon steel casing pipes.

In response to these questions, we established six research objectives 1) to determine the changes in porosity, water permeability, and compressive strength of autoclaved foam cement as a function of content of foaming reagent, 2) to identify the crystalline phases formed in the non-foamed and foamed cements after autoclaving, 3) to explore the microstructure developed within foamed cement, 4) to use the DC electrochemical potentiodynamic polarization test on carbon steel coupons covered with foamed cements, 5) to measure the ionic conductivity of foamed cement layers deposited on the steel's surfaces by AC electrochemical impedance spectroscopy (EIS), and 6) to determine the adherence of foamed cement to the surface of steel.

\subsubsection{Experimental}

Halliburton supplied the cocoamidopropy dimethylamine oxide-based foaming reagent under the trade name "ZoneSealant 2000". Calcium aluminate cement (CAC, Secar 60) and Class F fly ash, used as the solid reactants, were obtained from the Lafarge Aluminate Corp., and Pozament Corp., respectively. A 25 wt\% sodium polyphosphate -[$\left.\left(\mathrm{NaPO}_{3}\right)_{\mathrm{n}^{-}}, \mathrm{NaP}\right]$, supplied by the Aldrich Chemical Company Inc., was used as the cement-forming liquid reactant for modifying the CAC-blended fly ash solid reactant. The solid reactant, made up in a twin shell dry blender, had a constant ratio of CAC/fly ash of $60 / 40$ by weight. The weight ratio of the $25 \mathrm{wt} \% \mathrm{NaP}$ solution to the blend cement for the original cement slurry was 0.5 . In preparing the foamed slurries, $0,0.5,1.0,1.5$, 2.0, 3.0, 4.0, 5.0, 6.0, 7.0, 10.0, 15.0, and $20.0 \%$ foaming reagent by weight of total water in the $25 \mathrm{wt} \% \mathrm{NaP}$ solution was added to the original slurry, and then was mixed by shear-blender. This shear mixing led to the aeration of slurry by increasing the incorporation of air bubbles into the slurry, and we observed that the originally stiff slurry was converted into a smooth creamy one.

The density, g/cc, of the foamed cement slurries was determined 10 minutes after mixing using the fluid density balance. Then, the slurries were poured into two different cylindrical sized molds: One was 30-mm diam. x 60-mm long for measuring compressive strength and porosity; the other was 30-mm diam. 33-mm long for testing water 
permeability. The slurry-filled molds were left for 24 hours at room temperature, and then the hardened cement specimens were removed from the molds and autoclaved for 24 hours at $200^{\circ} \mathrm{C}$, which is the maximum temperature at location that the formed $\mathrm{CaP}$ cements were placed in geothermal wells thus far. The porosity of autoclaved cements was measured by helium comparison pyconometry. Water permeability through the cylindrical cement specimens under the pressure of $202.65 \mathrm{kNm}^{-2}$ was determined by the Ruska liquid permeameter. The results of these tests and measurements are the average from three specimens. Changes in the crystalline phase composition of autoclaved cements with different contents of foaming reagent were studied by X-ray diffraction(XRD). Scanning electron microscopy (SEM) was used to explore the microstructure developed in the foamed cements, and to reveal the morphological features of the underlying steel's surfaces after physically removing the autoclaved cement layers. For the latter, the chemistry of their surface was surveyed by the energydispersive X- ray spectrum (EDX) to obtain information on the extent of adherence of the foamed cement to steel's surface. DC electrochemical testing for corrosion was performed with the EG\&G Princeton Applied Research Model 362-1 Corrosion Measurement System. The electrolyte was a $1.0 \mathrm{M}$ sodium chloride. The specimen was mounted in a holder, and then inserted into an EG\&G Model K47 electrochemical cell. The test was conducted under an aerated condition at $25^{\circ} \mathrm{C}$, on an exposed surface area of $1.0 \mathrm{~cm}^{2}$. The polarization curves were measured at a scan rate of $0.5 \mathrm{mVs}^{-1}$ in the corrosion potential range from -1.35 to $-0.75 \mathrm{~V}$. AC electrochemical impedance spectroscopy (EIS) was used to evaluate the ability of the exposed cement layers to protect the steel from corrosion. The specimens were mounted in a holder, and then inserted into an electrochemical cell. Computer programs were prepared to calculate theoretical impedance spectra and to analyze the experimental data. The specimens with a surface area of $13 \mathrm{~cm}^{2}$ were exposed to an aerated $1.0 \mathrm{M}$ sodium chloride electrolyte at $25^{\circ} \mathrm{C}$, and single-sine technology with an input $\mathrm{AC}$ voltage of $10 \mathrm{mV}$ (rms) was employed over a frequency range of $10 \mathrm{KHz}$ to $10^{-2} \mathrm{~Hz}$. To estimate the protective performance of the coatings, the pore resistance, Rp, $\left(\mathrm{ohm}-\mathrm{cm}^{2}\right)$ was determined from the plateau in Bode-plot scans that occurred in low frequency regions. 


\subsubsection{Results}

The chemical foaming reagent, which incorporates fine air bubble cells into the cement slurry, significantly contributed to reducing the density of the fly ash-modified $\mathrm{CaP}$ cement slurry. Using such low-density cement slurry would resolve the problem of lost circulation. When the foamed $\mathrm{CaP}$ cement slurries were autoclaved at $200^{\circ} \mathrm{C}$, most of the air bubbles dispersed throughout the slurry led to the development of a porous structure exhibiting a uniform distribution of discrete pores (ranging from $\sim 290 \mu \mathrm{m}$ to $\sim$ $40 \mu \mathrm{m}$ ) in the set foam cement (Figure 5). Although the foaming reagent acted to inhibit the extent of reactions between monocalcium aluminate $\left(\mathrm{CaO} \cdot \mathrm{Al}_{2} \mathrm{O}_{3}\right)$ as the major phase in the calcium aluminate cement (CAC) solid reactant, and sodium polyphosphate (NaP) liquid reactant, the three crystalline phases, hydroxyapatite [ $\left.\mathrm{Ca}_{5}\left(\mathrm{PO}_{4}\right)_{3}(\mathrm{OH}), \mathrm{HOAp}\right]$, boehmite, $(\gamma-\mathrm{AlOOH})$, and hydrogarnet, $\left(3 \mathrm{CaO} \mathrm{Al}_{2} \mathrm{O}_{3} \cdot 6 \mathrm{H}_{2} \mathrm{O}, \mathrm{C}_{3} \mathrm{AH}_{6}\right)$, as hydrothermal reaction products at $200^{\circ} \mathrm{C}$, were responsible for strengthening the foamed $\mathrm{CaP}$ cement. These reaction products offered the improved compressive strength and reduced porosity of the foamed cement, compared with those of $\mathrm{N}_{2}$ gas-foamed Class $\mathrm{G}$ cement made from slurry of similar density. However, adding an excessive amount of foaming reagent dispersed undesirable coalescent bubble cells in the slurry, reflecting the conformation of continuous pore structure in set foam cement (Figure 6). This finding also suggested that the size of bubble cells created by the $\mathrm{N}_{2}$ gas-foaming technology under high pressure probably was smaller than that of air bubble cells made under no pressure. Thus, one major issue was the increase in water permeability of the cement along with the reduction in the slurry's density, raising concern that the maximum efficacy of cement in mitigating the corrosion of carbon steel well casing pipes was diminished (Table 2). For non-foamed $\mathrm{CaP}$ cement with a porosity of less than $11 \%$ and minimum water permeability, the three factors contributed to alleviating the brine-caused corrosion of carbon steel; 1) the excellent adherence of the cement layer to steel, providing a high coverage over the entire steel's surfaces at the interfacial contact zone between the cement and steel, 2) its retardation of the cathodic corrosion reactions, and, 3) its minimum conductivity of corrosive ionic electrolytes. Unfortunately, such efficacy of the cement in mitigating corrosion was diminished by increasing the extent of its foaming. The most effective amount of this foaming reagent in minimizing this loss of effectiveness and in reducing 
the slurry's density was $3 \%$ by weight of total water in the slurry. Adding this amount gave a slurry density of $1.43 \mathrm{~g} / \mathrm{cc}$, which is $25 \%$ lower that that of non-foamed slurry,

good compressive strength of $24.1 \mathrm{MPa}$, low water permeability of $1.6 \times 10^{-3}$ Darcy, and moderate adherence to steel.

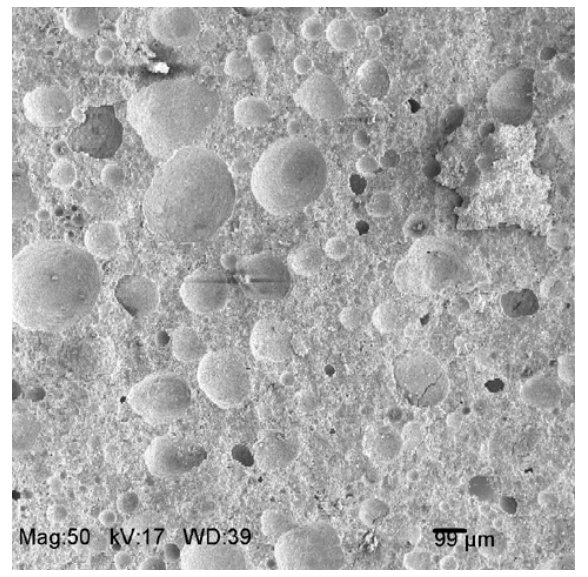

Figure 5. SEM image of discrete micro-size pores generated from the fine-air bubbles in the slurry with $1.42 \mathrm{~g} / \mathrm{cc}$ density.

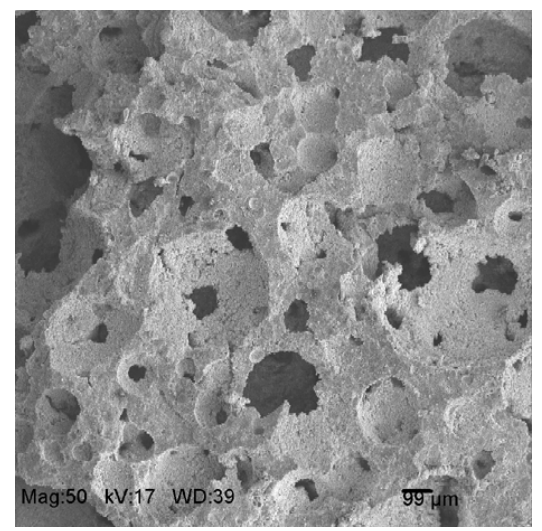

Figure 6. SEM image of undesirable coalescent pore structure generated from the slurry with $1.11 \mathrm{~g} / \mathrm{cc}$ density. 
Table 2. Changes in the density of the slurries, and in the porosity, compressive strength, and water permeability of $200^{\circ} \mathrm{C}$-autoclaved $\mathrm{CaP}$ foam cements as a function of the content of the foaming reagent.

\begin{tabular}{|c|c|c|c|c|}
\hline $\begin{array}{l}\text { Foaming } \\
\text { reagent, } \\
\text { wt\% }\end{array}$ & $\begin{array}{l}\text { Density of } \\
\text { slurry, g/cm }\end{array}$ & $\begin{array}{l}\text { Porosity of } \\
\text { autoclaved } \\
\text { cement, \% }\end{array}$ & $\begin{array}{l}\text { Compressive } \\
\text { strength of } \\
\text { autoclaved cement, } \\
\text { MPa }\end{array}$ & $\begin{array}{l}\text { Water permeability of } \\
\text { autoclaved cement, } \\
\text { Darcy }\end{array}$ \\
\hline 0 & 1.91 & 10.94 & 72.8 & $2.0 \times 10^{-5}$ \\
\hline 1 & 1.65 & 27.80 & 43.4 & $4.9 \times 10^{-5}$ \\
\hline 3 & 1.43 & 38.50 & 24.1 & $1.6 \times 10^{-3}$ \\
\hline 5 & 1.34 & 43.80 & 18.5 & $2.0 \times 10^{-2}$ \\
\hline 10 & 1.22 & 49.30 & 14.7 & $7.9 \times 10^{-2}$ \\
\hline 15 & 1.11 & 54.35 & 11.0 & $8.7 \times 10^{-2}$ \\
\hline 20 & 1.01 & 60.49 & 6.8 & \\
\hline
\end{tabular}

\subsubsection{Polymer-modified Air-foamed Slurry}

As described above, one critical issue remaining was the conversion of some coalesced air bubble cells into the formation of undesirable continuous pore structure, raising concerns that the cement would be highly permeable. The requirements of geothermal well cements are not only that they mechanically support the steel casing pipes, but also they should protect the casings against brine-caused corrosion. There is no doubt that an enhancement of water permeability through cement due to a continuous pore structure would promote the rate of the casing's corrosion.

Our approach to dealing with this problem is to incorporate organic polymers into the foamed cement. In an ideal polymer-modified foamed cement, the continuous pores would be sealed by a water-insoluble, high-temperature stable polymer, thereby restraining the transportation of brine through the cement. Thus, emphasis was directed towards assessing the usefulness of waterborne polymers as the additives in reducing the extent of water permeability of foamed CaP cement, and in mitigating the corrosion of carbon steel casings. On opting for apt polymers, our previous study of the effectiveness of polymer in improving the acid-resistance of $\mathrm{CaP}$ cement demonstrated that among the 
several different waterborne types, acrylic-styrene copolymer (ASC) was the most effective additive in abating acid erosion of the cement [16]. The ASC strongly adhered to the surfaces of cement hydrates and non-reacted cement grains, suggesting that the overall coverage of hydrates' and non-reacted gains' surfaces by the ASC film played an essential role in conferring the resistance to acid of the ASC-modified CaP cement. Based upon this information, we adapted the waterborne acrylic-based polymers to modify the foamed CaP cement. Furthermore, the polymer-modified CaP cements in our previous study were prepared at low temperature of $110^{\circ} \mathrm{C}$. Thus far, no exploration was made for the hydrothermal stability of polymers in the CaP cement at $200^{\circ} \mathrm{C}$.

Therefore, this study was divided into three phases. The first was to investigate the hydrothermal stability and the alternation in chemical structure of the polymers in the cement autoclaved at $200^{\circ} \mathrm{C}$. The second phase included monitoring the changes in the slurry's density and in the setting temperature of foamed cement slurries after adding the

polymer. The final phase covered the compressive strength and water permeability for the foamed cements after autoclaving at $200^{\circ} \mathrm{C}$. All the information obtained was integrated and correlated directly with the results from electrochemical studies of the corrosionprevention of steel by polymer-modified foam cements.

\subsubsection{Experimental}

Noveon, Inc supplied three waterborne acrylic-based polymer additives; a styrene acrylic emulsion (SAE, Trade Name, HYCARß26-1265), acrylic copolymer latex (ACL, Trade Name, HYCAR $® 26391)$, and carboxyl-modified acrylic latex (CAL, Carbobond $®$ 26373). The styrene butadiene emulsion (SBE, Trade Name, GOOD-RITE® SB-1459) also obtained from Noveon Corp., was used as the non-acrylic additive. Typical properties of these additives are shown in Table 3. All the acrylic-based additives are acid. Calcium aluminate cement (CAC, Secar 60) and Class F fly ash, used as the solid reactants, were obtained from the Lafarge Aluminate Corp., and Pozament Corp., respectively. A $25 \mathrm{wt} \%$ sodium polyphosphate -[-( $\left.\left.\mathrm{NaPO}_{3^{-}}\right)_{\mathrm{n}^{-}}, \mathrm{NaP}\right]$, supplied by the Aldrich Chemical Company Inc., was used as the cement-forming liquid reactant for modifying the CAC-blended fly ash solid reactant. The solid reactant, made up in a twin shell dry blender, had a constant ratio of CAC/fly ash of 60/40 by weight. The amounts of 
polymers as the solid state in this cement system were 5,10 , and $15 \%$ by total weight of CAC and fly ash. Halliburton supplied the cocoamidopropy dimethylamine oxide-based foaming reagent. The amount of foaming reagent used was $3 \%$ by weight of total water in the NaP solution and the polymer additive.

Table 3. Some properties of the waterborne polymer additives used in this study

\begin{tabular}{|l|l|l|l|}
\hline Polymer & PH & $\begin{array}{l}\text { Total solid of } \\
\text { polymer, \% }\end{array}$ & $\begin{array}{l}\text { Brookfield } \\
\text { viscosity spindle } \\
\text { No.2, 60 rpm, } \\
\text { centipoises }\end{array}$ \\
\hline SBE & 7.5 & 53 & $<500$ \\
\hline SAE & 2.6 & 49 & $<800$ \\
\hline ACL & 3.6 & 50 & 125 \\
\hline CAL & 2.6 & 58 & 90 \\
\hline
\end{tabular}

Thermogravimetric analysis (TGA) was used to determine the thermal decomposition temperature of the bulk polymers and the polymers in cement before and after exposure for 24 hours in autoclave at $200^{\circ} \mathrm{C}$. The alteration in molecular structure of the polymers in the cement after autoclaving was surveyed by Fourier Transform Infrared Spectroscopy (FT-IR). The density, g/cc, of the polymer-modified foam cements' slurries was determined 10 minutes after mixing using the fluid density balance. Then, the slurries were poured into two different cylindrical sized molds: One was 30-mm diam. x 60-mm long for measuring compressive strength; the other was 30-mm diam. x 33-mm long for testing water permeability. The slurry-filled molds were left for 24 hours at room temperature, and then the hardened cements were removed from the molds and autoclaved for 24 hours at $200^{\circ} \mathrm{C}$; this corresponded to the maximum temperature at the location where the foamed $\mathrm{CaP}$ cements have been placed in geothermal wells thus far. Water permeability through the cylindrical cement specimens under a pressure of 202.65 $\mathrm{kNm}^{-2}$ was determined by the Ruska liquid permeameter. A non-isothermal differential scanning calorimeter (DSC) with a heating rate of $10^{\circ} \mathrm{C} / \mathrm{min}$. in $\mathrm{N}_{2}$ gas was used to determine the temperature of onset of cement slurry's setting, and to compute the total energy generated in an acid-base exothermic reaction. AC electrochemical impedance spectroscopy (EIS) was used to evaluate the ability of the exposed cement layers to protect the steel from corrosion. DC electrochemical testing for corrosion was performed 
with the EG\&G Princeton Applied Research Model 362-1 Corrosion Measurement System.

\subsubsection{Results}

Among the waterborne acrylic-based polymer additives, the styrene acrylic emulsion (SAE) displayed the best performance in significantly improving the poor corrosion-preventing behavior of the air-foamed CaP cement after autoclaving at $200^{\circ} \mathrm{C}$. Also, the incorporation of SAE was responsible for further reducing the density of the foamed cement slurry. Like any other acrylic-based additives possessing a low $\mathrm{pH}$, the $\mathrm{Ca}^{2+}$ and $\mathrm{OH}^{-}$ions dissociated from CAC as the solid base reactant preferentially reacted with the carboxylic acid, - $\mathrm{COOH}$, groups within the SAE, rather than with sodium dihydrogen phosphate, $\mathrm{Na}^{+} \mathrm{H}_{2}\left(\mathrm{PO}_{4}\right)^{-}$from sodium polyphosphate $(\mathrm{NaP})$ solution as the acid reactant. This reaction at room temperature led to the formation of some Cacomplexed carboxylate groups within the SAE's molecular structure. The carboxylic acid $\rightarrow$ Ca-complexed carboxylate group transition in the cement was completed during the exposure for 24 hours in autoclave at $200^{\circ} \mathrm{C}$. Importantly, the formation of Cacarboxylate complexes played a pivotal role in remarkably enhancing the hydrothermal stability of the SAE polymer, reflecting the fact that the onset temperature of thermal decomposition of the $\mathrm{SAE}$ in the cement before exposure rose by $59^{\circ} \mathrm{C}$ to $469.9^{\circ} \mathrm{C}$ as it was autoclaved (Table 4). In contrast, the bulk SAE polymer without the cement failed after autoclaving it.

Table 4. Thermal decomposition temperatures, $T_{2}$, of polymers in the modified foam CaP cements before and after exposure in autoclave for 24 hours at $200^{\circ} \mathrm{C}$.

\begin{tabular}{|l|l|l|}
\hline Polymer in Cement & Before exposure, $\boldsymbol{T}_{\mathbf{2}},{ }^{\circ} \mathbf{C}$ & After exposure, $\boldsymbol{T}_{\mathbf{2}},{ }^{\circ} \mathbf{C}$ \\
\hline SBE & 378.2 & 382.7 \\
\hline SAE & 410.7 & 469.9 \\
\hline ACL & 406.1 & 460.4 \\
\hline CAL & 402.1 & 459.2 \\
\hline
\end{tabular}


On the other hand, the uptake of Ca by SAE governed the setting temperature of foamed cement slurry and the output of the exothermic energy generated by the acid-base reactions between the $\mathrm{CAC}$ and $\mathrm{NaP}$; namely, adding more SAE increased the setting temperature of cement and decreased in the generation of exothermic reaction energy, verifying that the SAE acted to retard the setting of cement slurry. The capacity of exothermic reaction energy was related directly to the magnitude of development of the compressive strength; an increment in its capacity was responsible for further strengthening the cement (Figure 7). Nevertheless, the compressive strength of the foam cements modified with all acrylic-based additives after autoclaving at $200^{\circ} \mathrm{C}$ was higher that that of the unmodified one autoclaved at the same temperature.

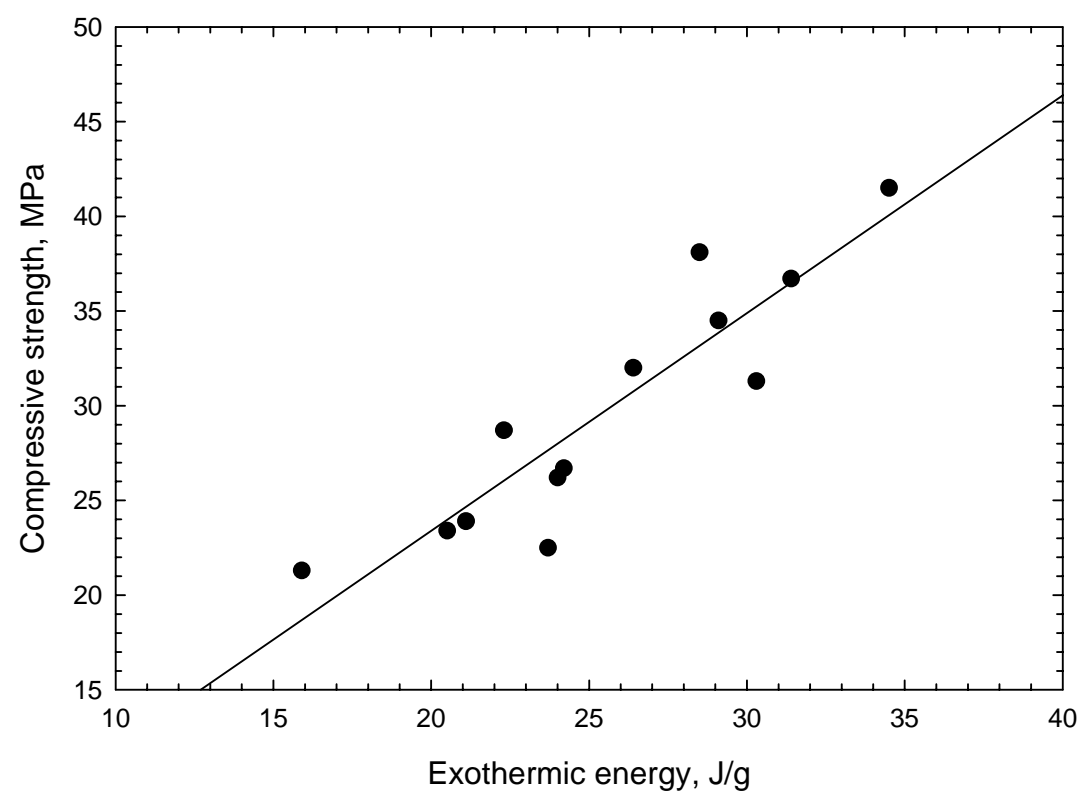

Figure 7. Relationship between the compressive strength of autoclaved foamed cements and the exothermic energy generated by acid-base reactions in the cement slurries.

The microstructure developed in the SAE-modified foam cement after autoclaving revealed that the SAE polymer containing Ca-carboxylate complexe groups bound together the reaction products and non-reacted products into the cohesive masses 
represented as a polymer/cement composite (Figure 8). Thus, the numerous craters and voids present in foamed cement were constructed of this composite. Further, some continuous pores were sealed with it, thereby minimizing the extent of water permeability through the foamed cement.

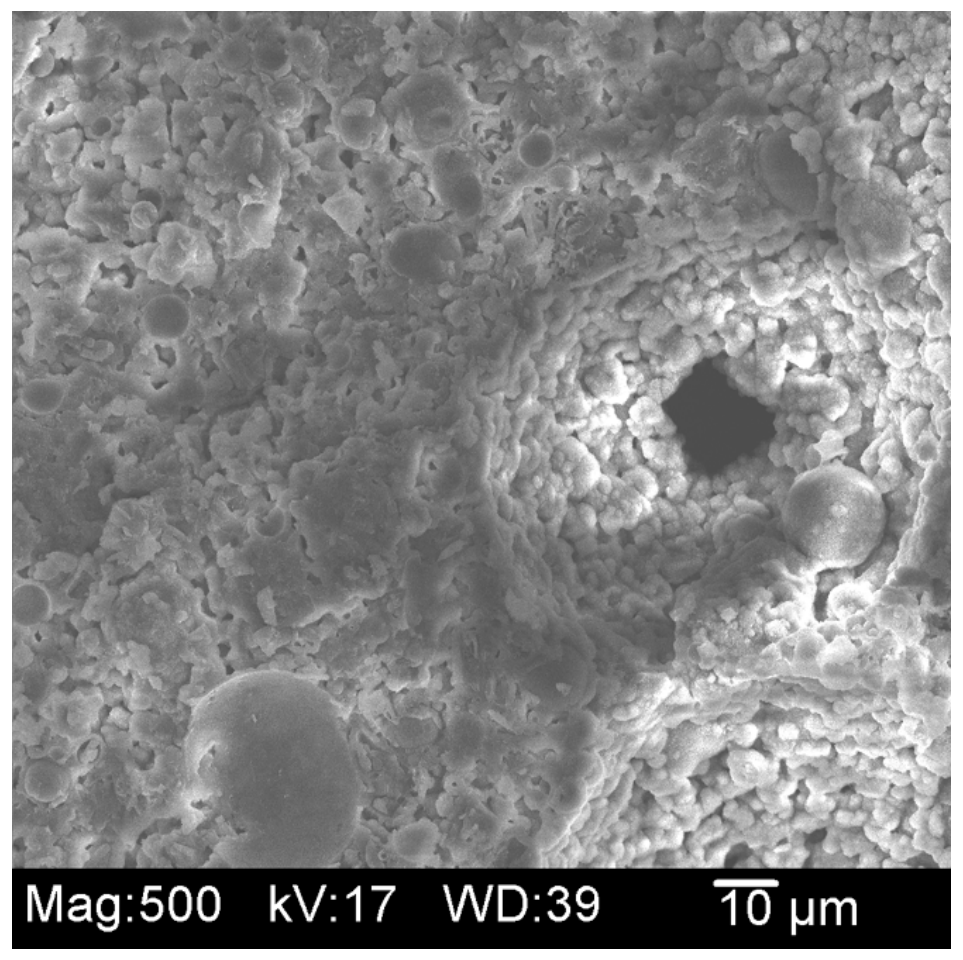

\section{Figure 8. SEM image for the fractured surface of $10 \mathrm{wt} \%$ SAE-modified foam cement after autoclaving.}

The advanced properties of foamed cement described above obtained by incorporating SAE contributed significantly to reducing the brine-induced corrosion rate of the underlying steel (Table 5). Such excellent corrosion-preventing performance by the foamed cement composite was due primarily to the following three factors; 1 ) it decreased the conductivity of corrosive $\mathrm{NaCl}$ ions, 2) it inhibited the cathodic oxygen reduction reaction at the corrosion sites of steel, and 3) it provided good coverage of the steel's surface. 
Table 5. Tafel analyses of potentiodynamic polarization curves for steel panels covered with SAE polymer-modified and unmodified foam cements.

\begin{tabular}{|l|l|l|l|l|c|}
\hline $\begin{array}{l}\text { Content of } \\
\text { polymer, } \\
\text { wt \% }\end{array}$ & $\begin{array}{l}\mathbf{E}_{\text {corr }}(\boldsymbol{I}=\mathbf{0}), \\
(\mathbf{V})\end{array}$ & $\begin{array}{l}\boldsymbol{\beta}_{\mathbf{a}} \\
(\mathbf{V} / \mathbf{d e c a d e})\end{array}$ & $\begin{array}{l}\boldsymbol{\beta}_{\mathbf{c}} \\
(\mathbf{V} / \mathbf{d e c a d e})\end{array}$ & $\boldsymbol{I}_{\text {corr, }}\left(\mathbf{A} / \mathbf{c m}^{2}\right)$ & $\begin{array}{l}\text { Corrosion } \\
\text { rate, (mpy) }\end{array}$ \\
\hline 0 & -0.4845 & 0.2250 & 0.5533 & $8.25 \times 10^{-5}$ & 37.71 \\
\hline 2 & -0.5914 & 0.2027 & 0.5718 & $5.73 \times 10^{-5}$ & 26.18 \\
\hline 5 & -0.4435 & 0.0630 & 0.2077 & $4.60 \times 10^{-5}$ & 2.10 \\
\hline 10 & -0.1968 & 0.0950 & 0.1543 & $2.51 \times 10^{-7}$ & 0.12 \\
\hline
\end{tabular}

* mpy: milli-inches per year

\subsection{Toughness}

\subsubsection{Ceramic Fiber Reinforcement}

One approach to improving the toughness of $\mathrm{CaP}$ cement is to reinforce it with strong, tough fibrous materials. The following criteria are used for selecting fibers so that they will improve the toughness of the cement: 1)good dispersiveness to achieve a uniform distribution in the cement slurry; 2)thermal resistance of $>300^{\circ} \mathrm{C}$; 3) lack of susceptibility to reactions with brine solutions containing alkali metals, alkaline earthmetals, $\mathrm{CO}_{2}$, and $\mathrm{H}_{2} \mathrm{~S}$; and 4) moderate adherence to the cement matrix.

Ceramic fibers such as alumina and aluminosilicate, however, are very attractive as alternative fibrous materials because of their stability at high temperatures and their great mechanical properties. Comparing the mechanical properties of these fibers, the alumina-based fiber had a higher modulus than that of the aluminosilicate-based fiber but its tensile strength was lower $[17,18]$. Thus, our objective was to assess the usefulness of these ceramic fibers for improving fracture toughness of the $\mathrm{CaP}$ cements. We also assessed the extent of the fiber's susceptibility to reactions with the pore solution of cement slurry at $280^{\circ} \mathrm{C}$, and the development of microstructure at the critical interfacial boundary between the fibers and the cement matrix. The data from these tests were correlated directly with the results obtained from the ductility-related mechanical tests of the fiber-reinforced cement composites.

\subsubsection{Experimental}


Two ceramic fibrous materials, $\alpha-\mathrm{Al}_{2} \mathrm{O}_{3}$ (Nextel 610) and $\alpha-\mathrm{Al}_{2} \mathrm{O}_{3} /$ mullite mixture (Nextel 720), were supplied by 3M Corporation. The size of these fibers was 10 to12 $\mu \mathrm{m}$ diam. and $~ 3 \mathrm{~mm}$ long. Calcium aluminate (CAC, Secar 60) and Class F fly ash, used as the solid reactants, were obtained from the Lafarge Aluminate Corp., and the Pozament Corp., respectively. A $25 \mathrm{wt} \%$ sodium polyphosphate $-\left[-\left(\mathrm{NaPO}_{3}-\right)_{\mathrm{n}}-\right.$, $\left.\mathrm{NaP}\right]$, supplied by the Aldrich Chemical Company Inc., was used as the cement-forming liquid reactant for modifying the CAC-blended fly ash solid reactant. The solid reactant, made up in a Twin Shell Dry Blender, had a constant ratio of CAC/fly ash of 60/40 by weight. In preparing the fiber-reinforced CaP cement composites, fibers of $0,0.2,0.5,0.7,1.0$, and $1.5 \%$ by weight of the total amount of three ingredients (CAC, fly ash, and NaP solution) were incorporated into the cement slurries. When the content of fibers in the composite slurries was increased, more NaP solution was added into the CAC/fly ash blends to obtain a workable consistency. All the ingredients were thoroughly mixed in a bowl for $3 \mathrm{~min}$ at room temperature, and were then cast into $30 \mathrm{~mm}$ diam. x 30mm long cylindrical molds for measuring water permeability and porosity. Square beam molds $(25 \mathrm{~mm}$ x $25 \mathrm{~mm}$ x $229 \mathrm{~mm}$ ) were used for the three-point flexure test with a153 mm span. These cast specimens were left to harden for 24 hours at $25^{\circ} \mathrm{C}$ in air. Then, they were removed from the molds, and exposed for 3 days in a 40,000 ppm $\mathrm{CO}_{2}$-laden $13 \mathrm{wt} \% \mathrm{NaCl}$ aqueous solution at $280^{\circ} \mathrm{C}$. The fracture toughness, $\mathrm{K}_{\mathrm{IC}}$, was obtained from the stress-strain curves in the flexure test of center-notched beam specimens. The notch with a width of $0.5 \mathrm{~mm}$ and a depth of $13 \mathrm{~mm}$ was made on the tensile side at the center position of the beam by a diamond-tipped blade.

\subsubsection{Results}

The surfaces of $\alpha-\mathrm{Al}_{2} \mathrm{O}_{3}$ phase-based ceramic fibers preferentially reacted with silicate in a $280^{\circ} \mathrm{C}$-pore solution extracted from sodium polyphosphate-modified fly ash/calcium aluminate blend $\mathrm{CaP}$ cement slurry, rather than with other ionic species such as sodium, phosphate, calcium, and aluminate. This reaction led to the $\alpha-\mathrm{Al}_{2} \mathrm{O}_{3} \rightarrow$ aluminosilicate phase transformation in the superficial layer of the fibers. However, the amount of aluminosilicate as the reaction product was too small to allow us to identify whether it was in a crystalline or amorphous phase. Nevertheless, the chemical affinity of 
the fiber's surface with the cement slurry in a hydrothermal environment at $280^{\circ} \mathrm{C}$ played an important role in developing moderate bonding at the critical interfacial boundary zones between the fibers and CaP cement matrix (Figure 9). The most effective content
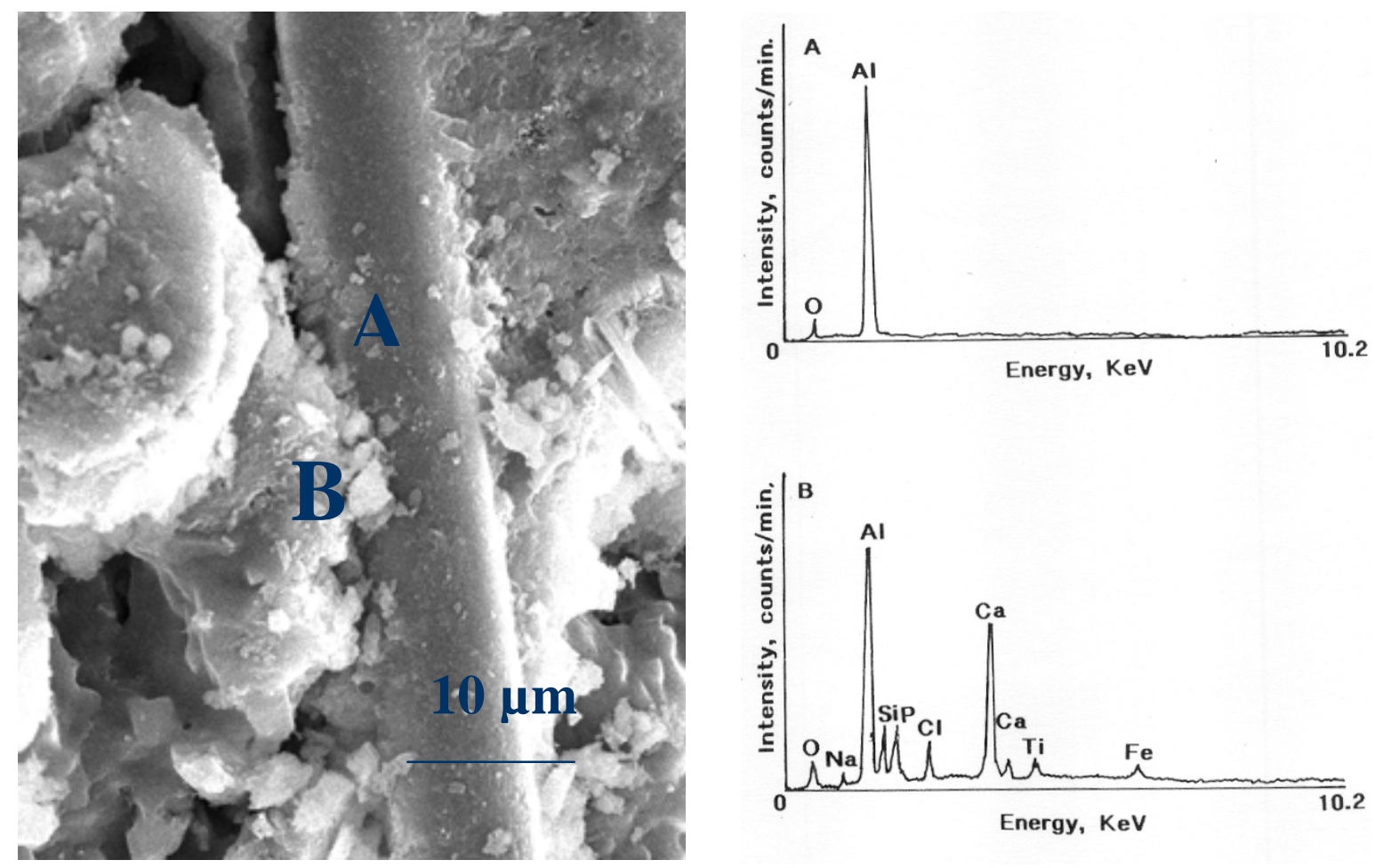

Figure 9. SEM-EDX analysis of fractured surfaces for $280^{\circ} \mathrm{C}$ autoclaved $\alpha-\mathrm{Al}_{2} \mathrm{O}_{3}$ fiber-reinforced CaP cements.

of fiber for improving the ductility of cement was approximately $1 \mathrm{wt} \%$, which provides a fracture toughness of $0.059 \mathrm{MN} / \mathrm{m}^{3 / 2}$, corresponding to an increment of $\sim 2.7$ times more over that of the non-reinforced cements. Increasing the amount of fiber to $1.5 \mathrm{wt} \%$ did not further improve its toughness because a porous structure was created in the cement bodies because of the entrapment of air (Figure 10).

In contrast, using the $\alpha-\mathrm{Al}_{2} \mathrm{O}_{3} /$ mullite mixed phase-based fibers, the mullite phase in fibers reacted aggressively with the $\mathrm{Na}$ in the cement slurry at $280^{\circ} \mathrm{C}$ to form the crystalline Na-P type zeolite phase. The in-situ mullite $\rightarrow$ zeolite phase transition in fibers not only develops the interfacial microstructure signifying that the zeolite reaction 
product strongly acts to couple the fibers to the matrix, but also converts the strong, flexible and tough original fibers into fragile and brittle ones (Figure 11). As a result, the propagation of cracks generated in the fiber-reinforced cement composites occurred through the fibers, suggesting that $\alpha-\mathrm{Al}_{2} \mathrm{O}_{3} /$ mullite mixed fiber was less effective for improving the fracture toughness than that of $\alpha-\mathrm{Al}_{2} \mathrm{O}_{3}$ fibers.

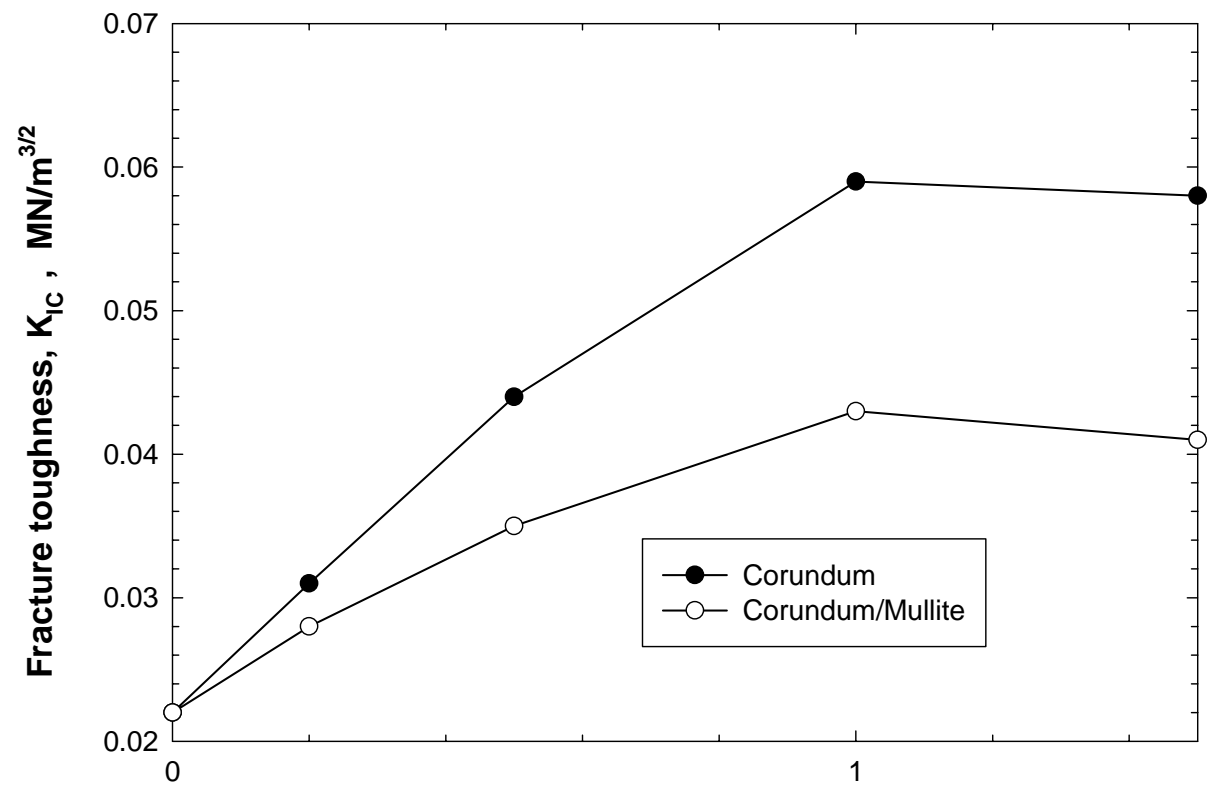

Fiber content, wt\%

Figure 10. Fracture toughness values, $\mathrm{K}_{\mathrm{IC}}$, plotted against the fiber content of the cement composites.

In contrast, using the $\alpha-\mathrm{Al}_{2} \mathrm{O}_{3} /$ mullite mixed phase-based fibers, the mullite phase in fibers reacted aggressively with the $\mathrm{Na}$ in the cement slurry at $280^{\circ} \mathrm{C}$ to form the crystalline Na-P type zeolite phase. The in-situ mullite $\rightarrow$ zeolite phase transition in fibers not only develops the interfacial microstructure signifying that the zeolite reaction product strongly acts to couple the fibers to the matrix, but also converts the strong, flexible and tough original fibers into fragile and brittle ones. As a result, the propagation of cracks generated in the fiber-reinforced cement composites occurred through the 
fibers, suggesting that $\alpha-\mathrm{Al}_{2} \mathrm{O}_{3} /$ mullite mixed fiber was less effective for improving the fracture toughness than that of $\alpha-\mathrm{Al}_{2} \mathrm{O}_{3}$ fibers.
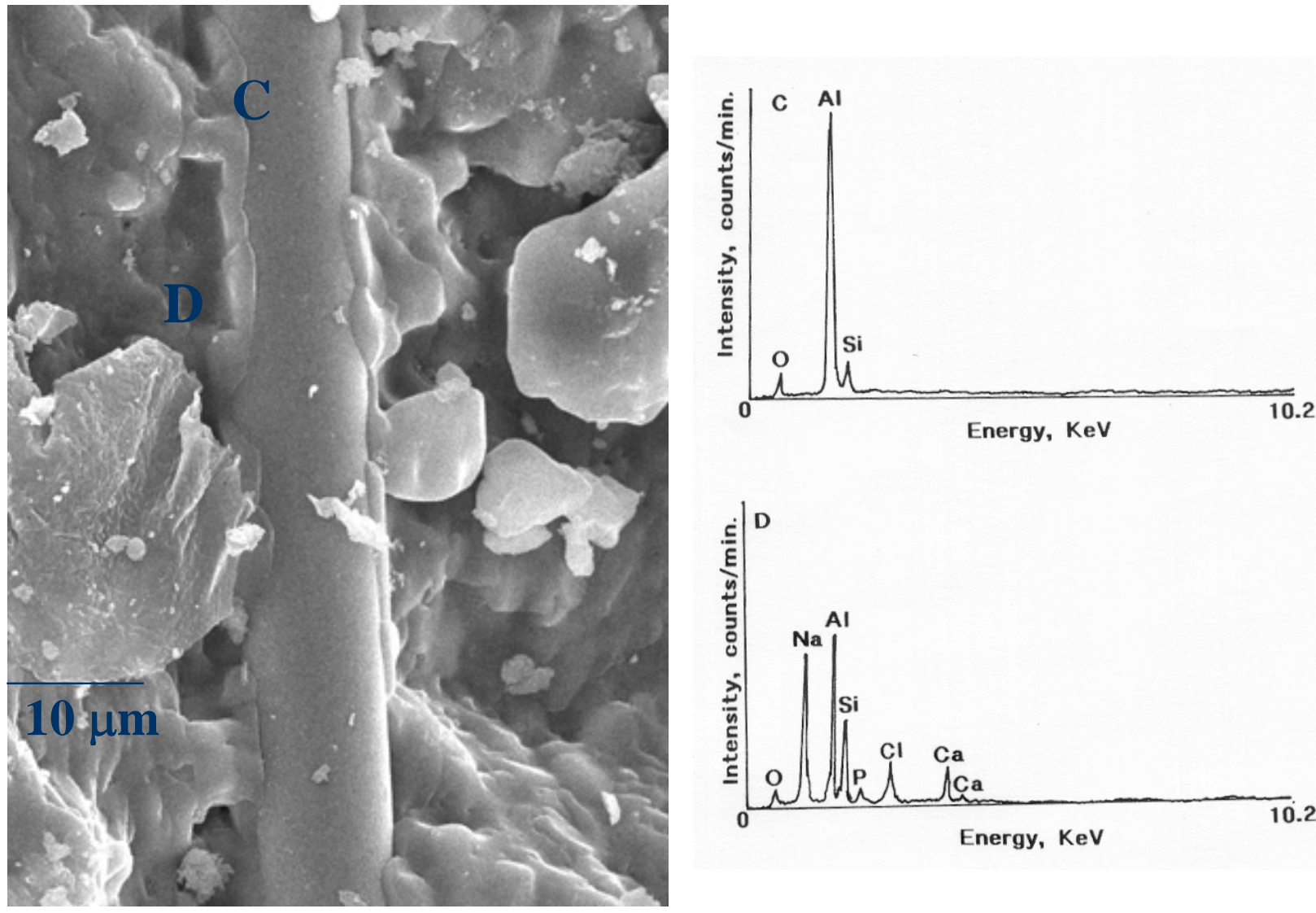

Figure 11. SEM-EDX analysis of fractured surfaces for $280^{\circ} \mathrm{C}$ autoclaved $\alpha$ $\mathrm{Al}_{2} \mathrm{O}_{3} /$ mullite fiber-reinforced $\mathrm{CaP}$ cements.

\subsubsection{Milled Carbon Microfiber Reinforcement}

Recently, advanced milling technology made it possible to produce an extremely short carbon microfiber, while maintaining all of these mechanical properties and the filament's shape. The milled fiber is $100-200 \mu \mathrm{m}$ long with a $7.5 \mu \mathrm{m}$ diam. Thus, as part of our ongoing research aimed at improving the toughness-related properties of $\mathrm{CaP}$ cement, much attention herein was given to investigating the characteristics of this milled carbon microfiber to use as the reinforcing material for $\mathrm{CaP}$ cement. The characteristics to be investigated included the chemistry of the fibers governing the degree of wetting of 
their surfaces by cement slurry, the affinity of the fibers' surfaces for the pore solution of cement, and the adherence of fibers' surfaces to the cement matrix. All the information on these parameters was integrated and correlated directly with results obtained from toughness-related mechanical tests of the fiber-reinforced cement composites.

\subsubsection{Experimental}

Asbury Graphite Mills, Inc. supplied the milled carbon microfibers (AGM-94). These carbon fibers derived from polyacrylonitrile (PAN) precursor were $7.5 \mu \mathrm{m}$ in diameter and 100-200 $\mu \mathrm{m}$ long. For the comparison with the milled microfibers, the chopped carbon microfibers (7.5 $\mu \mathrm{m}$ diam. by $3 \mathrm{~mm}$ long) from Asbury Graphite Mills, Inc., was also used. Calcium aluminate (CAC, Secar 60) and Class F fly ash, used as the solid reactants, were obtained from the Lafarge Aluminate Corp., and Pozament Corp., respectively. A $25 \mathrm{wt} \%$ sodium polyphosphate -[-( $\left.\left.\mathrm{NaPO}_{3^{-}}\right)_{\mathrm{n}^{-}}, \mathrm{NaP}\right]$, supplied by the Aldrich Chemical Company Inc., was used as the cement-forming liquid reactant for modifying the CAC-blended fly ash solid reactant. The solid reactant, made up in a twin shell dry blender, had a constant ratio of CAC/fly ash of 60/40 by weight. In preparing the fiber-reinforced cement composite slurries, the milled microfibers at 2 (3.2), 5 (7.5), 8 (12.2), 11 (17.0), and 14 (21.8) percent by weight (volume) of the total amount (volume) of CAC and fly ash, were incorporated into the cement slurries. In contrast, when chopped microfibers were incorporated, the maximum content attainable was $1.0 \mathrm{wt} \%$; beyond this amount, it was very difficult to make a cement slurry with uniformly dispersed fibers because fibers segregated from the cement slurry due to their balling up, curling up, and entanglement. All ingredients were thoroughly mixed in a bowl for 3 min at room temperature, and then were cast into $30 \mathrm{~mm}$ diam. x $60 \mathrm{~mm}$ length cylindrical molds for measuring porosity. Square beam molds (25 mm x 25 mm x 229 mm) were used for the three-point flexure test with $153 \mathrm{~mm}$ span. These cast specimens were left for 24 hours in atmospheric environment to harden. Then, they were removed from the molds, and exposed for 24 hours in an autoclave at $280^{\circ} \mathrm{C}$. Stress-strain diagrams were illustrated from flexure tests of center-notched and non-notched beam specimens. The fracture toughness, $\mathrm{K}_{\mathrm{IC}}$, was computed with data obtained from the stress-strain curves of center-notched beam specimens. The notch with a width of $0.5 \mathrm{~mm}$ and a depth of $13 \mathrm{~mm}$ 
was made on the tensile side at the center position of the beam by a diamond-tipped blade.

\subsubsection{Results}

In comparison with chopped carbon microfibers, the major advantage of the milled carbon microfibers, $7.5 \mu \mathrm{m}$ in diam. x 100-200 $\mu \mathrm{m}$ long (Figure 12), was that we could incorporate a large amount of them into the fly ash-modified CaP geothermal cement. This advantage significantly improved ductility of the cement; in fact, the stressstrain curves of the $280^{\circ} \mathrm{C}$ autoclaved $14 \mathrm{wt} \%$ ( $21.8 \mathrm{vol} \%$ ) milled fiber-reinforcedcement composites revealed that the maximum stress and the strain at flexure failure were $~ 28 \%$ and $39 \%$ greater, respectively, than that of CaP cement composites reinforced with $1 \mathrm{wt} \%$ (1.6 vol\%) chopped fibers, the maximum that could be added (Figure 13). The other factor playing an important role in improving the ductility was the chemistry at the fibers' surfaces. Graphite was identified as the major component
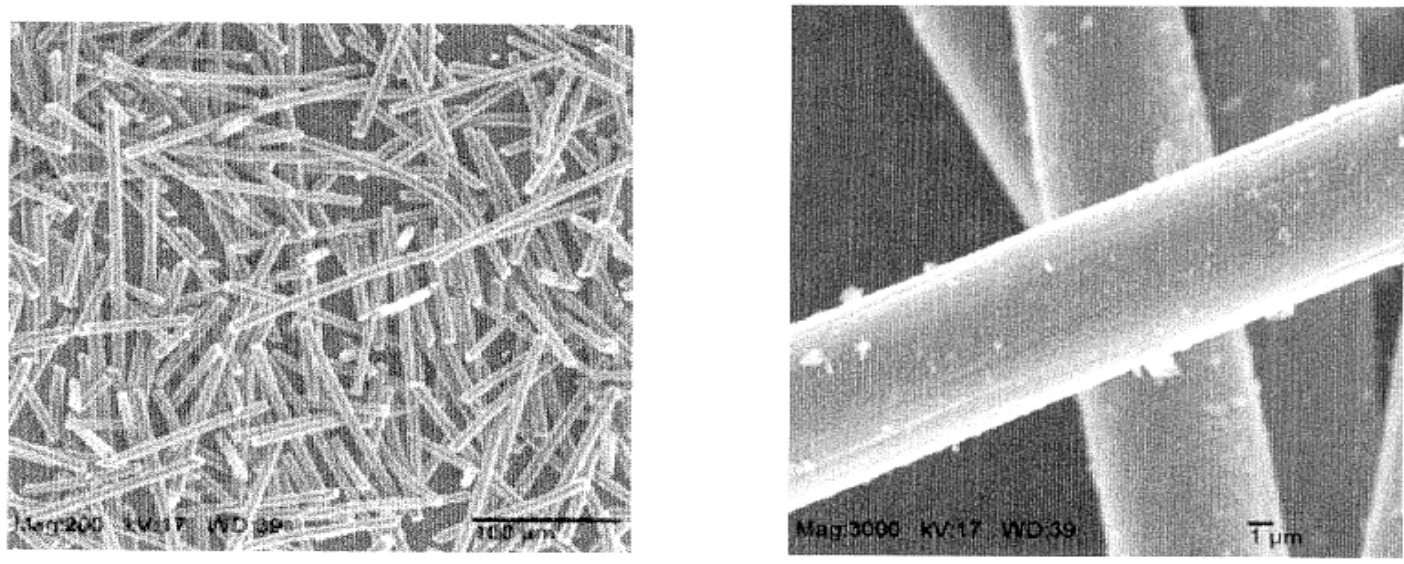

Figure 12. SEM microphotographs of “as-received” milled carbon microfibers.

occupying the outermost surface sites of the fibers, in coexistence with oxidized carbon moieties, such as carbonyl and carboxyl. The moisture-sensitive carboxyl functional moieties contributed to improving three properties that are essential attributes of the fibers. One property was the enhancement of the dispersiveness of the fibers in the 


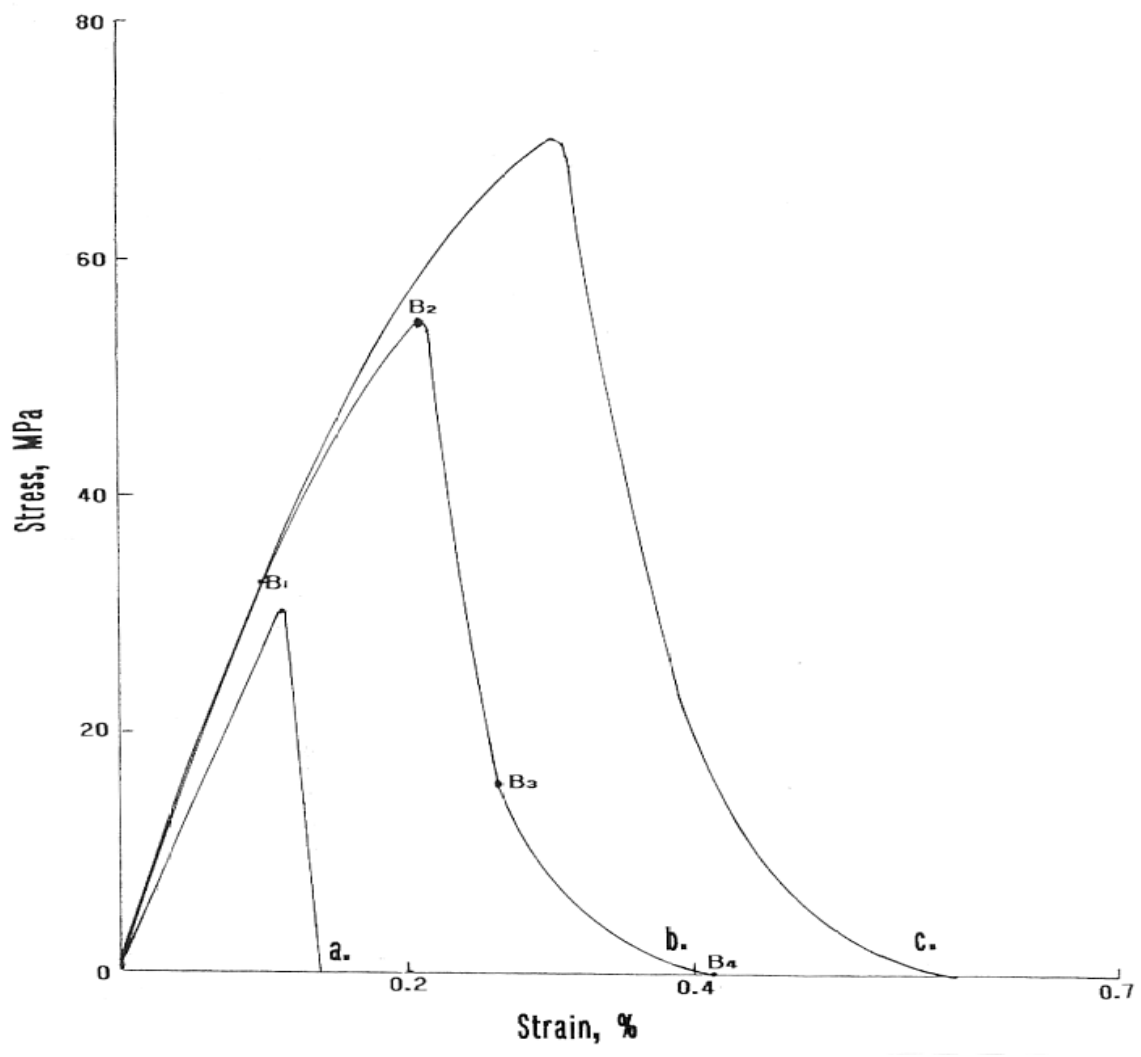

Figure 13. Comparison of the features of the stress-strain curves taken from (a) nonreinforced cement, (b) $1 \mathrm{wt} \%$ chopped-carbon fiber- and (c) $14 \mathrm{wt} \%$ milled-carbon microfiber-reinforced cements.

cement slurry, thereby resulting in a uniform distribution of multidirectional fibers in the cement matrix. Second was the abatement of the air- trapping effect of the fibers during mixing with the cement slurry. Third was their proclivity for the deposition of quartz present in the cement slurry. Further, the quartz deposited on the fiber's surfaces has a strong affinity for the hydroxyapatite and analcime phases as the hydrothermal reaction products of the cement, implying that the quartz acts to couple the two layers, the fiber and the cement matrix. Such a coupling effect provided an effective bond at the interfaces between the fiber and the matrix, thereby resulting in cohesive bond failure under stress forces that the loss in adhesion took place in the matrix close to the fiber (Figure 14). Therefore, these properties of the fibers incorporated in the cement matrix were 
responsible for the conspicuous improvement of fracture toughness and displacement of 3.1- and 2.7-fold, respectively, compared with non-reinforced cements (Figure 15).
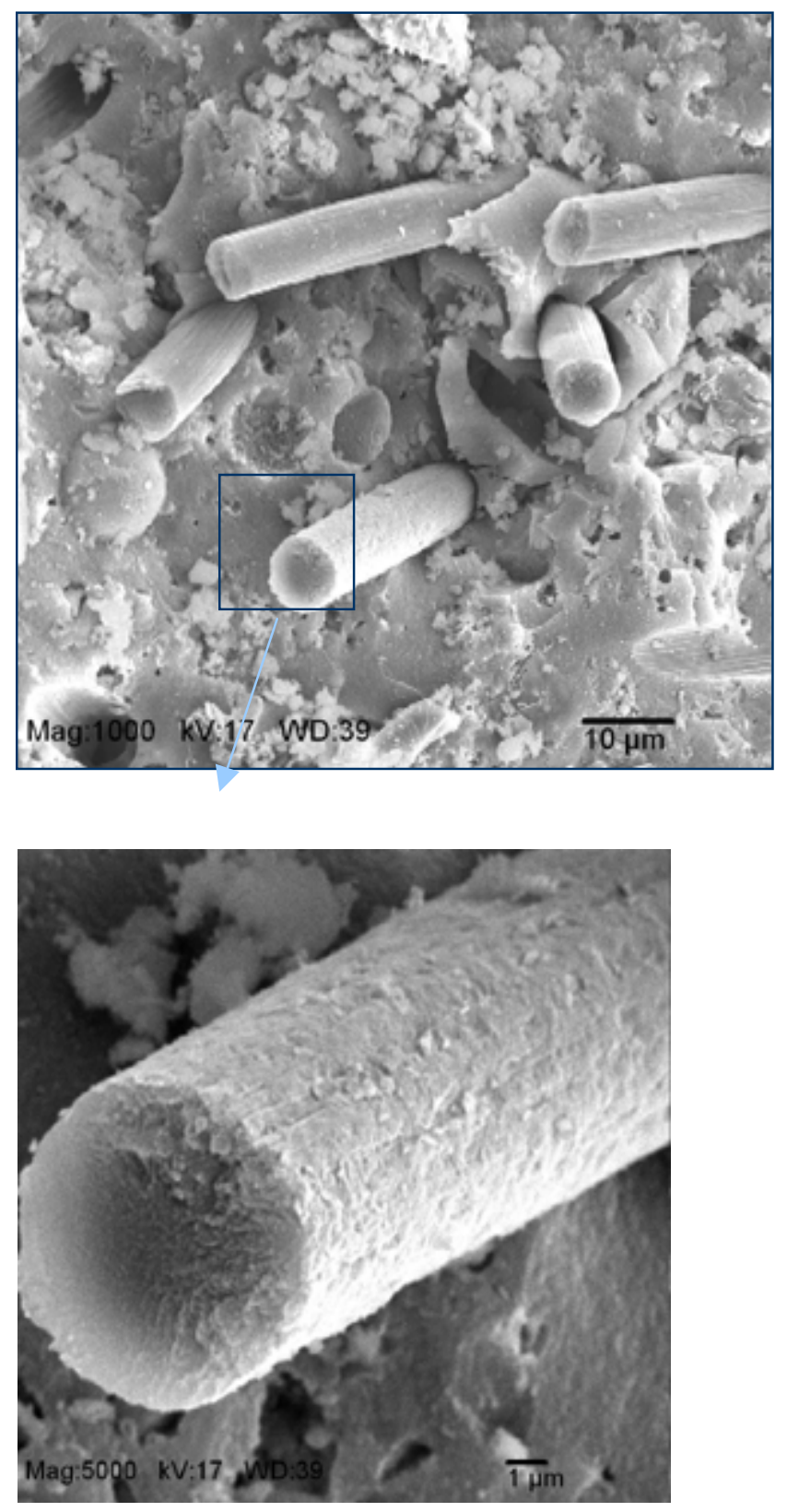

Figure 14. Fractured surfaces of $14 \%$ milled carbon fiber-reinfoced composite after a 3-day autoclave exposure at $280^{\circ} \mathrm{C}$. 


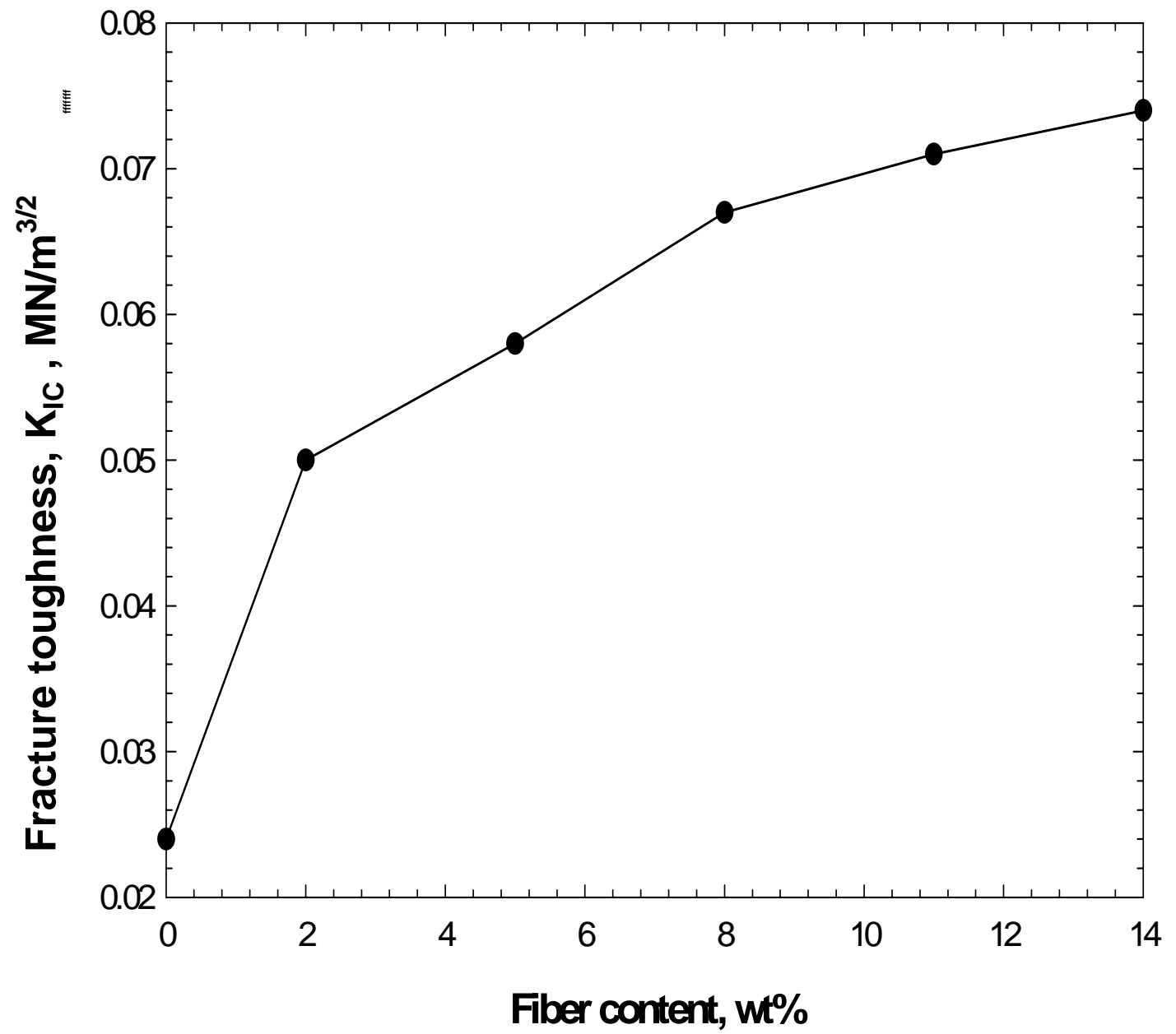

Figure 15. Fracture toughness values, $\mathrm{K}_{\mathrm{TC}}$, plotted against the fiber content of the cement composites.

\subsection{Bond Durability to Casing Pipe Surface}

Our work now shifted to investigating the bond durability of the tough carbon fiber-reinforced cement composites adhering to the casing pipe, which is one of the important factors governing the integrity of the cement covering the casing pipes under a repeated superheat-cold fatigue cycles. Two different cements, $\mathrm{CaP}$ and conventional Class G, were employed. 


\subsubsection{Experimental}

Asbury Graphite Mills, Inc., supplied the milled carbon microfibers (AGM-94). These carbon fibers derived from a polyacrylonitrile (PAN) precursor were $7.5 \mu \mathrm{m}$ in diameter and 100-200 $\mu \mathrm{m}$ long. The formulation of CaP cement slurry consisted of 38wt\% calcium aluminate, 25wt\% Class F fly ash, 9wt\% sodium polyphosphate, and $45 w t \%$ water. The conventional Class $\mathrm{G}$ well cement slurry was prepared by mixing all ingredients including 43wt\% Class G cement, 19wt\% silica flour, and 38wt\% water. In preparing the pumpable fiber-incorporated cement slurries, the slurry’s consistencyrelated experiment demonstrated that the maximum content of the carbon fiber was $6 \%$ by the total weight of $\mathrm{CaP}$ and Class $\mathrm{G}$ cement slurries.

The fiber-reinforced cement composite-sheathed pipe specimens for evaluating the bond durability were prepared in the following sequence: First, the steel pipe, one-in. diam. by 4-in. long, was inserted through the one-in. wide bottom hole in the plastic mold, 2-in. diam. by 2-in. height; second, the fiber-incorporated slurries were poured into the space in the pipe-inserted mold, and then left for 2 days at room temperature for curing. The cured composite-sheathed pipe specimens were removed from the molds (Figure 16), and then exposed in an autoclave to conduct the superheat-cooling fatigue cycle testing. The temperature-control program of the autoclave was set at an increasing rate of $4.0^{\circ} \mathrm{C} / \mathrm{min}$. to reach the maximum temperature of $250^{\circ} \mathrm{C}$, and was left as such for the next 15 hours. Afterward, the autoclave was turned off, allowing the specimens 9 hours to cool down naturally, thereby leading to a 24-hour cycle. The test began on April 26, 2005 and the plan is to proceed with 200 heat/cold cycles. The bond durability was evaluated from the results of shear-bond strength at the interfaces between the reinforced cement and steel pipe (Figure 17). 


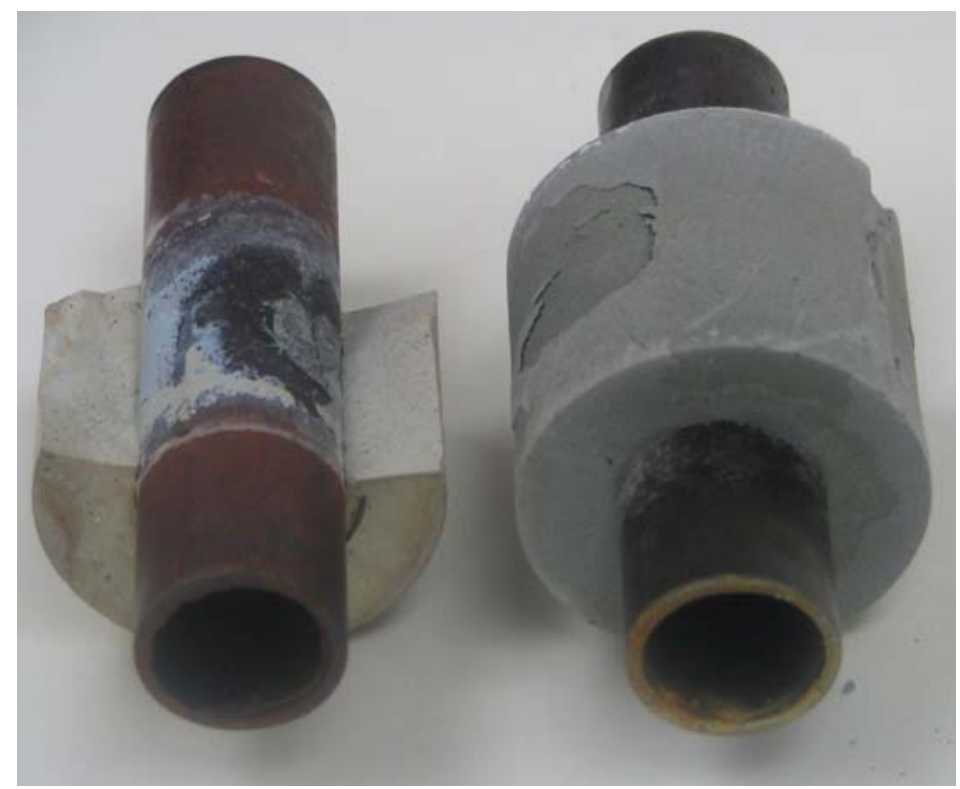

Figure 16. Cement composite-sheathed carbon steel pipe specimens.

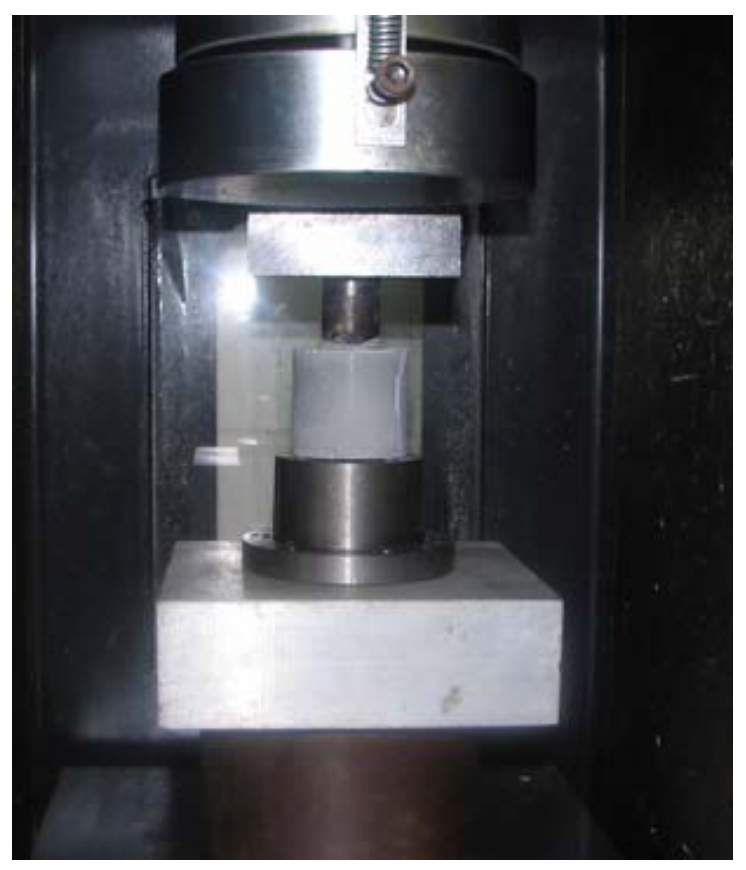

Figure 17. Shear bond test by compressing the pipe embedded in the cement composite. 


\subsubsection{Results}

Figure 18 depicts the changes in shear-bond strength of the $\mathrm{CaP}$ and Class $\mathrm{G}$ composite-sheathed pipe specimens as a function of superheating-cooling cycle. For the $\mathrm{CaP}$ cement composite, its shear bond strength before testing was 52.5 psi. In the first 100 cycles, this strength markedly rose 59\% to 83.4 psi; beyond that, it seemed to level off, suggesting that the adherence of 100-cycled CaP cement to pipe's surface became even stronger than that of non-cycled specimens. In contrast, the conventional Class $G$ well cement had no effectiveness in improving its adherence to the pipe's surfaces during the cycle testing. In fact, the bond strength of the Class $\mathrm{G}$ cement declined between 0 and 70 cycles; the bond strength of 50.8 psi after 70 cycles was $14 \%$ lower than that of the non-cycled specimens. After 70 cycles, there was no significant change in bond strength.

In an attempt to understand why the bond strength of conventional Class G well cement became weak, we conducted SEM, EDX, and XRD analyses for the 70-cycled cements after the shear-bond strength test. Figure 19 shows the surface morphology of the cements' remnants over the pipe's surface. The SEM image disclosed a peculiar feature, which highlighted the interlocking structure of the thin plate-like crystals. This interlocking structure caused the development of an undesirable porous microstructure of the cement layer formed in the interfacial critical boundary regions between pipe and cement. EDX spectrum ascertained that these thin plate crystals were associated with the $\mathrm{CaO}-\mathrm{SiO}_{2}-\mathrm{H}_{2} \mathrm{O}$ system, corresponding to a possible xonotlite crystal phase because of the presence of a prominent peak of Ca element and a moderate line intensity of Si and O elements. This finding was strongly supported from phase identification studies by XRD (not shown). In contrast, the SEM image (Figure 20) from the CaP cements' remnants clinging to pipe's surface after 70 cycles was characterized by the dense microstructure of hybrid crystals covering the pipe's surface. The EDX spectrum for these crystals exhibited that the major elements were $\mathrm{Fe}, \mathrm{Al}$, and $\mathrm{O}$, with lesser amounts of $\mathrm{Na}, \mathrm{Si}, \mathrm{P}$, and $\mathrm{Ca}$. Since $\mathrm{Fe}$ and some $\mathrm{O}$ belonged to the $\mathrm{F}_{2} \mathrm{O}_{3}$ layer that was present at the outermost surface sites of carbon steel pipe, we believe that the hybrid crystals left on the $\mathrm{F}_{2} \mathrm{O}_{3}$ layer corresponded to the hydrothermal reaction products of $\mathrm{CaP}$ cement, such as hydroxyapatite, boehmite, hydrogarnet, and analcime phases. In fact, XRD analysis revealed the presence of these reactions products. 
Thus, the development of porous microstructure caused by an excessive growth of xonotlite crystals in the Class $\mathrm{G}$ cement composite at the interfacial contact zones during the cycle testing can be taken as the major reason why the bond strength of the Class $\mathrm{G}$ cement to pipe declined as a function of cycle. Such bond failure raised concerns about the corrosion of the casing. Unlike the Class G cement, the CaP cement layer adhering to the pipe's surface had a dense microstructure, which not only contributed to great interfacial bond durability, but also provided the protection of pipes against brine-caused corrosion.

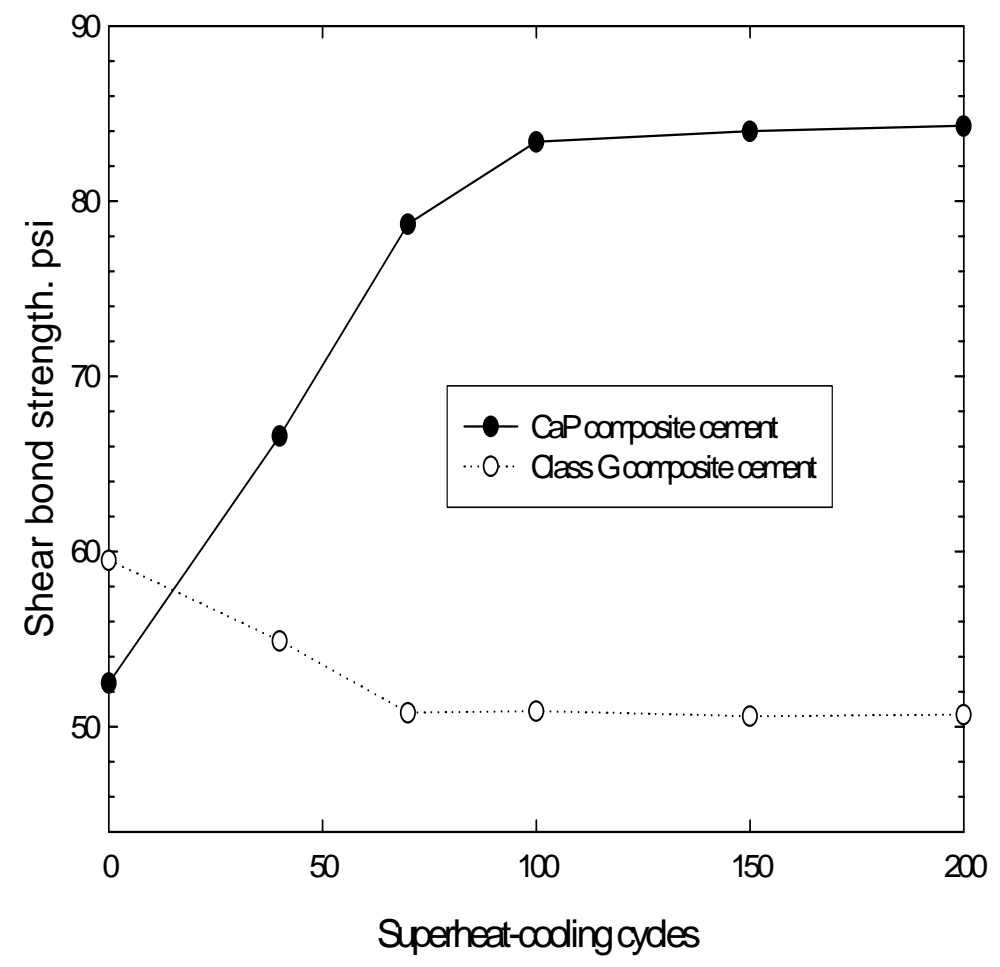

Figure 18. Changes in shear bond strength of the cement composite-sheathed steel pipe specimens as a function of superheat-cooling cycle. 

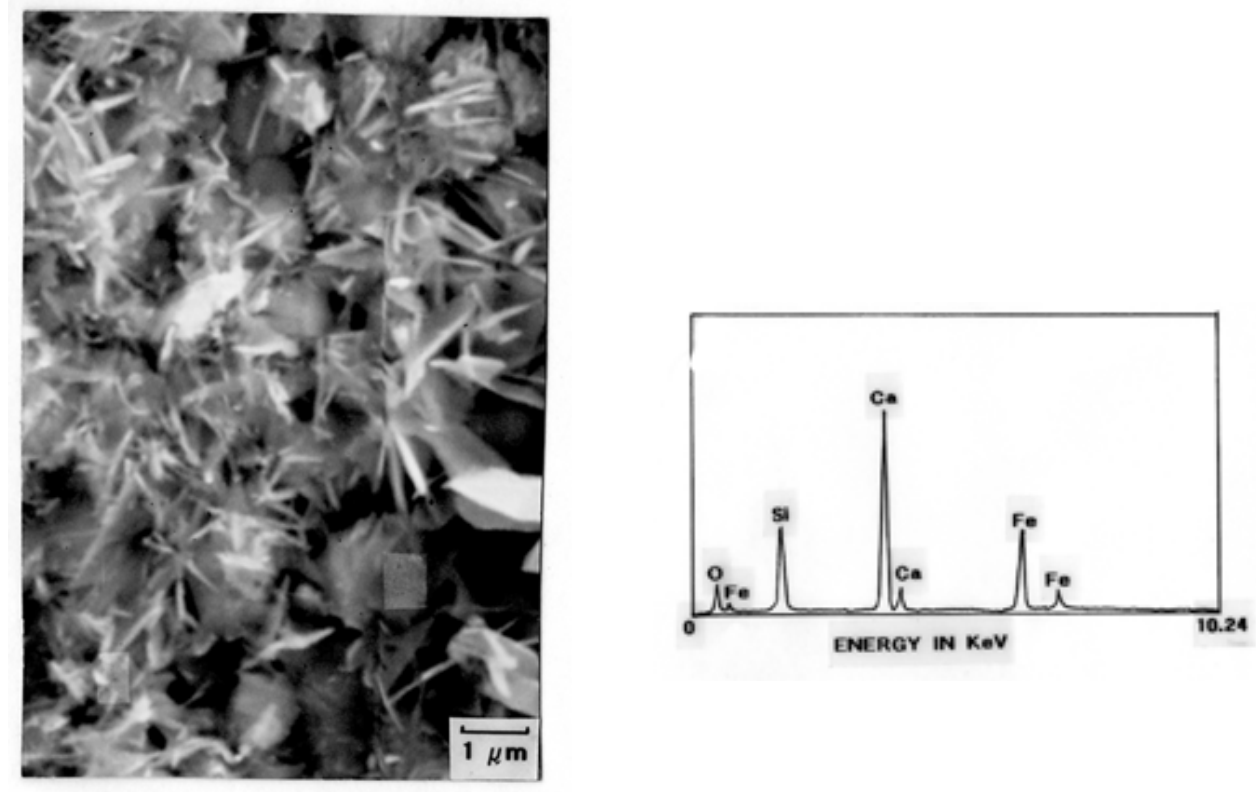

Figure 19. SEM image coupled with EDX analysis of Class G cement remnants clinging to pipe's surface after shear-bond strength test at 70 cycled cement/pipe joints.
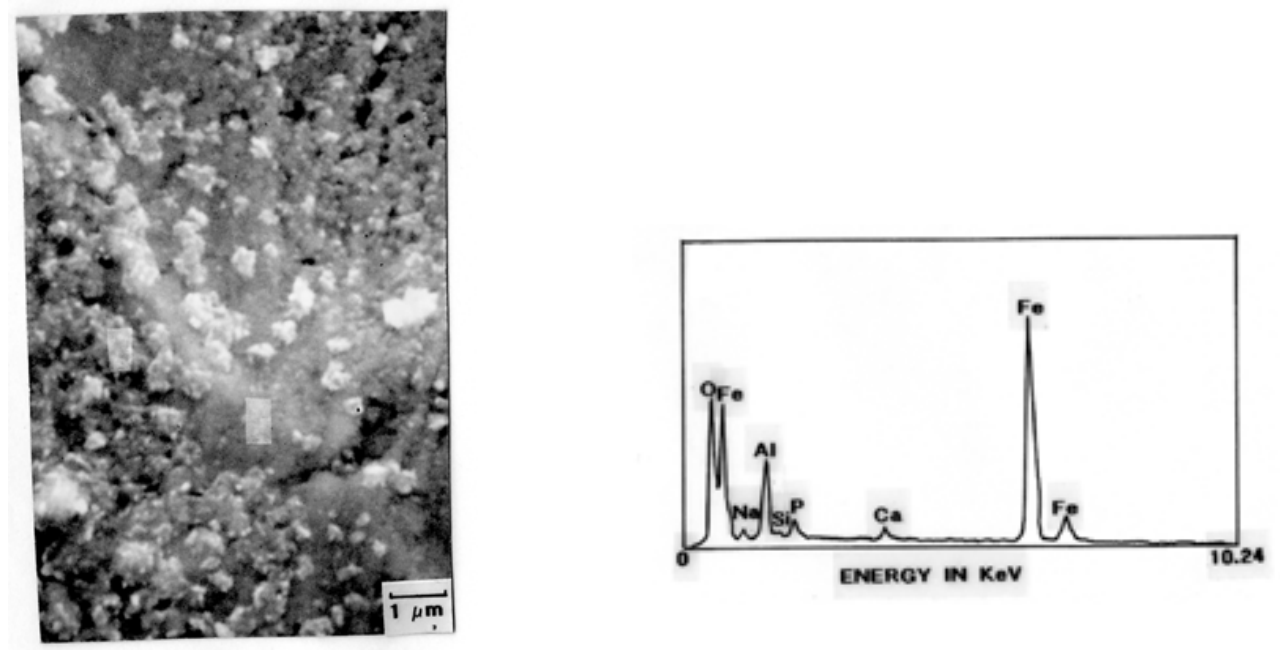

Figure 20. SEM-EDX analysis of CaP cement remnants clinging to pipe's surface after 70 cycles. 


\subsection{Field Demonstration}

Field-applicable fly ash-modified CaP cement was developed and formulated in collaboration with two industrial partners, Unocal Corporation and Halliburton Energy Services. The cement met the following seven criteria: 1) Compatible with conventional field placement technologies; 2) formed water-soluble carbonates, $<5 \mathrm{wt} \%$ after 1 year in 40,000 ppm $\mathrm{CO}_{2}$-laden brine at $300^{\circ} \mathrm{C}$; 3) compressive strength > 500 psi at $24 \mathrm{hr}$ age; 4) maintenance of pumpability for at least 3 hours at $90^{\circ} \mathrm{C}$; 5 ) bond strength to steel $>50$ psi; 6) water permeability $<1 \times 10^{-4}$ Darcy; 7) resistance to mild acid ( $\mathrm{pH} \sim 5$ ) at $300^{\circ} \mathrm{C}$, < 5wt\% loss after 30 days exposure; and 8) cost, <\$15/bag. In 1997, Unocal and Halliburton had emplaced this cement in the geothermal wells in northern Sumatra, Indonesia [19]. Four wells have been completed with this new cement. These cementing jobs represent the first field applications of this new cement ever performed. Although the full-scale field application showed a very promising result, there remained one important question that must be asked: The question is that how durable are these downhole cements in supporting casing pipes during a long-term exposure in high $\mathrm{CO}_{2}$ brine at $280^{\circ} \mathrm{C}$ ?

To answer to this question, an attempt was made to conduct long-term monitoring tests for the downhole cements. However, one difficulty encountered was the fact that an $\sim 1000 \mathrm{~m}$ depth of these Indonesian wells was too deep to remove the downhole cement specimens. For dealing with this problem, we decided on conducting a long-term exposure tests for up to 18 months in the laboratory (BNL) under environmental conditions simulating those at the bottom of wells. A simulated geothermal brine containing a 20,000 ppm $\mathrm{CO}_{2}$, and $400 \mathrm{ppm} \mathrm{H}_{2} \mathrm{~S}$ was composed of $11.8 \mathrm{wt} \% \mathrm{NaCl}, 2.45$ wt\% KCl, 7.04 wt\% $\mathrm{CaCl}_{2}, 0.12$ wt\% LiCl, 0.12 wt\% $\mathrm{SrCl}_{2}, 0.04$ wt\% $\mathrm{BaCl}_{2}, 0.85$ wt\% $\mathrm{FeCl}_{2}, 0.43 \mathrm{wt} \% \mathrm{MnCl}_{2}, 0.10 \mathrm{wt} \% \mathrm{ZnCl}_{2}$, and $77.05 \mathrm{wt} \%$ water at a temperature of $280^{\circ} \mathrm{C}$. In February 1999, qualitative analyses of the cement specimens exposed for up to 7 months were completed.

The post-test analyses included changes in compressive strength, phase identification and transformation, and development of microstructure.

\subsubsection{Experimental}


The chemical composition of Indonesian Penta fly ash used consisted of $59.2 \mathrm{wt} \%$ silica, $22.7 \mathrm{wt} \%$ aluminum oxide, $6.5 \mathrm{wt} \%$ iron oxide, $0.5 \mathrm{wt} \%$ magnesium oxide, 0.2 wt $\%$ sulfur trioxide, $0.1 \mathrm{wt} \%$ sodium oxide, $4.8 \mathrm{wt} \%$ calcium oxide, $1.9 \mathrm{wt} \%$ titanium dioxide, $0.1 \mathrm{wt} \%$ strontium oxide, $0.1 \mathrm{wt} \%$ barium oxide, $0.2 \mathrm{wt} \%$ manganese oxide, and $0.6 \mathrm{wt} \%$ potassium oxide; there was a $3.1 \mathrm{wt} \%$ loss on ignition. The $\mathrm{x}$-ray powder diffraction (XRD) data showed that the fly ash includes two major crystalline phases, mullite and quartz. Commercial calcium aluminate cement (CAC, Refcon) obtained from Lehigh Cement Company, was used to blend with the fly ash. Its chemical constituents were as follows: $57.4 \mathrm{wt} \%$ aluminum oxide, $34.2 \mathrm{wt} \%$ calcium oxide, $5.7 \mathrm{wt} \%$ silica, 1.2 $\mathrm{wt} \%$ iron oxide, $0.36 \mathrm{wt} \%$ sulfur trioxide, and $1.14 \mathrm{wt} \%$ other. CAC had three crystalline phases, gehlenite (2 $\left.\mathrm{CaO} \mathrm{Al}_{2} \mathrm{O}_{3} \cdot \mathrm{SiO}_{2}, \mathrm{C}_{2} \mathrm{AS}\right)$, monocalcium aluminate $\left(\mathrm{CaO} \cdot \mathrm{Al}_{2} \mathrm{O}_{3}, \mathrm{CA}\right)$, and calcium dialuminate $\left(\mathrm{CaO} \cdot 2 \mathrm{Al}_{2} \mathrm{O}_{3}, \mathrm{CA}_{2}\right)$. A $25 \mathrm{wt} \%$ granular sodium polyphosphate [-(-NaPO $\left.\left.3^{-}\right)_{-}, \mathrm{NaP}\right]$, as an intermediate fertilizer made in China, was dissolved in water, and then was employed as the cement-forming aqueous reactant to modify the CACblended fly ash solid reactants. The composition of the solid reactants, made by mixing in a Twine Shell Dry Blender, had a CAC/fly ash ratio of 60/40 by weight. The formulation of the SFCB cement slurry used in the field was a $35.1 \mathrm{wt} \%$ CAC, $23.4 \mathrm{wt} \%$ fly ash, 10.4 $\mathrm{wt} \% \mathrm{NaP}$, and $31.1 \mathrm{wt} \%$ water. All those ingredients were thoroughly mixed and cast into cylindrical molds ( $30 \mathrm{~mm}$ diam x $60 \mathrm{~mm}$ long), and then allowed them to harden for 24 hours at $25^{\circ} \mathrm{C}$ in air. Following this, they were removed from the molds, and exposed for up to 7 months in the simulated Indonesian geothermal brine. The specimens were examined to identify their phase composition and transformation, and to explore alterations in microstructure. All data were integrated and correlated directly with the changes in compressive strength as a function of exposure time.

XRD and Fourier transform infrared spectroscopy (FT-IR) were used to identify the phase composition formed in this cement, and to gain information on the transformation of phases caused by exposure to the $280^{\circ} \mathrm{C}$ brine. Scanning electron microscopy (SEM) coupled with energy-dispersive x-ray spectroscopy (EDX) was employed to explore the microstructure developed in the exposed specimens, and to detect its chemical components. Compressive strength tests revealed the changes in 
mechanical behavior of the specimens as a function of exposure time; the result given is the average value from three specimens.

\subsubsection{Results}

In the first 7 days of exposure, three well-formed crystalline phases, hydroxyapatite $\left[\mathrm{Ca}_{5}\left(\mathrm{PO}_{4}\right)_{3}(\mathrm{OH}), \mathrm{HOAp}\right]$ and analcime $\left(\mathrm{NaAlSi}_{2} \mathrm{O}_{6} \cdot \mathrm{H}_{2} \mathrm{O}, \mathrm{AN}\right)$ as the major phase, and boehmite ((-AlOOH, BO) as the minor one, were responsible for generating the ultimate compressive strength of the cement specimens, reflecting the development of densified microstructure in the cement bodies. Extending the exposure time to 4 months led to the in-situ transformation of AN into cancrinite $\left[\mathrm{Na}_{8}(\mathrm{Al}, \mathrm{Si})_{12} \mathrm{O}_{24} \mathrm{CO}_{3} .3 \mathrm{H}_{2} \mathrm{O}, \mathrm{CAN}\right]$ brought about by intercalation of $\mathrm{CO}_{3}$ in $\mathrm{AN}$ molecular structure. Such AN 6 CAN phase transition not only changed the dense microtexture of the cement into a porous one, but also caused some loss of strength (Figure 21). However, there was no decomposition of the cement by this in-situ phase transformation, nor was any carbonation-related erosion revealed. Once this

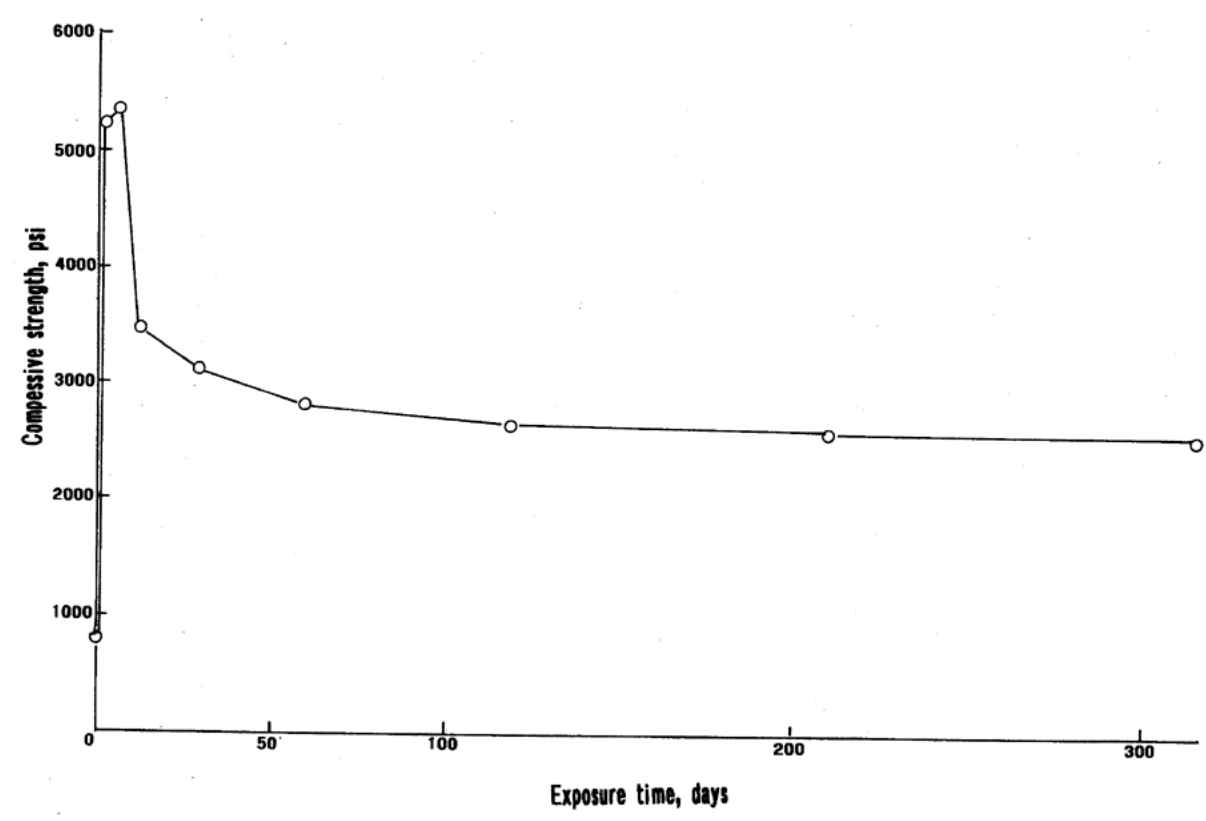

Figure 21. Changes in compressive strength of the cements as a function of exposure time. 
transformation neared completion after 4 months, no marked change in strength was determined, while the HOAp remained as one of the major phases in the cement bodies. Nevertheless, the phase composition of the cements after 7 months exposure consisted of HOAp and CAN as the major phases, and the AN as the minor one (Table 6).

Table 6. Changes in the phase composition for fly ash-modified CaP cements as a function of exposure time

\begin{tabular}{|c|c|c|}
\hline Exposure time & Major phase & Minor phase \\
\hline 1 day & $\mathrm{Ca}_{5}\left(\mathrm{PO}_{4}\right)_{3}(\mathrm{OH})$ & $\begin{array}{l}\mathrm{NaAlSi}_{2} \mathrm{O}_{6} \cdot \mathrm{H}_{2} \mathrm{O},(-\mathrm{AlOOH}, \\
2 \mathrm{CaO} . \mathrm{Al}_{2} \mathrm{O}_{3} \cdot \mathrm{SiO}_{2}, \mathrm{Na}_{2} \mathrm{CO}_{3} \\
\mathrm{CaO} . \mathrm{Al}_{2} \mathrm{O}_{3}, \mathrm{SiO}_{2}, \mathrm{CaCO}_{3}\end{array}$ \\
\hline 7 days & $\begin{array}{l}\mathrm{Ca}_{5}\left(\mathrm{PO}_{4}\right)_{3}(\mathrm{OH}), \\
\mathrm{NaAlSi}_{2} \mathrm{O}_{6} \cdot \mathrm{H}_{2} \mathrm{O}\end{array}$ & $\begin{array}{l}\text { (-AlOOH, } 2 \mathrm{CaO} . \mathrm{Al}_{2} \mathrm{O}_{3} \cdot \mathrm{SiO}_{2} \text {, } \\
\mathrm{Na}_{2} \mathrm{CO}_{3}, \mathrm{SiO}_{2}, \mathrm{CaCO}_{3}\end{array}$ \\
\hline 14 days & $\begin{array}{l}\mathrm{Ca}_{5}\left(\mathrm{PO}_{4}\right)_{3}(\mathrm{OH}) \\
\mathrm{NaAlSi}_{2} \mathrm{O}_{6} \cdot \mathrm{H}_{2} \mathrm{O}\end{array}$ & $\begin{array}{l}\mathrm{Na}_{5}(\mathrm{AlSi})_{12} \mathrm{O}_{24} \mathrm{CO}_{3} .3 \mathrm{H}_{2} \mathrm{O} \\
\left(-\mathrm{AlOOH}_{2} \mathrm{Na}_{2} \mathrm{CO}_{3}, \mathrm{SiO}_{2}\right. \\
\mathrm{CaCO}_{3}\end{array}$ \\
\hline 1 month & $\begin{array}{l}\mathrm{Ca}_{5}\left(\mathrm{PO}_{4}\right)_{3}(\mathrm{OH}), \\
\mathrm{Na}_{5}(\mathrm{AlSi})_{12} \mathrm{O}_{24} \mathrm{CO}_{3} \cdot 3 \mathrm{H}_{2} \mathrm{O}\end{array}$ & $\begin{array}{l}\mathrm{NaAlSi}_{2} \mathrm{O}_{6} \cdot \mathrm{H}_{2} \mathrm{O},(-\mathrm{AlOOH}, \\
\mathrm{SiO}_{2}\end{array}$ \\
\hline 4 months & $\begin{array}{l}\mathrm{Ca}_{5}\left(\mathrm{PO}_{4}\right)_{3}(\mathrm{OH}), \\
\mathrm{Na}_{5}\left(\mathrm{AlSi}_{12} \mathrm{O}_{24} \mathrm{CO}_{3} .3 \mathrm{H}_{2} \mathrm{O}\right.\end{array}$ & $\mathrm{NaAlSi}_{2} \mathrm{O}_{6} \cdot \mathrm{H}_{2} \mathrm{O}$ \\
\hline 7 months & $\begin{array}{l}\mathrm{Ca}_{5}\left(\mathrm{PO}_{4}\right)_{3}(\mathrm{OH}), \\
\mathrm{Na}_{5}\left(\mathrm{AlSi}_{12} \mathrm{O}_{24} \mathrm{CO}_{3} .3 \mathrm{H}_{2} \mathrm{O}\right.\end{array}$ & $\mathrm{NaAlSi}_{2} \mathrm{O}_{6} \cdot \mathrm{H}_{2} \mathrm{O}$ \\
\hline
\end{tabular}

\subsection{Cost-effective CaP Cement Systems}

Regarding the chemistry of calcium aluminate cement (CAC) as the starting material, two calcium aluminate compounds, monocalcium aluminate $\left(\mathrm{CaO} . \mathrm{Al}_{2} \mathrm{O}_{3}, \mathrm{CA}\right)$ and calcium bialuminate $\left(\mathrm{CaO} .2 \mathrm{Al}_{2} \mathrm{O}_{3}, \mathrm{CA}_{2}\right)$, and one calcium aluminate silicate, gehlenite (2CaO. $\mathrm{Al}_{2} \mathrm{O}_{3} \cdot \mathrm{SiO}_{2}, \mathrm{C}_{2} \mathrm{AS}$ ), in the $\mathrm{CAC}$ played an important role in promoting the generation of hydroxyapatite (HOAp) and boehmite (BO) reaction products. However, one intriguing question remained unanswered. Are other calcium aluminate compounds, such as tricalcium aluminate $\left(3 \mathrm{CaO} \mathrm{Al}_{2} \mathrm{O}_{3}, \mathrm{C}_{3} \mathrm{~A}\right)$ in the cement, as effective in deriving these reaction products as are CA and $\mathrm{CA}_{2}$. As is well documented [20,21], in Class $\mathrm{C}$ fly ash as the coal combustion by-products, $\mathrm{C}_{3} \mathrm{~A}$ coexists with other chemical compounds, such as quartz, lime, and calcium sulfate. We deemed it worthwhile to investigate the usefulness of Class C fly ash as replacement for CAC because not only 
does this confer an economical advantage in making the CaP cement, but it also abates an ash-disposal problem.

Thus, the current study was directed toward investigating the characteristics of the sodium polyphosphate-modified Class F fly ash/Class C fly ash bend cements after autoclaving them at $250^{\circ} \mathrm{C}$ for their use as acid-resistant geothermal well cements. Among the characteristics to be investigated were the $\mathrm{pH}$ values of the pore solution in the cement slurries, the total energy generated in exothermal acid-base reactions of cement slurries along with a quantitative analysis of reaction product responsible for the total output of this reaction energy, the porosity, water permeability and compressive strength of autoclaved cements. We also identified the crystalline phases assembled in autoclaved cement bodies. All the data obtained were integrated and correlated directly with the information on the resistance of autoclaved cements to a $\mathrm{CO}_{2}$-laden $\mathrm{H}_{2} \mathrm{SO}_{4}$ solution (pH 1.1) at $90^{\circ} \mathrm{C}$.

\subsubsection{Experimental}

The Boral Material Technologies Inc supplied both the Class $C$ fly ash (C) and Class F fly ash (F). The chemical constituents of the oxides for these fly ash reactants were as follows: $36.2 \% \mathrm{SiO}_{2}, 19.1 \% \mathrm{Al}_{2} \mathrm{O}_{3}, 6.7 \% \mathrm{Fe}_{2} \mathrm{O}_{3}, 24.6 \% \mathrm{CaO}, 5.4 \% \mathrm{MgO}, 1.7$ \% $\mathrm{SO}_{3}, 1.7 \% \mathrm{Na}_{2} \mathrm{O}, 0.5 \% \mathrm{~K}_{2} \mathrm{O}, 3.7 \%$ loss in ignition for $\mathrm{C}$; and, $38.6 \% \mathrm{SiO}_{2}, 38.6 \%$ $\mathrm{Al}_{2} \mathrm{O}_{3}, 12.0 \% \mathrm{Fe}_{2} \mathrm{O}_{3}, 0.5 \% \mathrm{CaO}, 1.4 \% \mathrm{MgO}, 1.9 \% \mathrm{SO}_{3}, 1.5 \% \mathrm{Na}_{2} \mathrm{O}, 1.9 \% \mathrm{~K}_{2} \mathrm{O}$ and $3.4 \%$ loss in ignition for F. The x-ray diffraction (XRD) analysis of these fly ashes showed that the crystalline components of $\mathrm{C}$ consisted mainly of four major phases, quartz $\left(\mathrm{SiO}_{2}\right)$, tricalcium aluminate $\left(3 \mathrm{CaO} \cdot \mathrm{Al}_{2} \mathrm{O}_{3}\right)$, calcium sulfate anhydrate $\left(\mathrm{CaSO}_{4}\right)$, and lime $(\mathrm{CaO})$, while $\mathrm{F}$ had three major phases, quartz $\left(\mathrm{SiO}_{2}\right)$, mullite $\left(3 \mathrm{Al}_{2} \mathrm{O}_{3} \cdot 2 \mathrm{SiO}_{2}\right)$, and hematite $\left(\mathrm{Fe}_{2} \mathrm{O}_{3}\right)$. Granular sodium polyphosphate, -[-(- $\left.\left.\mathrm{Na}^{+} \mathrm{PO}_{3}^{-}\right)_{\mathrm{n}^{-}}, \mathrm{NaP}\right]$, was obtained from the Aldrich Chemical Company Inc. The NaP then was dissolved in water to make a $25 \mathrm{wt} \%$ solution for use as the cement-forming acid aqueous reactant. The base reactants, mixed in a twin shell dry blender, had five C/F ratios, 100/0, 90/10, 70/30, 50/50, and 30/70 by weight. In preparing the cement slurries, a $66.7 \mathrm{wt} \%$ base reactant for each $\mathrm{C} / \mathrm{F}$ ratios then was mixed thoroughly with the acid reactant of 33.3wt\% (25wt\% $\mathrm{NaP}$ solution) at room temperature. 


\subsubsection{Results}

In sodium polyphosphate (NaP)-modified Class $\mathrm{C}$ fly ash (C)/Class F fly ash (F) cement systems, the basic nature of $\mathrm{C}$ promoted exothermic acid-base reactions with the $\mathrm{NaP}$ solution as an acidic cement-forming reactant. This reaction, followed by hydration, at temperature range of $25-100^{\circ} \mathrm{C}$, led to the formation of hydroxyapatite $\left[\left(\mathrm{Ca}_{3}\left(\mathrm{PO}_{4}\right)_{3}(\mathrm{OH}), \mathrm{HOAp}\right]\right.$ as the reaction derivative. In contrast, $\mathrm{F}$ being acidic underwent no acid-base reaction with the NaP. Correspondingly, the total exothermic energy generated by the acid-base reaction depended on the proportion of $\mathrm{C}$ to F; namely, incorporating more $\mathrm{F}$ into this cement system reduced the output of reaction energy (Figure 22). The x-ray diffraction analysis for the $250^{\circ} \mathrm{C}$-autoclaved cement systems

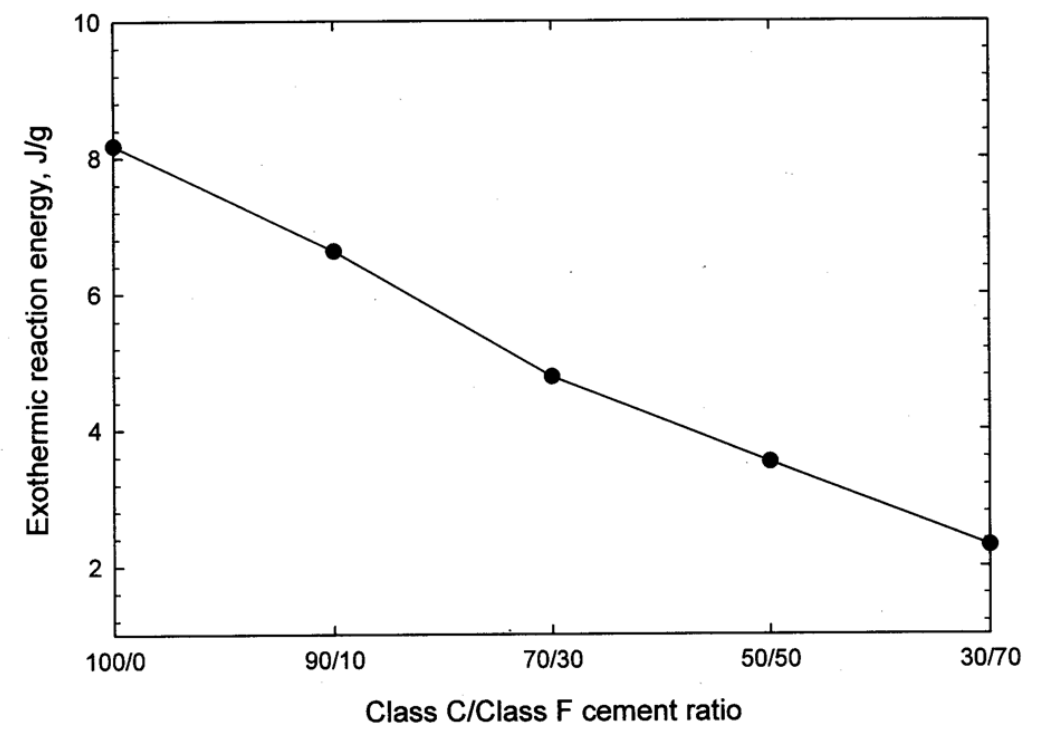

Figure 22. Changes in exothermic reaction energy of cement slurries as a function of C/F ratio.

revealed that the NaP preferentially reacted with two chemical ingredients in the $\mathrm{C}$, calcium sulfate and lime to form the HOAp, rather than tricalcium aluminate $\left(\mathrm{C}_{3} \mathrm{~A}\right)$. Thus, autoclaved cement made with a C/F ratio of 100/0 included well-formed HOAp as the major crystalline phase coexisting with two remaining non-reacted reactants, $\mathrm{C}_{3} \mathrm{~A}$ and quartz. The HOAp phase provided the following three properties needed for geothermal 
well cement, 1) lowering of porosity, 2) development of good compressive strength, and 3) minimum water permeability. When some amount of $C$ was replaced with $F$, the analcime ( $\left.\mathrm{NaAlSi}_{2} \mathrm{O}_{6} \cdot \mathrm{H}_{2} \mathrm{O}\right)$ phase in the zeolitic mineral family was formed as the other crystalline reaction product. Analcime was synthesized by hydrothermal reactions between the $\mathrm{Na}$ from $\mathrm{NaP}$ and the mullite $\left(3 \mathrm{Al}_{2} \mathrm{O}_{3} \cdot 2 \mathrm{SiO}_{2}\right)$ in $\mathrm{F}$ at $250^{\circ} \mathrm{C}$. In fact, the phase composition in cement made with 70/30 ratio consisted of HOAp as the major phase and analcime as the minor phase. The 50/50 ratio cement made by adding more $\mathrm{F}$ had two major phases, HOAp and analcime, and with the 30/70 ratio, the analcime phase became a single major reaction product, while HOAp was poorly formed (Table 7).

Although the HOAp phase played a pivotal role in conferring good strength and minimum water permeability of the cement, it was susceptible to reactions with sulfuric

Table 7. Phase compositions for the $250^{\circ} \mathrm{C}$-autoclaved phosphate-based cements with $\mathrm{C} / \mathrm{F}$ ratios of $100 / 0,70 / 30,50 / 50$, and $30 / 70$.

\begin{tabular}{|c|c|c|c|}
\hline \multirow{2}{*}{ C/F ratio } & \multicolumn{2}{|c|}{ Reaction products } & $\begin{array}{c}\text { Remaining non- } \\
\text { reacted reactant }\end{array}$ \\
\cline { 2 - 4 } & Major phase & Minor phase & Quartz, $\mathrm{C}_{3} \mathrm{~A}$ \\
\hline $100 / 0$ & HOAp & - & Quartz, $\mathrm{C}_{3} \mathrm{~A}$, mullite \\
\hline $70 / 30$ & HOAp & Analcime & Quartz, $\mathrm{C}_{3} \mathrm{~A}$, mullite \\
\hline $50 / 50$ & HOAp, Analcime & - & Quartz, $\mathrm{C}_{3} \mathrm{~A}$, mullite \\
\hline $30 / 70$ & Analcime & HOAp & \\
\hline
\end{tabular}

acid and sodium sulfate, leading to the formation of crystalline bassanite as the acid corrosion products in $\mathrm{CO}_{2}$-laden $\mathrm{H}_{2} \mathrm{SO}_{4}$ solution ( $\mathrm{pH} 1.1$ ) at $90^{\circ} \mathrm{C}$. In contrast, the extent of susceptibility of the analcime phase formed in the $\mathrm{C} / \mathrm{F}$ blend cements to hot strong acid was much less than that of the HOAp; therefore, analcime-rich cement displays an excellent resistance to hot acid (Figure 23).

Overall from the viewpoints of having minimum water permeability, a good strength, and a low rate of acid erosion, the most effective C/F ratio cement was 70/30 in 
this series. Thus, cost-effective acid-resistant geothermal well cement could be formulated by a combination of the coal combustion by-products, C and F.

Nevertheless, we recommended the use of inexpensive Class C fly ash (2.0 $\$ / \mathrm{lb})$ as a coal-combustion by-product for formulating the economic CaP geothermal well cement. Correspondingly, the expensive calcium aluminate cement (35.0 $\$ / \mathrm{lb}$ ) would be replaced by Class $\mathrm{C}$ fly ash. Thus, the newly formulated CaP cement did not use any conventional hydraulic cement.

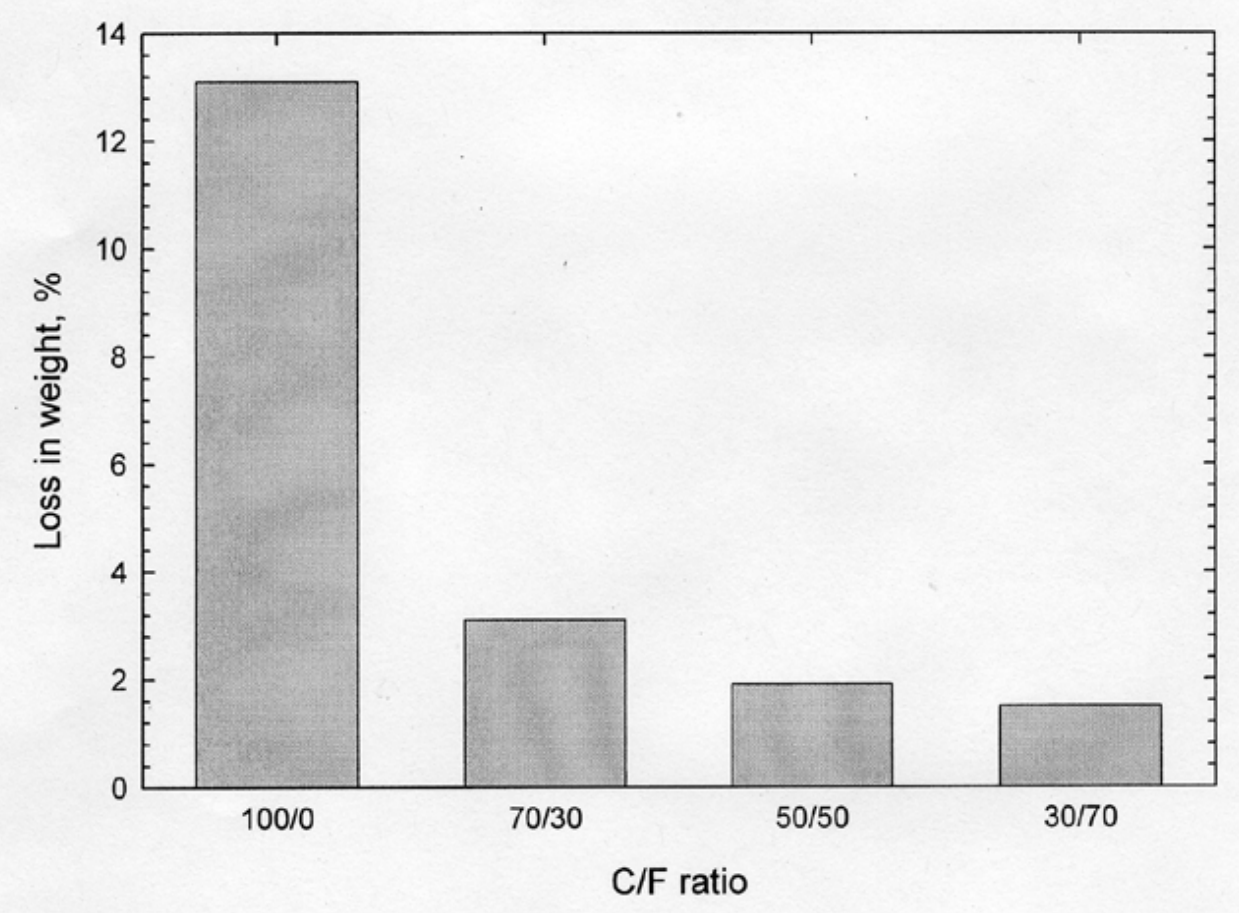

Figure 23. Acid erosion of autoclaved cements made with 100/0-, 70/30-, 50/50-, and $30 / 70-\mathrm{C} / \mathrm{F}$ ratios after exposure for 15 days to $\mathrm{CO}_{2}$-laden $\mathrm{H}_{2} \mathrm{SO}_{4}$ solution $(\mathrm{pH}, 1.1)$ at $90^{\circ} \mathrm{C}$.

\subsection{Conclusions}

1. Citric acid added as set retarder significantly contributed to enhancing the setting temperature and to extending the thickening time of a calcium aluminate 
phosphate (CaP) geothermal cement slurry consisting of calcium aluminate cement (CAC) as the base reactant and sodium polyphosphate (NaP) solution as the acid reactant. The set-retarding activity of citric acid was due to the uptake of $\mathrm{Ca}^{2+}$ ions from the CAC by carboxylic acid groups within the citric acid. This uptake led to the precipitation of a Ca-complexed carboxylate compound as a setretarding barrier layer on the CAC grains' surfaces. However, this barrier layer was vulnerable to disintegration by the attack of free $\mathrm{Ca}^{2+}$ ions from CAC, and also to degradation at elevated temperature, thereby promoting the generation of exothermic energy from acid-base reactions between the CAC and NaP after the barrier was broken. The exothermic reaction energy that was promoted in this way minimized the loss in strength of the citric acid-retarded cement. The phase composition assembled in both retarded and non-retarded cements after autoclaving at $180^{\circ} \mathrm{C}$ encompassed three reaction products, hydroxyapatite (HOAp), hydrogrossular and boehmite, which are responsible for strengthening the autoclaved cement. The first two reaction products were susceptible to reactions with sulfuric acid and sodium sulfate to form crystalline bassanite scale as the corrosion product. The boehmite phase possessed a great resistance to acid and sulfate. Although the bassanite scales clinging to the cement's surfaces were the major factor governing the loss in weight, they served in protecting the cement from further acid- and sulfate-corrosion until their spallation eventually occurred. Nevertheless, the repetitive processes of HOAp and hydorgrossular $\rightarrow$ bassanite $\rightarrow$ spallation played an important role in extending the useful lifetime of $\mathrm{CaP}$ cement in a low $\mathrm{pH}$ environment at $180^{\circ} \mathrm{C}$.

2. Air-foamed low-density calcium aluminate phosphate ( $\mathrm{CaP}$ ) cement slurry was prepared by mixing it with chemical foaming reagent at room temperature without any pressure, followed by autoclaving at $200^{\circ} \mathrm{C}$. When the porosity, compressive strength, and water permeability of the autoclaved $\mathrm{CaP}$ foam cement made from a $1.22 \mathrm{~g} / \mathrm{cc}$ slurry density was compared with those of $\mathrm{N}_{2}$ gas-foamed Class $\mathrm{G}$ cement made from a slurry of similar density under high pressure and hydrothermal temperature at $288^{\circ} \mathrm{C}$, the $\mathrm{CaP}$ cement revealed some advanced 
properties, such as a higher compressive strength and lower porosity. These advanced properties were due to the hybrid formation of three crystalline hydrothermal reaction products; hydroxyapatite, boehmite, and hydrogarnet phases. However, one shortcoming was an increase in water permeability because of the formation of an undesirable continuous porous structure caused by coalesced air bubble cells, suggesting that an appropriate lesser amount of foaming reagent be used to create a conformation in which fine discrete airbubble cells are uniformly dispersed throughout the slurry. For non-foamed cement, three major factors contributed to protecting carbon steel against corrosion: 1) good adherence to steel, reflecting a high extent of coverage by the cement layer over the steel's surfaces; 2) retardation of cathodic corrosion reactions; and, 3) minimum conductivity of corrosive ionic electrolytes. However, adding an excessive amount of foaming reagent did not offer as effective corrosion protection as that of non-foamed cement.

3. Styrene acrylic emulsion (SAE) displayed good potential as high-temperature stable anti-corrosion additive for air-foamed $\mathrm{CaP}$ geothermal well cements. SAE also aided in incorporating additional air bubble cells into the chemically foamed cement, so further reducing the density of the cement's slurry. When SAE was mixed with three reactants, calcium aluminate cement (CAC), Class F fly ash, and sodium polyphosphate $(\mathrm{NaP})$ solution, as starting materials of $\mathrm{CaP}$ cement at room temperature, some carboxylic acid groups within SAE reacted with the $\mathrm{Ca}^{2+}$ ions dissociated from CAC to form Ca-complexed carboxylate groups. When autoclaved at $200^{\circ} \mathrm{C}$, this in-situ carboxylic acid $\rightarrow$ Ca-complexed carboxylate group transition was completed. This transition played important role in enhancing the hydrothermal stability of SAE polymer in the autoclaved cement. A specific action of the SAE polymer in the cement was to bind together reaction products and non-reaction products into cohesive masses, forming a polymer/cement composite structure. The microstructure developed in $200^{\circ} \mathrm{C}$ autoclaved cement revealed that this composite layer created the numerous craters and voids derived from air bubble cells in the slurry. The corrosion rate of steel 
reduced nearly two orders of magnitude, when it was coated with this foamed composite. The following three factors of the foamed composite contributed to such a significant abatement of steel's corrosion: 1) A decrease in the conductivity of corrosive $\mathrm{NaCl}$ ion; 2) an inhibition of the cathodic oxygen reduction reaction at the corrosion sites of steel; and 3) the provision of a good coverage of steel's surface by the composite layer.

4. We assessed the usefulness of two ceramic fibers, $\alpha-\mathrm{Al}_{2} \mathrm{O}_{3}$ and $\alpha-\mathrm{Al}_{2} \mathrm{O}_{3} /$ mullite mixture, for improving the toughness of fly ash-modified $\mathrm{CaP}$ cement, which is used for completing geothermal wells. At the hydrothermal temperature of $280^{\circ} \mathrm{C}$, the reaction between the $\alpha-\mathrm{Al}_{2} \mathrm{O}_{3}$ phase-based fiber's surfaces and silicate in the cement slurry was responsible for the development of a moderate bonding at the interfaces between the fibers and the cement matrix. This development improved fracture toughness to 2.7 times more than that of non-reinforced cements. In contrast, adding $\alpha-\mathrm{Al}_{2} \mathrm{O}_{3} /$ mullite mixed phases-based fibers did little to improve the fracture toughness because of the transformation of the mullite into Na-P type zeolite. This mullite $\rightarrow$ zeolite phase transition was caused by the hydrothermal reaction of mullite with the $\mathrm{Na}$ in the cement. This transition generated a strong linkage between the fibers and the matrix; however, it also converted the strong, flexible, and tough fibers into fragile, brittle fibers. Correspondingly, cracks generated in the cement composites propagated through the fibers, but not at the fiber/matrix interfaces.

5. The usefulness of the milled carbon microfibers ( $7.5 \mu \mathrm{m}$ diam. $\mathrm{x} 100-200 \mu \mathrm{m}$ long) in improving the toughness and ductility of $\mathrm{CaP}$ cement was investigated. The chemical composition occupying at the outermost surface site of the fibers consisted of graphite as the principal component coexisting with functional oxidized carbon moieties, such as carbonyl and carboxyl. These functional moieties contributed significantly to improving the following three properties, deemed essential for good reinforcing fibers. First was the extent of dispersiveness of the fibers in the cement slurry, second was the minimization of 
air-trapping by fibers during mixing with the slurry, and third was their affinity for the chemical species present in the pore solution of the cement. We found that large amounts of fibers could be incorporated into the cement slurry, so greatly enhancing the first and second properties. Further, such large amounts had no critical influence on the porosity of the hardened cement bodies. For the third property, we showed that the preferential uptake of quartz in the cement slurry by these surface moieties led to an excellent adherence of the fibers to the cement matrix. Integrating all these factors was reflected in an increase in the fracture toughness and displacement of the non-reinforced cements that rose 3.1- and 2.7fold, respectively, by incorporating 14 wt\% (21.8 vol.\%) fibers.

6. The carbon microfiber-reinforced $\mathrm{CaP}$ cement composites that possess toughness, and yet avoid shrinkage have a high potential for use as thermal stress-resistant cementing materials in the production and injection wells. The results from the superheating-cooling fatigue cycle test (one cycle $=250^{\circ} \mathrm{C}$ for 15 hours $+25^{\circ} \mathrm{C}$ for 9 hours) for the composite-sheathed casing pipe specimens revealed that the bond durability at interfaces between cement and pipe was one of the important factors governing the resistance to thermal stresses of cements. The microstructure of the crystalline phases as hydrothermal reaction products formed in the cement layer adhering directly to the surfaces of pipes during the cycle testing played a pivotal role in controlling the bond durability. The CaP cement layer generated at the interfacial critical boundary regions had an ideal dense microstructure due to the agglomeration of hybrid crystals of hydroxyapatite, boehmite, hydrogarnet, and analcime phases as the hydrothermal reaction products of $\mathrm{CaP}$ cement. This dense microstructure led to the increase in shear bond strength at interfaces between the cement and pipe; in fact, its strength of non-cycled specimens rose 59\% to 83.4 psi after 100 cycles, beyond that, it leveled off. In contrast, the interfacial layer of the conventional Class $\mathrm{G}$ well cement composite developed an undesirable porous microstructure in the first 70 cycles. This porous microstructure was composed of interlocked well-grown thin plate-like crystals of the xonotlite phase as the major reaction product of Class $\mathrm{G}$ cement, and it was detrimental to the cement-adhering 
performance to pipe, thereby resulting in the decline in interfacial shear bond strength attributable to poor bond durability.

7. To assess the durability of fly ash-modified $\mathrm{CaP}$ cement, which was used to complete geothermal wells in Indonesia, the cement specimens were exposed for up to 7 months in autoclave containing a simulated geothermal brine with 20,000 ppm $\mathrm{CO}_{2}$ and $400 \mathrm{ppm} \mathrm{H}_{2} \mathrm{~S}$ at $280^{\circ} \mathrm{C}$. Hydrothermal reactions between sodium polyphosphate ( $\mathrm{NaP}$ ) and fly ash or calcium aluminate cement (CAC) generated two major crystalline phases, hydroxyapatite (HOAp) and analcime (AN), which were responsible for developing a densified microstructure in cement bodies, offering their ultimate compressive strength. The AN phase favorably intercalated $\mathrm{CO}_{2}$, transforming it into the cancrinite (CAN) phase. The AN 6 CAN phase transition continuously took place during exposure between 7 days and 4 months. This phase transition caused the alteration of a dense microtexture into a porous one, thereby resulting in some loss of strength. However, once the conversion of AN into CAN neared completion, there was no further significant change in compressive strength. After 7 months exposure, the phase composition of cements consisted of HOAp and CAN as the major phases, and AN as the minor one. No decomposition of the cements was observed, nor was they're any carbonation-caused erosion, suggesting that the $\mathrm{CaP}$ cements have excellent durability in a hostile geothermal environment.

8. We investigated the usefulness of the coal-combustion by-products, Class $\mathrm{C}$ fly ash (C) and Class F fly ash (F), in developing cost-effective acid-resistant CaP cements for geothermal wells. In the temperature range of $20-100^{\circ} \mathrm{C}$, sodium polyphosphate $(\mathrm{NaP})$ as the acidic cement-forming solution preferentially reacted with calcium sulfate and lime in the $\mathrm{C}$ as the base solid reactant through the exothermic acid-base reaction route, rather than with the tricalcium aluminate in C. This reaction led to the formation of hydroxyapatite (HOAp). In contrast, there was no acid-base reaction between the $\mathrm{F}$ as the acidic solid reactant and $\mathrm{NaP}$. After autoclaving the cements at $250^{\circ} \mathrm{C}$, a well-crystallized HOAp phase was 
formed in the NaP-modified C cement that was responsible for densifying the cement's structure, thereby conferring low water permeability and good compressive strength on the cement. However, the HOAp was susceptible to hot $\mathrm{CO}_{2}$-laden $\mathrm{H}_{2} \mathrm{SO}_{4}$ solution ( $\mathrm{pH} 1.1$ ), allowing some acid erosion of the cement. On the other hand, the mullite in F hydrothermally reacted with the $\mathrm{Na}$ from $\mathrm{NaP}$ to form the analcime phase. Although this phase played a pivotal role in abating acid erosion, its generation created an undesirable porous structure in the cement. We demonstrated that blending fly ash with a C/F ratio of 70/30 resulted in the most suitable properties for acid-resistant $\mathrm{CaP}$ cement systems.

\subsection{Patent}

U.S. Patent (Number: 5,246,496) entitled "Phosphate-bonded calcium aluminate cements” was issued on September 21, 1995.

\subsection{Technology Transfer}

Halliburton commercialized this CaP cement under the trade name "ThermaLock Cement” in 1999. As of 2006, more than 1000 tons of “ThermaLock®” were used to complete geothermal wells in Indonesia, Japan, and U.S.A., and in the other applications including the P\&A injector in Oklahoma, steam injection wells in Kuwait and New Zealand, casing repair and liner completions for $\mathrm{CO}_{2}$ flood field in Kansas, foamed for steam injections in California, 18,000-ft. sour gas injection wells in Wyoming and foamed for off-shore use in North Sea worldwide. One major reason for it becoming increasingly popular was that drilling and cementing operators estimated the useful service life of this cement to be about 20 years before repairs will be needed. In contrast, the conventional well cements severely deteriorate in such $\mathrm{CO}_{2}$-rich geothermal wells after only one year, and the damaged wells must be repaired in a remedial operation involving redrilling and recementing. The estimated annual cost of remediation is $\$ 150,000$ per well. There are no repair costs annually whatsoever for wells completed with this cement, thereby eliminating substantial expenses for remedial operations.

\subsection{Award}


In 2000, this ThermaLock cement was selected for the prestigious "Research and Development (R\&D) 100 Award.

\subsection{Publications}

- Sugama, T., Brothers L., and Kaspereit D., "Air-foamed Polymer/Calcium Aluminate Phosphate Cement Composites for Geotherml Wells", Construction Mater., (submitted).

- Sugama, T. "Citric acid as a set retarder for calcium aluminate phosphate cements” J. Adv. in Cem. Res., 18, 47-57 (2006).

- Sugama T., Brothers L., and Van de Putte T., "Air-foamed Calcium Aluminate Phosphate Cement for Geothermal Wells”, Cem. Concr. Comp. , 27, 758-768 (2005).

- Sugama, T., Brothers L., and Weber, L., "Acid-resistant Polydimethylsiloxane Additive for Geothermal Well Cement in $150^{\circ} \mathrm{C}_{2} \mathrm{SO}_{4}$ Solution", J. Adv. in Cem. Res., 15, 35-44 (2003).

- Sugama, T., Weber, L., and Brothers, L., "Ceramic Fiber-reinforced Calcium Aluminate/Fly Ash/Polyphosphate Cements as a Hydrothermal Temperature of $280^{\circ} \mathrm{C}^{\prime}$, J. Adv. in Cem. Res., 14, 25-34 (2002).

- Sugama, T. and Brothers, L., "Calcium Aluminate Cements in Fly Ash/Calcium Aluminate Blend Phospahte Cement Systems: Their Role in Inhibiting Carbonation and Acid Corrosion at Low Hydrothermal Temperature”, J. Mater. Sci., 37, 3163-3173 (2002).

- Sugama, T., Weber, L., and Brothers, L., "Hot Acid Resistance of Polymermodified Calcium Phosphate Cements”, J. Adv. in Cem. Res., 12, 181-189 (2000).

- Sugama, T., Weber, L., and Brothers, L., "Sodium Polyphosphate-Modified Fly Ash/Calcium Aluminate Blend Cement: Durability in Wet, Harsh Geothermal Environments”, Mater. Letters, 44, 45-53 (2000).

- Sugama, T., Weber, L., and Brothers, L., "Resistance of Sodium Polyphosphatemodified Fly Ash/Calcium Aluminate Blend Cements to $\mathrm{Hot}_{2} \mathrm{SO}_{4}$ Solution", Cem. Conc. Res., 299 , 1969-1976 (1999).

\section{Economical Slag-based Cement Systems}

\subsection{Sodium Silicate-activated Slag Cements $\left(\mathrm{Na}_{2} \mathrm{O}-\mathrm{CaO}-\mathrm{SiO}_{2}-\mathrm{MgO}-\mathrm{H}_{2} \mathrm{O}\right.$ System)}


As part of our ongoing research program aimed at formulating high-temperature acid-resistant geothermal cements, attention in this study focused on evaluating the resistivity of alkali-activated slag cements to hot $\mathrm{CO}_{2}$-laden $\mathrm{H}_{2} \mathrm{SO}_{4}$. A finely granulated blast-furnace slag (GGBFS) yielded as by-product during the steel-manufacturing process, is very attractive for use as a cementitious material because of its great resistance to sulfate attack, its ability to mitigate alkali silica reactions, and its low price. However, its low rate of hydration in terms of a latent pozzolanic property has been the major issue in using it directory in some applications. As many investigators have reported [22-29], alkaline activators, such as caustic alkalis, non-silicate salts, and silicates, have been incorporated into the slag cement to stimulate its latent hydrolytic properties, and also to promote its hydration. The primal assignment of these activators was to rupture the bonds in the network structure of glassy slag, and then to dissociate the ionic calcium, silica, magnesium, and aluminum species from the slag in the activated cement slurry. We employed one of these activators, sodium silicate, in this study. The sodium silicateactivated slag cements were exposed in an autoclave at temperatures of $100^{\circ}, 200^{\circ}$, and $300^{\circ} \mathrm{C}$. The factors to be evaluated for the autoclaved cements included the changes in compressive strength, porosity, and water permeability as a function of $\mathrm{SiO}_{2} / \mathrm{Na}_{2} \mathrm{O}$ mol. ratio in the sodium silicate activator, autoclave temperature, and activator content, the identification of phase composition assembled in autoclaved cements, and the development of microstructure in cements with at different temperatures. Our particular interest was to investigate whether these factors retard or promote the rate of acid erosion of the autoclaved cements. To obtain this information, the autoclaved cement specimens were immersed for up to 15 days in a $\mathrm{CO}_{2}$-laden $\mathrm{H}_{2} \mathrm{SO}_{4}$ solution ( $\mathrm{pH} 1.1$ ) at $90^{\circ} \mathrm{C}$. All the information obtained then was correlated directly with the acid erosion-related studies, including the changes in weight, the phase transition, and the alternation of microstructure for the exposed cements.

\subsubsection{Experimental}

A finely granulated blast-furnace slag (GGBFS) cement called "NewCem” was supplied by Lafarge North America Inc. It had the following chemical composition: 38.48wt\% $\mathrm{CaO}, 35.18 w t \% \mathrm{SiO}_{2}, 12.55 w t \% \mathrm{Al}_{2} \mathrm{O}_{3}, 10.58 w t \% \mathrm{MgO}, 1.05 w t \% \mathrm{Fe}_{2} \mathrm{O}_{3}$, 
$0.42 \mathrm{wt} \% \mathrm{TiO}_{2}, 0.93 \mathrm{wt} \% \mathrm{~S}^{2-}$, and $0.13 \mathrm{wt} \% \mathrm{SO}_{3}$. The Blaine fineness of this cement was $5,500 \mathrm{~cm}^{2} / \mathrm{g}$. Three sodium silicate aqueous solutions under the commercial product name "N®”, "STAR®”, and "D®”, supplied by the PQ Corporation, were used as the alkali activators; the $\mathrm{SiO}_{2} / \mathrm{Na}_{2} \mathrm{O}$ ratio for these activators was 3.22 for $\mathrm{N} \circledast$, 2.50 for STAR ${ }^{\circledR}$, and 2.00 for $\mathrm{D}{ }^{\circledR}$. These solutions were diluted with a deionized water to make 5-, 10-, 15-, and 20-wt\% activating solutions.

Test specimens were prepared in accordance with the following sequence. First, the cement slurries were mixed thoroughly with the activating solution at a solution-toslag ratio of 0.6. Second, the cement slurry was cast into cylindrical molds, $30 \mathrm{~mm}$ in diameter and $60 \mathrm{~mm}$ long, and allowed to harden for 24 hours at room temperature. Finally, the hardened cement specimens were removed from the molds and autoclaved for 24 hours at $100^{\circ}, 200^{\circ}$, or $300^{\circ} \mathrm{C}$. Afterward, the autoclaved cements were immersed for up to 15 days in an $\mathrm{H}_{2} \mathrm{SO}_{4}$ solution $(\mathrm{pH} 1.1)$ at $90^{\circ} \mathrm{C}$ containing $0.5 \mathrm{wt} \%$ sodium hydrogen carbonate $\left(\mathrm{NaHCO}_{3}\right)$ as a source of $\sim 3000 \mathrm{ppm} \mathrm{CO} 2 ; \mathrm{H}_{2} \mathrm{SO}_{4}+2 \mathrm{NaHCO}_{4}$ $\rightarrow \mathrm{Na}_{2} \mathrm{SO}_{4}+2 \mathrm{CO}_{2}+2 \mathrm{H}_{2} \mathrm{O}$. To maintain the $\mathrm{pH}$ at 1.1, the $\mathrm{H}_{2} \mathrm{SO}_{4}$ solution was replenished with a fresh solution every 5 days. The volume proportion of the cement specimens to the acid solution was 1 to 25 .

\subsubsection{Results}

When sodium silicate-activated slag (SSAS) cement was autoclaved at hydrothermal temperatures of $100^{\circ} \mathrm{C}, 200^{\circ} \mathrm{C}$, and $300^{\circ} \mathrm{C}$, the improvement in its compressive strength and the reduction of its porosity and water permeability were generated by the following factors: 1 ) sodium silicate activators with a high $\mathrm{SiO}_{2} / \mathrm{Na}_{2} \mathrm{O}$ mol. ratio, 2) a high concentration of sodium silicate in the activator solution, 3) the autoclaving temperature, and 4) the phase composition formed in the cements and its transition together with the alternation of microstructure. In the first factor, the incorporation of an activator with a $\mathrm{SiO}_{2} / \mathrm{Na}_{2} \mathrm{O}$ mol. ratio of 3.22 into the slag cement conferred greater compressive strength for the SSAS cements autoclaved at $100^{\circ} \mathrm{C}$ and $200^{\circ} \mathrm{C}$, compared with lower mol. ratios (Figure 24). However, after autoclaving at $300^{\circ} \mathrm{C}$, there were no significant changes in compressive strength for the slag cements activated by sodium silicate with a $\mathrm{SiO}_{2} / \mathrm{Na}_{2} \mathrm{O}$ mol. ratio ranging from 3.22 to 2.00. 
Considering the second factor, slag activated by $20 \mathrm{wt} \%$ sodium silicate in water displayed outstanding compressive strengths of 68.8 MPa, 82.9 MPa, and 34.2 MPa at autoclaving temperatures of $100^{\circ} \mathrm{C}, 200^{\circ} \mathrm{C}$, and $300^{\circ} \mathrm{C}$, corresponding to $\sim$ seven-fold, three-fold, and five-fold increase over those of non-activated cements autoclaved at the same temperatures (Figure 25). Concurrently, the 20wt\% activator reduced the cement's porosity by $40 \%, 45 \%$, and $25 \%$, at $100^{\circ} \mathrm{C}, 200^{\circ} \mathrm{C}$, and $300^{\circ} \mathrm{C}$, respectively, compared with the non-activated cements. In regard to the third factor, autoclaving temperature

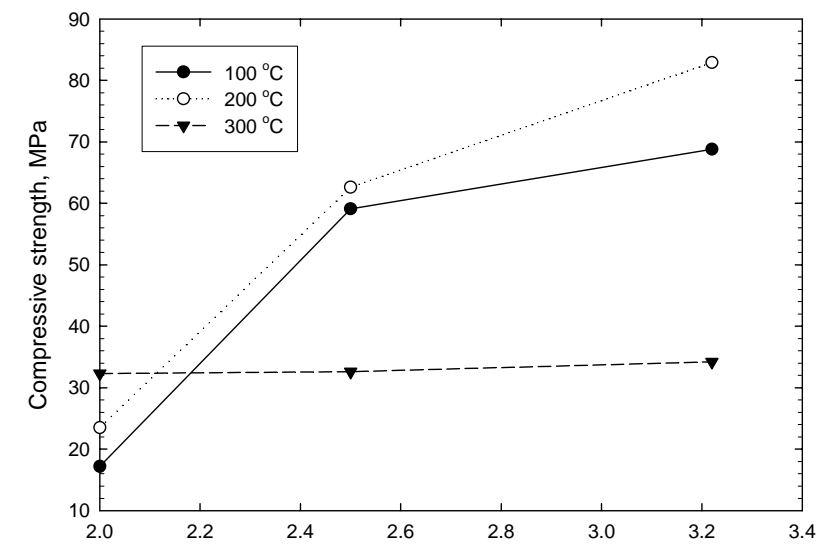

Figure 24. Effect of the $\mathrm{SiO}_{2} / \mathrm{Na}_{2} \mathrm{O}$ ratios in sodium silicate activators on the compressive strength of slag cements autoclaved at $100{ }^{\circ} \mathrm{C}$, $200{ }^{\circ} \mathrm{C}$, and $300{ }^{\circ} \mathrm{C}$.

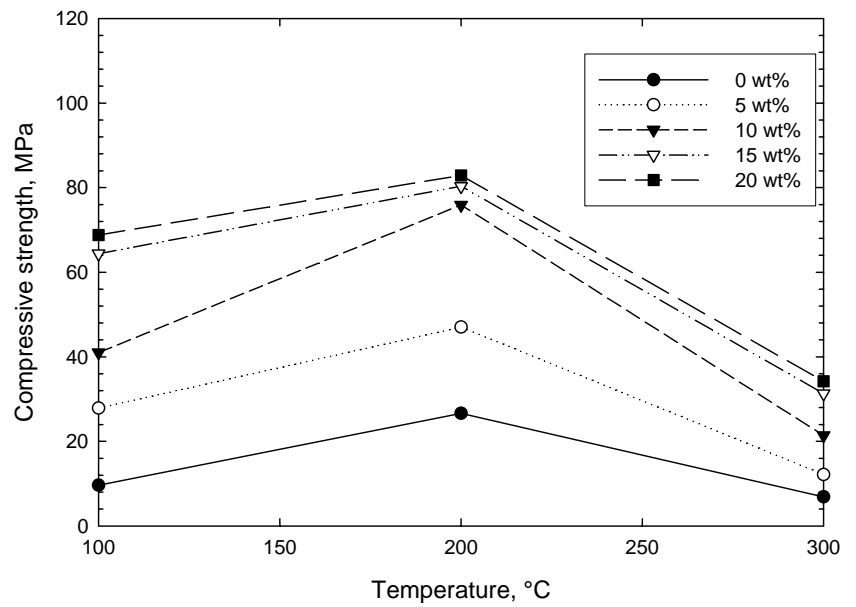

Figure 25. Changes in compressive strength of the cements made with $0,5,10,15$, and 20 wt $\%$ sodium silicate solutions as a function of temperature. 
greatly modulated the compressive strength, porosity and water permeability of the cements; an increase in temperature up to $200^{\circ} \mathrm{C}$ contributed significantly to strengthening and densifying the cement, thereby resulting in the development of compressive strength of more than $80 \mathrm{MPa}$, a reduced porosity of as little as $27 \%$, and minimum water permeability of less than $3.0 \times 10^{-5}$ darcy (Table 8). In contrast, elevating the temperature to $300^{\circ} \mathrm{C}$ caused a retrogression of strength and an increase in porosity and water permeability. The changes in these mechanical and physical properties were

Table 8. Water permeability and porosity for the cements autoclaved at temperatures up to $300^{\circ} \mathrm{C}$.

\begin{tabular}{|c|c|c|}
\hline $\begin{array}{c}\text { Autoclave } \\
\text { temperature, } \\
{ }^{\circ} \mathbf{C}\end{array}$ & Porosity, \% & Water permeability, darcy \\
\hline 100 & 30.8 & $5.7 \times 10^{-5}$ \\
\hline 200 & 26.6 & $2.9 \times 10^{-5}$ \\
\hline 300 & 43.8 & $1.4 \times 10^{-4}$ \\
\hline
\end{tabular}

correlated directly with the fourth factor. The $100^{\circ} \mathrm{C}$-autoclaved SSAS cement formed the semi-crystalline and amorphous calcium silicate hydrate (CSH) phases, which bind nonreacted and partially reacted slag particles together into coherent masses (Figure 26). At $200^{\circ} \mathrm{C}$, some CSH phases were transformed into the tobermorite phase. The combination of $\mathrm{CSH}$ and tobermorite phases was responsible for the attainment of ultimate compressive strength, and the minimum porosity and water permeability of the SSAS cement (Figure 27). At $300^{\circ} \mathrm{C}$, the tobermorite $\rightarrow$ xonotlite phase transition took place in the cement bodies, while the most of CHS was converted into well-crystallized tobermorite. However, an excessive growth of these well-formed tobermorite and xonotlite crystals caused the development of undesirable porous microstructure, reflecting a decrease in compressive strength, and an increase in porosity and water permeability (Figure 28). When these phases formed in the SSAS cements came in contact with a $\mathrm{CO}_{2}$-laden $\mathrm{H}_{2} \mathrm{SO}_{4}$ solution $\left(\mathrm{pH} \mathrm{1.1)}\right.$ at $90^{\circ} \mathrm{C}$, all the phases were vulnerable to the reaction with acid, causing the deposition of bassanite, $\mathrm{CaSO}_{4} \cdot 1 / 2 \mathrm{H}_{2} \mathrm{O}$, scales as the corrosion product over the cement's surfaces. Although the bassanite scales served as 

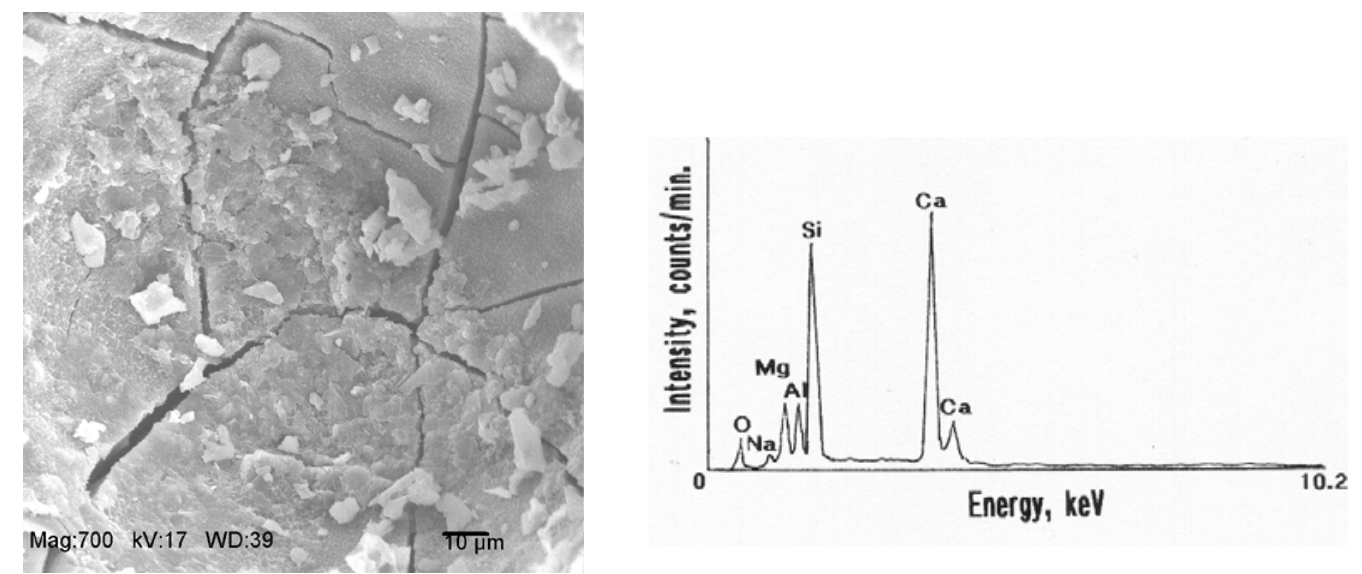

Figure 26. SEM microphotograph and EDX spectrum of CSH phase formed in $100^{\circ} \mathrm{C}$-autoclaved cement.
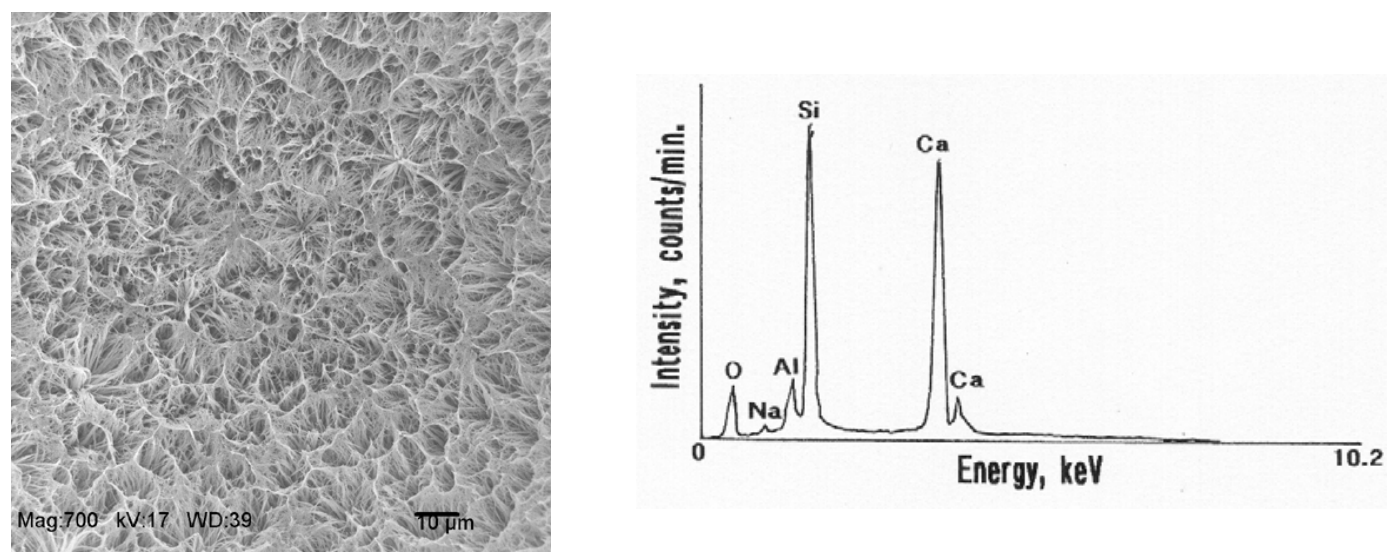

Figure 27. SEM image coupled with EDX spectrum for combination of CSH and Tobermorite phases formed in $200^{\circ} \mathrm{C}$ cement. 

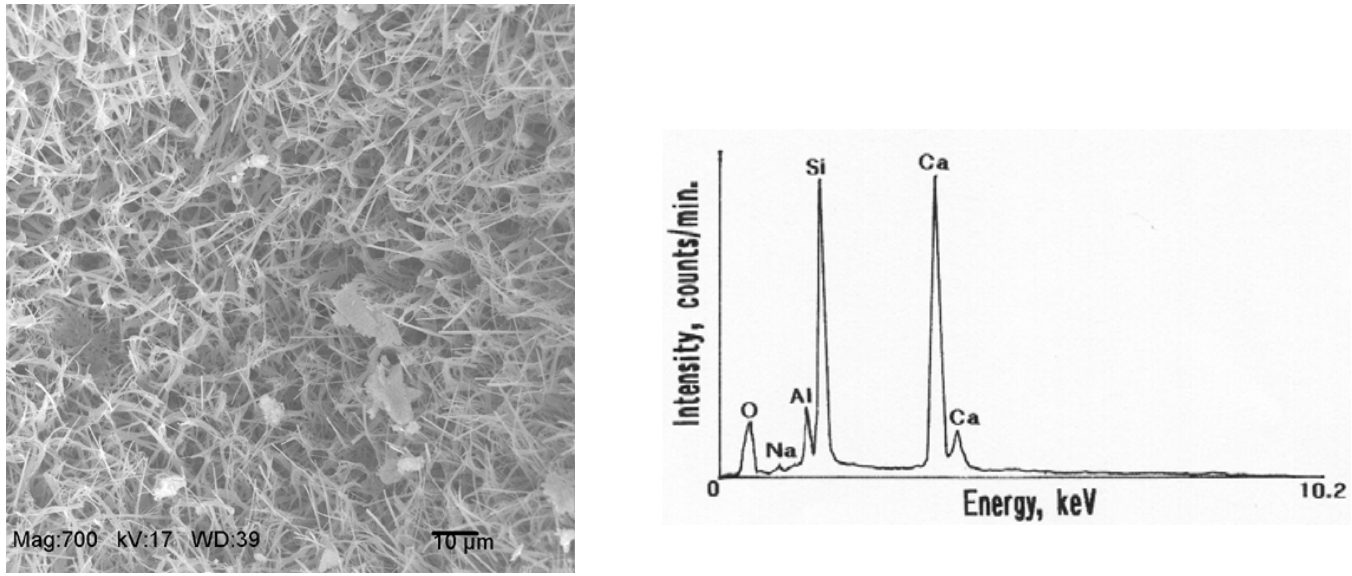

Figure 28. SEM-EDX for combination of well-formed tobermorite and xonotlite crystals assembled in $300^{\circ} \mathrm{C}$ cement.

a primary barrier against a further acid attack, their spallation promoted an overall loss in the weight of cement. Among these phases, the CSH phases formed at temperatures up to $200^{\circ}$ played a pivotal role in retarding the rate of acid erosion. As such, a CSH destitute of Ca preferentially reacted with $\mathrm{Mg}$ dissociated from the slag to form the lizardite phase, $\left[\mathrm{Mg}_{2} \mathrm{Si}_{2} \mathrm{O}_{5}(\mathrm{OH})_{4}\right]$

$$
\begin{array}{ll}
\underset{\mathrm{CaO} . \mathrm{SiO}_{2} \cdot \mathrm{xH}_{2} \mathrm{O}+\mathrm{H}_{2} \mathrm{SO}_{4} \longrightarrow \mathrm{Phase}}{\mathrm{CSH} \text { phase }} & \begin{array}{l}
\mathrm{CaSO}_{4} \cdot 1 / 2 \mathrm{H}_{2} \mathrm{O}+\mathrm{H}_{2} \mathrm{SiO}_{4}{ }^{2-} \\
\text { Bassanite phase }
\end{array} \\
2 \mathrm{H}_{2} \mathrm{SiO}_{4}{ }^{2-}+2 \mathrm{Mg}^{2+}+\mathrm{H}_{2} \mathrm{O} \longrightarrow & \begin{array}{l}
\mathrm{Mg}_{2} \mathrm{Si}_{2} \mathrm{O}_{5}(\mathrm{OH})_{4}+2 \mathrm{H}^{+} \\
\text {Lizardite phase }
\end{array}
\end{array}
$$

The newly formed lizardite not only served to retard the rate of acid erosion, but also to retain the integrity of the cementitious structure, avoiding catastrophic acid erosion. In contrast, the susceptibility of Ca-depleted tobermorite and xonotlite phases to reactions with Mg showed little, if any. 
Accordingly, the SSAS cement has a high potential for completing the upper region of geothermal wells, which contains a highly concentrated acid and some $\mathrm{CO}_{2}$ at temperatures up to $200^{\circ} \mathrm{C}$.

\subsection{Sodium Silicate-activated Fly Ash/Slag Blend Cements $\left(\mathrm{Na}_{2} \mathrm{O}-\mathrm{CaO}-\mathrm{Al}_{2} \mathrm{O}_{3}-\mathrm{SiO}_{2^{-}}\right.$ $\mathrm{MgO}-\mathrm{H}_{2} \mathrm{O}$ System)}

Work in the previous section 3 showed that there were no crystalline hydrates containing essential sodium. As is well known [30], when sodium silicate, $-\left(\mathrm{Na}_{2} \mathrm{O} \mathrm{SiO}_{2}-\right.$ )$_{n^{-}}$, is dissolved in water, its hydrolysis yields polysilicic acid, -[-O-Si(OH $\left.)_{2-}\right]_{n^{-}}$, and sodium hydroxide, $n \mathrm{NaOH}$, in the first stage of its dissolution. In the second dissolution stage, polysilicic acid is transformed into monosilicic acid, $n \mathrm{Si}(\mathrm{OH})_{4}$; finally, ionized monosilicic acid is formed by the reactions between monosilicic acid and hydroxyl ions; $\mathrm{Si}(\mathrm{OH})_{4}+2 \mathrm{OH}-\Leftrightarrow\left(\mathrm{H}_{2} \mathrm{SiO}_{4}\right) 2-+2 \mathrm{H}_{2} \mathrm{O}$. Thus, sodium hydroxide hydrolysate acts as an alkali activator that promotes rupture of the bonds in the network structure of glassy slag, following by the dissociation of ionic calcium, silica, magnesium, and aluminum species from the slag in the activated cement slurry. The dissociated calcium ion then hydrothermally reacts with the ionized monosilicic acid derivative to form calcium silicate hydrates. Correspondingly, the free $\mathrm{Na}$ ions appear to remain in this cementitious structure, although some may leach out during autoclaving. This might be the reason why Na-containing crystalline hydrate phases did not form in the activated slag cement after autoclaving at temperatures up to $300^{\circ} \mathrm{C}$.

Trying to transform non-reacted Na ions into Na-intercalated crystal hydration products, our particular interest is to incorporate the Class F fly ash generated from coalcombustion power plants into the sodium silicate-activated slag cement system. As already reported [31] and by other investigators [32-36], sodium silicate and $\mathrm{NaOH}$ activators were used to stimulate the latent pozzolanic properties of the Class F fly ash that consisted of two major crystalline components, mullite and quartz. In particular, the mullite $\left(3 \mathrm{Al}_{2} \mathrm{O}_{3} .2 \mathrm{SiO}_{2}\right)$ phase favorably reacted with these activators to form the zeolite phases in the $\mathrm{Na}_{2} \mathrm{O}-\mathrm{Al}_{2} \mathrm{O}_{3}-\mathrm{SiO}_{2}-\mathrm{H}_{2} \mathrm{O}$ system. Our previous study revealed that the zeolite

possesses a better resistance to $\mathrm{H}_{2} \mathrm{SO}_{4}$ than do Ca-containing hydration products [37]. 
Based upon the information described above, the objective of the current study was to assess the potential of sodium silicate-activated slag/Class F fly ash blend cement as an acid-resistant geothermal well cementitious material. The cement specimens were prepared by varying two parameters, slag/fly ash weight ratio, $\mathrm{SiO}_{2} / \mathrm{Na}_{2} \mathrm{O}$ mol. ratio in the sodium silicate, followed by autoclave treatment at $100^{\circ}, 200^{\circ}$, and $300^{\circ} \mathrm{C}$. The factors assessed included the setting time of cement slurries at room temperature, compressive strength, porosity, water permeability and the phase composition and development of the microstructure. All the information obtained was correlated directly with acid erosion-related studies, including weight loss and the visual observation of the appearance of the cements after exposure for 15 days in a $\mathrm{CO}_{2}$-laden $\mathrm{H}_{2} \mathrm{SO}_{4}$ solution (pH 1.1) at $90^{\circ} \mathrm{C}$.

\subsubsection{Experimental}

Lafarge North America Inc. supplied a finely granulated blast-furnace slag (GGBFS) cement, trademark "NewCem", with the following chemical composition: 38.48wt\% CaO, 35.18wt\% $\mathrm{SiO}_{2}, 12.55 w t \% \mathrm{Al}_{2} \mathrm{O}_{3}, 10.58 w t \% \mathrm{MgO}, 1.05 w t \% \mathrm{Fe}_{2} \mathrm{O}_{3}$, $0.42 \mathrm{wt} \% \mathrm{TiO}_{2}, 0.93 \mathrm{wt} \% \mathrm{~S} 2-$, and $0.13 \mathrm{wt} \% \mathrm{SO}_{3}$. The Blaine fineness of this cement was $5,500 \mathrm{~cm} 2 / \mathrm{g}$. The chemical constituents of the Class F fly ash obtained from the Pozament Corp. were 38.57wt\% $\mathrm{SiO}_{2}$, 38.57wt\% $\mathrm{Al}_{2} \mathrm{O}_{3}, 11.95 w t \% \mathrm{Fe}_{2} \mathrm{O}_{3}, 1.36 w t \%$ $\mathrm{MgO}, 1.52 \mathrm{wt} \% \mathrm{Na}_{2} \mathrm{O}, 1.94 \mathrm{wt} \% \mathrm{SO}_{3}, 0.47 \mathrm{wt} \% \mathrm{CaO}$, and $1.94 \mathrm{wt} \% \mathrm{~K}_{2} \mathrm{O}$. The Blaine fineness of this fly ash was 10,585 cm2/g. Three aqueous solutions of sodium silicate under the commercial product name “N®”, “STAR®”, and “D®”, supplied by the PQ Corporation, were used as alkali activators; the $\mathrm{SiO}_{2} / \mathrm{Na}_{2} \mathrm{O}$ ratio for these activators was 3.22 for $\mathrm{N} \AA$ solution, 2.50 for $\mathrm{STAR} \AA$ solution, and 2.00 for $\mathrm{D}{ }^{\circledR}$ solution. These solutions were diluted with a deionized water to make $20 \mathrm{wt} \%$ activating solutions, at $\mathrm{pH}$ 10.97 for $\mathrm{N} \AA, 11.38$ for $\mathrm{STAR} \AA$, and 11.92 for $\mathrm{D} \AA$. Test specimens were prepared in the following sequence. First, the slag cement was mixed with the fly ash in a twin shell dry blender to prepare the blended cements with slag/fly ash ratios of 90/10, 80/20, 70/30, 60/40, and 50/50 by weight. The unblended slag cement was used as the control. Second, the blended and unblended cements were mixed thoroughly with the activating solution at a solution-to-cement ratio of 0.6 . Third, the cement slurry was cast into 
cylindrical molds, $30 \mathrm{~mm}$ in diameter and $60 \mathrm{~mm}$ long, and left to harden for at least 24 hours at room temperature. Finally, the hardened cement specimens were removed from the molds and autoclaved for 24 hours at $100^{\circ}, 200^{\circ}$, or $300^{\circ} \mathrm{C}$. The durability of autoclaved cements was tested by immersion for 15 days in an $\mathrm{H}_{2} \mathrm{SO}_{4}$ solution (pH 1.1) at $90^{\circ} \mathrm{C}$ containing $0.5 \mathrm{wt} \%$ sodium hydrogen carbonate $\left(\mathrm{NaHCO}_{3}\right)$ as a source of $\sim 3000$ ppm $\mathrm{CO}_{2}$. To maintain the $\mathrm{pH}$ at 1.1, the $\mathrm{H}_{2} \mathrm{SO}_{4}$ solution was replenished with a fresh solution every 5 days. The volume proportion of the cement specimens to the acid solution was 1 to 25 .

\subsubsection{Results}

The following results can be drawn from our investigation of the potential of sodium silicate-activated slag/Class F fly ash blend (SSASF) cementitious material as an acid-resistant geothermal well cement. In the slurry state of the SSASF cement, its setting time at room temperature depended primarily on the $\mathrm{SiO}_{2} / \mathrm{Na}_{2} \mathrm{O}$ mol. ratio in the sodium silicate activator; using 3.22 and 2.50 ratios contributed to a long setting time of more than 1000 min (Figure 29). In contrast, the slurry made with a 2.00 ratio set rapidly in less than $25 \mathrm{~min}$. Since cement slurries for geothermal wells are required to possess a setting time of at least $240 \mathrm{~min}$ at hydrothermal temperatures of $90^{\circ}-120^{\circ} \mathrm{C}$, the 2.00 ratio was clearly inadequate as an alkali activator. Also, substituting slag for fly ash prolonged the setting time. For instance, using the 2.50 ratio, the setting time of slurry made with slag without fly ash was extended as long as $617 \mathrm{~min}$ to $1767 \mathrm{~min}$, when the $50 \mathrm{wt} \%$ of the total amount of slag was replaced by fly ash.

For the 3.22 and $2.50 \mathrm{SiO}_{2} / \mathrm{Na}_{2} \mathrm{O}$ ratio-made SSASF cements, autoclaving at $100^{\circ} \mathrm{C}$ showed that their porosity increases as more slag is replaced by fly ash, reflecting a decrease in their compressive strength (Figure 30 and 31). Although a similar tendency was observed in $200^{\circ} \mathrm{C}$-autoclaved cements, the increased temperature was responsible for densifying all the cements, thereby offering decreased porosity and improved compressive strength. At $300^{\circ} \mathrm{C}$, the porosity of $100 / 0$ and $90 / 10$ slag/fly ash ratio cements strikingly increased, causing retrogression in compressive strength. In contrast, the structure of the 70/30,60/40, and 50/50 slag/fly ash ratio cements became denser and was responsible for a further improvement of strength. These cements were exposed for 


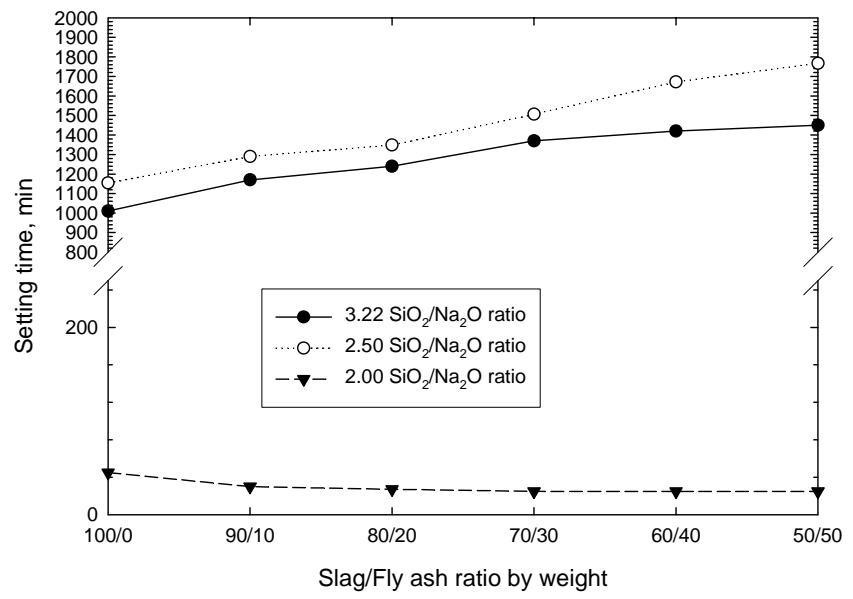

Figure 29. Final setting time of cement slurries made by the combination of 3.22 , 2.50, and 2.00 $\mathrm{SiO} / \mathrm{Na} 2 \mathrm{O}$ ratio sodium silicate activators and 100/0, 90/10, 80/20, $70 / 30,60 / 40$, and 50/50 slag/fly ash ratio blend cements at room temperature.
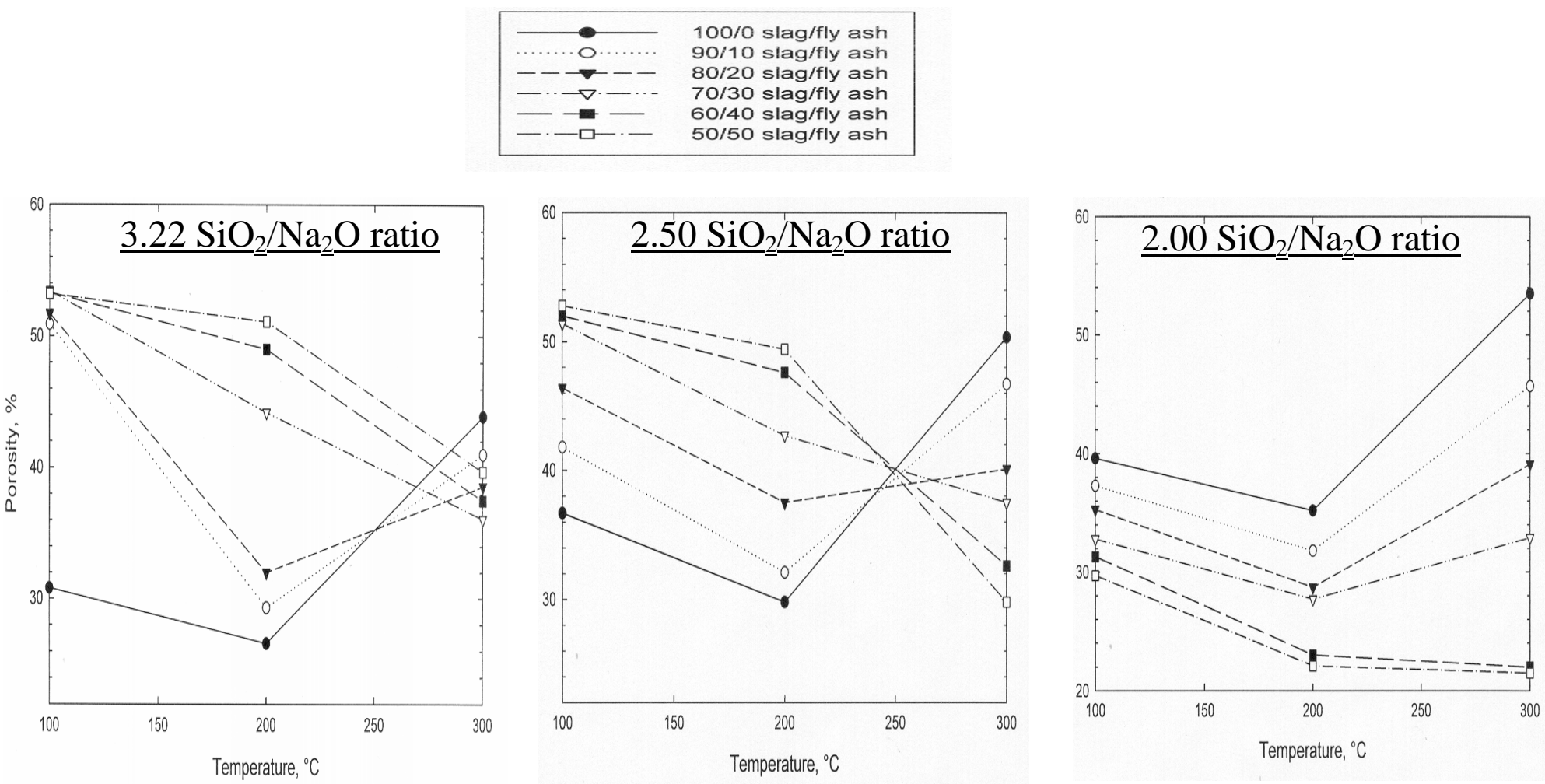

Figure 30. Changes in the porosity of slag/fly ash blend cements activated with sodium silicate of $3.22,2.50$, and $2.00 \mathrm{SiO}_{2} / \mathrm{Na}_{2} \mathrm{O}$ ratios as a function of autoclaving temperature. 

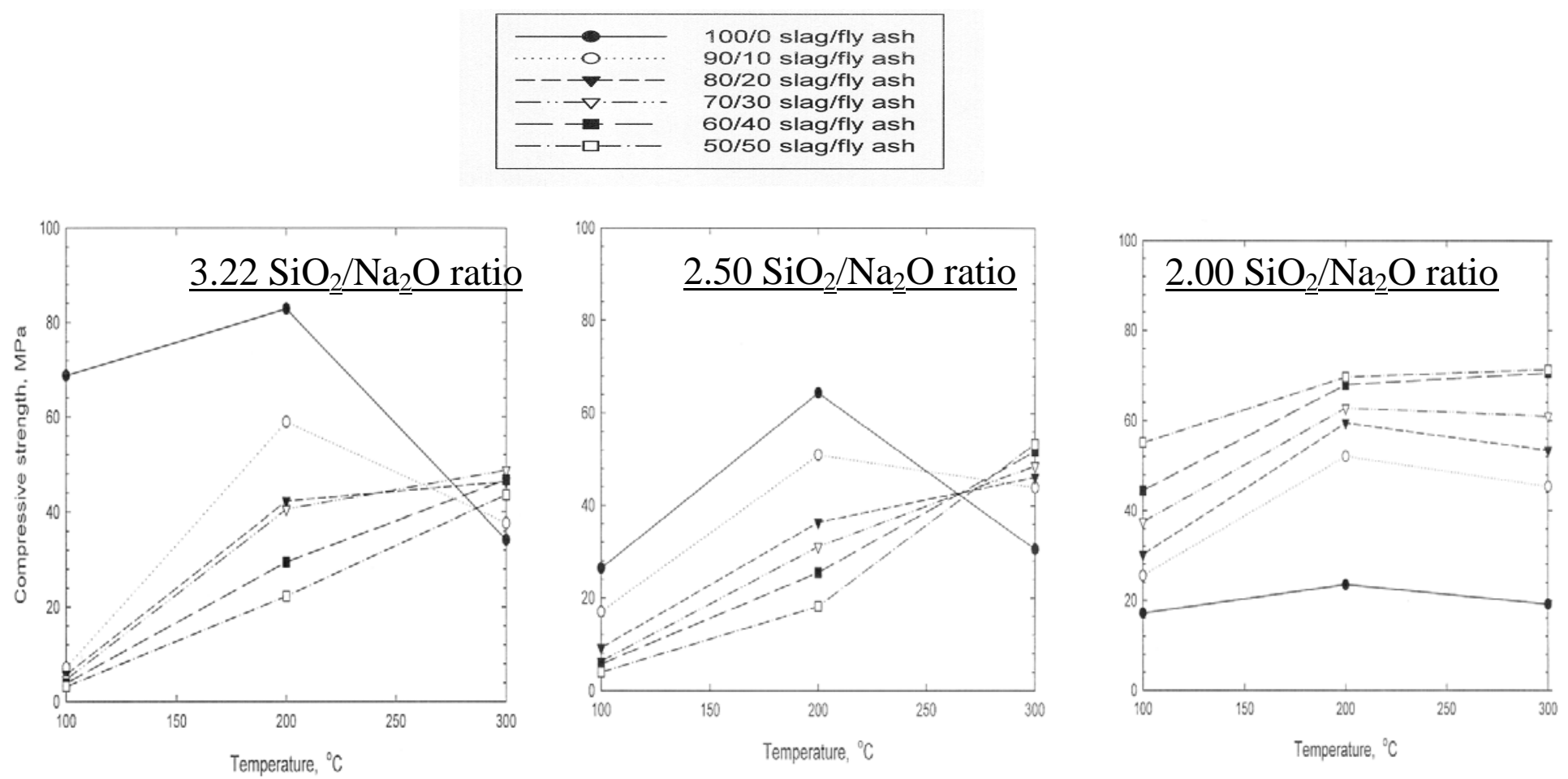

\section{Figure 31. Changes in the compressive strength of slag/fly ash blend cements activated with sodium silicate of 3.22, 2.50, and 2.00 $\mathrm{SiO}_{2} / \mathrm{Na} 2 \mathrm{O}$ ratios as a function of autoclaving temperature.}

15 days to $\mathrm{CO}_{2}$-laden $\mathrm{H}_{2} \mathrm{SO}_{4}(\mathrm{pH} 1.1)$ at $90^{\circ} \mathrm{C}$, and the magnitude of acid erosion was estimated from two phenomena: the volume expansion by in-situ growth of the crystalline bassanite, $\mathrm{CaSO}_{4} \cdot 1 / 2 \mathrm{H}_{2} \mathrm{O}$, phase as the corrosion product of the cement; and, the loss in weight. The $2.50 \mathrm{SiO}_{2} / \mathrm{Na}_{2} \mathrm{O}$ ratio-activated SSASF cement displayed a better performance in mitigating acid erosion compared with that with a $3.22 \mathrm{SiO}_{2} / \mathrm{Na}_{2} \mathrm{O}$ ratio. More importantly, the incorporation of more fly ash into the blend cement lowered the extent of acid erosion. Consequently, the most effective SSAFS formulation in withstanding the attack of hot acid was the combination of $2.50 \mathrm{SiO}_{2} / \mathrm{Na}_{2} \mathrm{O}$ ratio sodium silicate activator and 50/50 slag/fly ash ratio cement. There was less than $7 \%$ weight loss by acid erosion in this effective cement autoclaved at temperatures up to $300^{\circ} \mathrm{C}$ (Figure 
32). The XRD study revealed that the cementitious structure of $100^{\circ} \mathrm{C}$-autoclaved cement was comprised of an unknown amorphous compound and semi-crystalline CSH, and raising the temperature to $200^{\circ} \mathrm{C}$ led to the incorporation of the analcime phase in the zeolitic mineral family in the cementitious structure. At $300^{\circ} \mathrm{C}$, analcime became the major crystalline phase coexisting with Na-P type zeolite and xonotlite as the minor crystalline phases. In conjunction with our exploration at the interfacial boundary zone
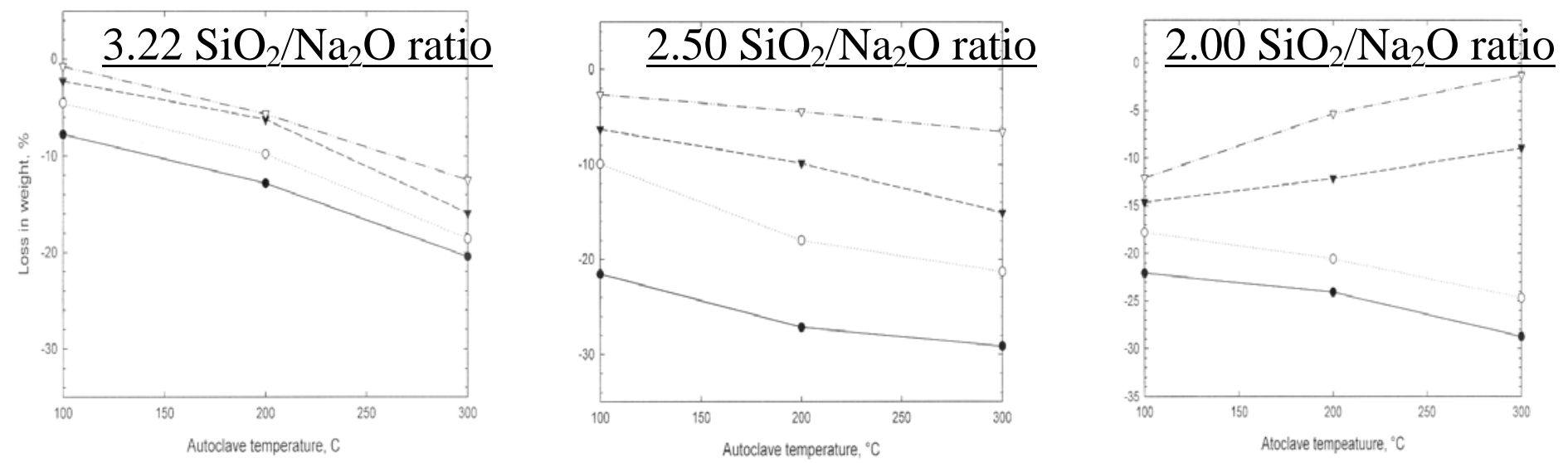

Figure 32. Weight loss of slag/fly ash blend cements activated with sodium silicate of 3.22, 250, and $2.00 \mathrm{SiO} / \mathrm{Na}_{2} \mathrm{O}$ ratios after exposure for 15 days to $\mathrm{CO}_{2}$-laden $\mathrm{H}_{2} \mathrm{SO}_{4}(\mathrm{pH} 1.1)$ at $90^{\circ} \mathrm{C}$.

between the fly ash and cementitious matrix, we believe that the analcium and Na-P type zeolite phases were formed by hydrothermal interactions between the mullite in fly ash and $\mathrm{Na}$ ion dissociated from the activator. Hence, the $\mathrm{NaOH}$ hydrolysate derived from the hydrolysis of sodium silicate not only acted as the alkali activator, but also played an essential role in assembling the zeolite structure. Assuming that the amorphous phase formed in the $100^{\circ} \mathrm{C}$ cement is associated with sodium aluminosilicate-related hydrates, 
we believe that the zeolite-related phases contributed significantly to enhancing the resistance to hot acid of SSASF cement autoclaved at temperatures up to $300^{\circ} \mathrm{C}$.

\subsection{Conclusions}

1. We evaluated the usefulness of sodium silicate-activated slag (SSAS) cement for completing geothermal wells containing highly concentrated $\mathrm{H}_{2} \mathrm{SO}_{4}$ and some $\mathrm{CO}_{2}$. Using a $20 \mathrm{wt} \%$ sodium silicate solution $\left(\mathrm{SiO}_{2} / \mathrm{Na}_{2} \mathrm{O}\right.$ mol. ratio of 3.22) as the alkali activator, the SSAS cements autoclaved at temperatures up to $200^{\circ} \mathrm{C}$ displayed an outstanding compressive strength of more than $80 \mathrm{MPa}$, and a minimum water permeability of less than $3.0 \times 10^{-5}$ darcy. The combination of calcium silicate hydrate (CSH) and tobermorite phases was responsible for strengthening and densifying the autoclaved cement. At $300^{\circ} \mathrm{C}$, an excessive growth of well-formed tobermorite and xonotlite crystals generated an undesirable porous microstructure, causing the retrogression of strength and enhancing water permeability. Although all the phases formed in the autoclaved cements were vulnerable to reactions with $\mathrm{H}_{2} \mathrm{SO}_{4}$, so depositing bassanite scales as corrosion product over the cement's surfaces, the CSH phase played an important role in retarding the rate of acid erosion. Thus, after the uptake of Ca by $\mathrm{H}_{2} \mathrm{SO}_{4}$, Ca-destitute CSH preferentially reacted with Mg from slag to form the lizardite phase that not only retarded the rate of acid erosion, but also retained the integrity of the cementitious structure. Therefore, the SSAS cement has a high potential as an acid-resistant geothermal well cement at temperatures up to $200^{\circ} \mathrm{C}$.

2. Sodium silicate-activated slag/Class F fly ash (SSASF) blend cements were prepared by varying two parameters, the $\mathrm{SiO}_{2} / \mathrm{Na}_{2} \mathrm{O}$ mol. ratio in the sodium silicate activator, and the slag/fly ash weight ratio, and then autoclaving them at $100^{\circ}, 200^{\circ}$, and $300^{\circ} \mathrm{C}$. The usefulness of the autoclaved SSASF cements as acidresistant geothermal well cements was evaluated by exposing them for 15 days to $90^{\circ} \mathrm{C} \mathrm{CO}_{2}$-laden $\mathrm{H}_{2} \mathrm{SO}_{4}$ (pH 1.1). Among the combination of these two parameters, the most effective one in inhibiting acid erosion consisted of 50/50 slag/fly ash ratio cement and $2.50 \mathrm{SiO}_{2} / \mathrm{Na}_{2} \mathrm{O}$ ratio activator. The weight loss by 
acid erosion of this cement was less than $7 \%$. The major contributor to such minimum acid erosion was the zeolite phase formed by interactions between the mullite in fly ash and the Na ion liberated from the activator. Further characteristics of this cement included a long setting time for its slurry of $\sim 1770$

min at room temperature, and a water permeability ranging from $2.4 \times 10^{-4}$ to 1.9 $\mathrm{x} 10^{-5}$ Darcy, and a compressive strength from 4.0 to $53.4 \mathrm{MPa}$ after autoclaving at $100^{\circ}-300^{\circ} \mathrm{C}$ for 24 hours.

\subsection{Publications}

- Sugama T., Brothers L., and Van de Putte T., "Acid-resistant Cements for Geothermal Wells: Sodium Silicate Activated Slag/Fly Ash Blends”, J. Adv. in Cem. Res., 17, 65-75 (2005).

- Sugama T. and Brothers L., "Sodium-silicate-activated Slag for Acid-resistant Geothermal Well Cements”, J. Adv. in Cem. Res., 16, 77-87 (2004). 


\section{References}

[1] T. Sugama and N.R. Carciello, Cem. Concr. Res., 22 (1992) 783.

[2] United State Patent, Phosphate-bonded calcium aluminate cements, No. 5,246,496, (1993).

[3] T. Sugama and N.R. Carciello, J. Am. Ceram. Soc., 74 (1991) 1023.

[4] T. Sugama and J.M. Hill, J. Am. Ceram. Soc., 75 (1992) 2076.

[5] M. Nagai, T. Saeki, and T. Nishino, J. Am. Ceram. Soc., 73 (1990) 1456.

[6] T. Sugma and N.R. Carciello, Cem. Concr. Res., 23 (1993) 1409.

[7] T. Sugama and N.R. Carciello, Cem. Concr. Res., 25 (1995) 91.

[8] T. Sugama and E. Wetzel, J. Mater. Sci., 29 (1994) 5165.

[9] R. Moore, M. Oil, D. Bour, S. Reed, R. Hemandez, Sco. Petro. Eng SEP 84563, 2003, pp. 69-77.

[10] R. Montman, D.L. Sutto, W.M. Harms, B.G. Mody, Oil Gas J., (1982) 209.

[11] G.C. Hoff, Cem. Concr. Res., 2 (1972) 91.

[12] R. Brezny and D.J. Green, J. Am. Ceram. Soc., 74 (1991) 1061.

[13] T.D. Tonyan and L.J. Gibson, J. Mater. Sci., 27 (1992) 6371.

[14] T.G. Richard, ACI Journal, April, (1977) 173-177.

[15] P.J. Tikalsky, J. Pospisil, and W. MacDonald, Cem. Conc. Res., 34 (2004) 889.

[16] T. Sugama, L. Weber, and L.E. Brothers, Adv. Cem. Res., 12 (2000) 181.

[17] A.K. Dhingra, A.K. in: Advances in inorganic fiber developments, Vandenberg, E.J. [Ed.], pp.227-269. Plenum Press. New York (1982).

[18] J.D. Birchall, J.A.A. Bradbury, and J. Dinwoodie, in: Alumina Fibers in Handbook of Composites. Watt W. and Perov, B.V. [Eds.], pp.115-155. North-Holland. Amsterdam, Netherlands (1985).

[19] L. Weber, E. Emerson, K. Harrusm, and L.E. Brothers, “The application of a new corrosion resistant cement in geothermal wells, in: Geothermal Resources Council Transactions, Sand Diego, CA, USA, September 20-23, 1998.

[20] S. Schlorholtz, T. Demirel, and JM. Pitt, Cem. Concr. Res., 14 (1984) 499.

[21] R. Hill and K. Daugherty, Cem. Concr. Res. 26 (1996) 1131.

[22] X. Wu, W. Jiang and D.M. Roy, Cem. Conc. Res., 20 (1990) 961.

[23] C. Shi, X. Wu and M. Tang, Cem. Conc. Res., 21 (1991) 91. 
[24] D.M. Roy and M.R. Silsbee, Alkali activated cementitious materials: An overview. Mat. Res. Soc. Symp. Proc., 245 (1992) 153.

[25] J. Davidovits, High-alkali cements for $21^{\text {st }}$ century concretes. In Concrete technology, past, present, and future [Mehta P.K. (ed.)], ACI, SP-144, 1994, pp 383-397. [26] C. Qing-Hua, A. Tagnit-Hamou, and S. Sarkar, Strength and microstructural properties of water glass activated slag. Mat. Res. Soc. Symp. Proc., 1992, 245, 49-54.

[27] D.M. Roy, Cem. Conc. Res., 29 (1999) 249.

[28] A.R. Brough and A. Atkinson, Cem. Conc. Res., 32 (2002) 865.

[29] G. Qian, D.D. Sun, J.H. Tay, Z. Lai, and G. Xu, Cem. Conc. Res., 32 (2002) 1377.

[30] F.G.R. Gimblett, Inorganic Polymer Chemistry, Butterworth , London, pp. 165-167, 1963.

[31] T. Sugama and N. Carciello, Adv. Cem. Bas. Mater., 3 (1996) 45.

[32] J.L. LaRosa, S. Kwan, and M.W. Grutzeck, J. Am. Ceram. Soc., 75 (1992) 1574.

[33] M.W. Grutzeck and D.D. Siemer, J. Am. Ceram. Soc., 80 (1997) 2449.

[34] Z. Xie and Y. Xi, Cem. Conc. Res., 31 ( 2001) 1245.

[35] P.J. Williams, J.J. Biernacki, L.R. Walker, H.M. Meyer, C.J. Rawn and J. Bai, Cem. Conc. Res., 32 (2002) 963.

[36] W.K. Lee and J.S.J. Van Deventer, Cem. Conc. Res., 32 (2002) 577.

[37] T. Sugama, L.E. Brother and L. Weber, Adv. Cem. Res., 15 (2003) 35. 
